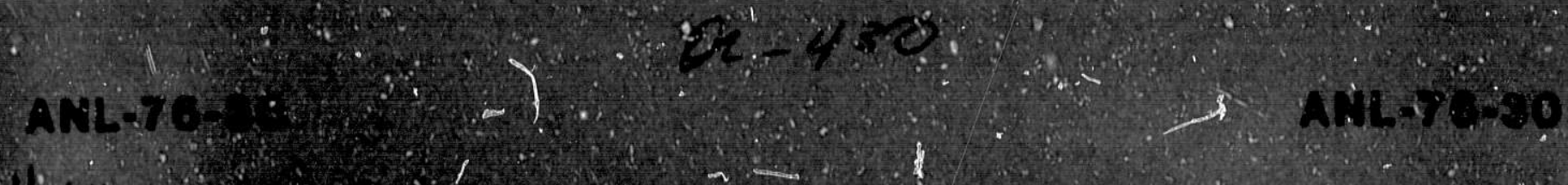

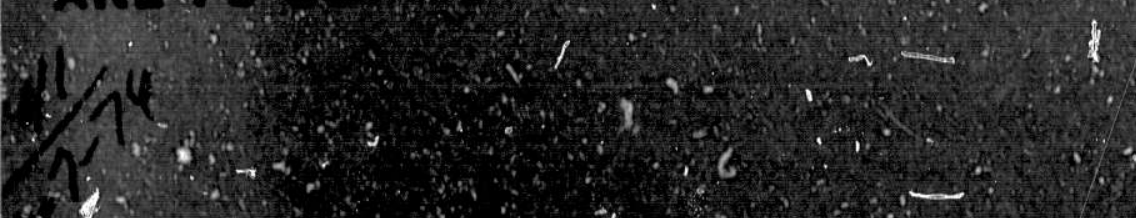

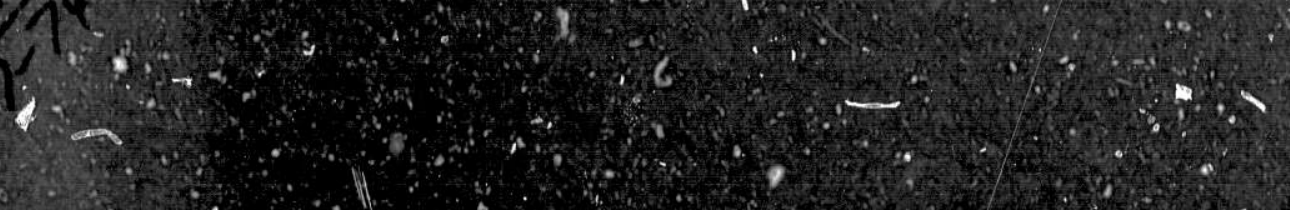

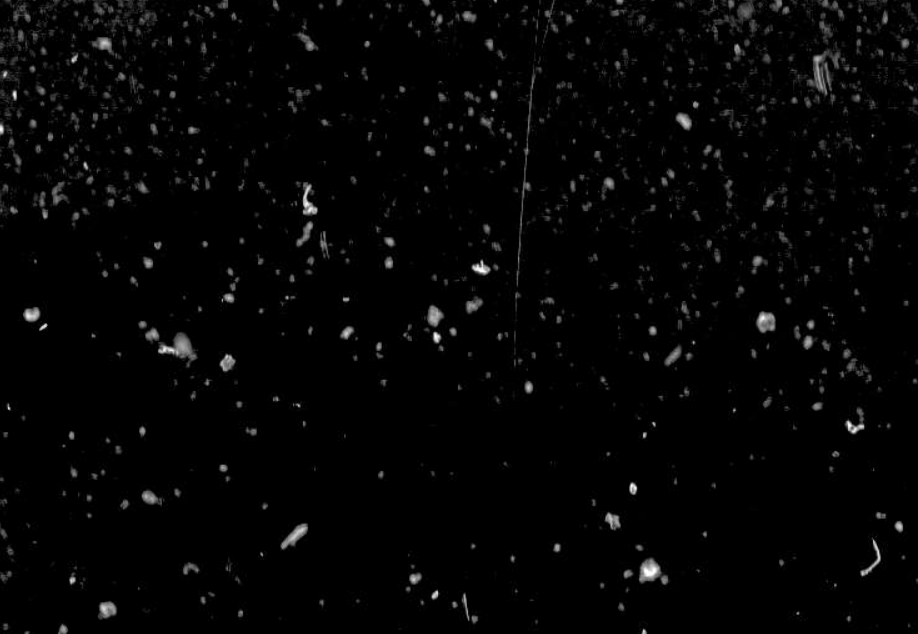

s.<smiles>[131IH]</smiles> 

ANL - 76- 30

\section{ARGONNE NATIONAL LABORATORY \\ 9700 South Cass Avenue \\ is gonne. Illinois 69439}

PI.UTONIUM SAFETY TRAINING COI ASE

by

H. J. Moe

Te cupationel Health and Safety Division

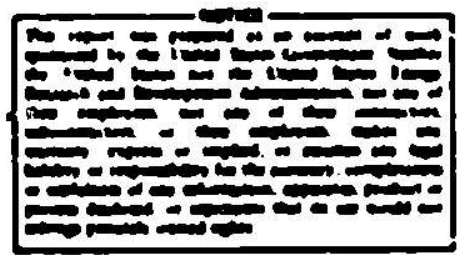

Merch 1976 

TABLE CF CONTENTS

Pape

ABSTRAC:

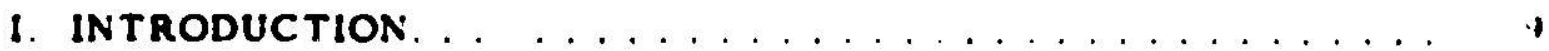

A. General Salety-design Appreach. .............. 10

B. Safetv-desisn Philosophy ................... II

C. Operational Salety Meaturee .................. 12

D. Healih́n-physice Measures .................. 12

E. Saloty Achievement .................... Is

U. PROPERTIES OF PLUTONIUM. . . . . . . . . . . . . . It

A. Chemical and Phyeical Propertles ................ It

B. Rediologic Propercies . .................. Is

1. Int roduction ........................ 15

2. Atomic Structuro .................... Is

3. Radioactive Deray. ... ................ 16

4. Types of Radiation ..................... 16

5. Plutonium formation. . . . . .............. 19

6. Radioactive Decay of Plutonium. . . . . . . . . . . . 21

7. Spontancous-ficaion Neutron Radiation ........... 21

8. Noutron Emiesion trom Compounde .............. 23

C. Nuclear Propertios ...................... 24

I. Neutron Reactione. ..................... 24

2. Fiseion........................ 24

3. Fiseton in Plutonium. . ............... 26

D. Pyrophoric Properties . . . . . . . . . . . . . . 27

E. Propertles of Treneplutonium Nuclides . . . . . . . . . . . . 28

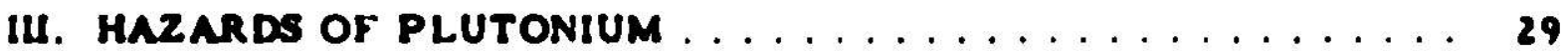

A. Radiation Hexards . . . . . . . . . . . . . . . 29

1. Reletive Hezarde ...................... 24

2. Blolonical Eilncts of Radiation ................ 31

3. External and Internal Exposure Aepecte . . . . . . . . . . 35

4. Radlation-protection Standarde ............... 37

5. External Dose Rates from Plutonium . . . . . . . . . . . 38 
TABLE OF CONTENTS

Page

B. Toxic Hazards . . . . . . . . 41

1. Toxicity of Internal Emitters ......... 41

2. Toxic Features of Plutonium. . . . . . . . . . . . . . 42

3. Toxic Effects of Plutonium . . . . . . . . . . . . . . 44

4. Toxic Index . . . . . . . . . . . . . . . . . . . . . 45

C. Criticality Hazards .................. 45

D. Fire and Explosion Hazards ........... 47

1. Personnel Hazards .......................449

2. Contamination Hazards ................. 49

3. Plant Damage....................... 49

4. Criticality Hazards . . . . . . . . . . . . . . . 50

E. Hazards of Transplutonium Nuclides. . . . . . . . 50

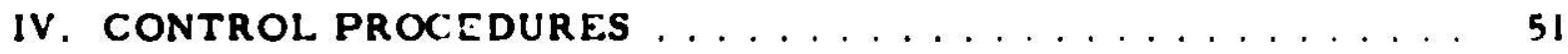

A. Introduction ....................... $\ldots 1$

B. Contamination Control .................. 53

I. Philosophy of Contamination Control ........... 53

2. Contamination-control Practices ............ 55

3. Control Prublems . . . . . . . . . . . . . . . . . 56

4. Health-physirs Control Messures ............ 56

C. Internal Exposure Control. . . . . . . . . . . 61

1. Personnel Monitorink Measures ...............6 61

2. The rapeutic Measures................... 62

3. Protective Equipment ............ 62

D. External Exposure Control ...................63

1. Exposure.control Practices .................664

2. Shielding ....................... 64

3. Health-physics Control Measures ............ 65

E. Nuclear Safoty ..................... 67

1. Control Mothods . . . . . . . . . . . . . . . . . 67

2. Administrative Control. .................. 69

3. Monttoring and Dosimetry Practices .............. 69

F. Fire salety. ...................... 70

I. General Discuseion. ................... 70

2. Fire Extinquiehment ................. 71 
TABLE OF CONTENTS

Page

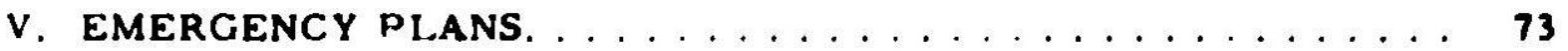

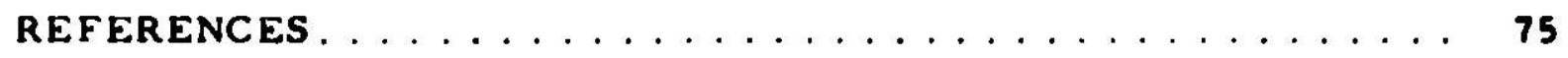




\section{LIST OF FIGURES}

No.

Title

Pake

1. Confinement and Containment for a Plutonium Laboratory. .

2. Atomic Structure of ${ }^{239} \mathrm{PL}_{\mathrm{L}}$

3. Formation of Plutonium Isotopes and Daughters

4. Plutonium Isotopic Composition a a Function of Uranium Burnup. 20

5. Fission Procesa in "S due to a Thermal Neutron ... 25

6. Mechanisms of Inhalation and Ingestion of Radioactive Matter 36

7. Prompt Radiation Dose from a Burnt of 10's Fissions..... 47

8. Design for Contamination Cont rol. . . . . . 54

9. Sihematic Diagram of Typical Filter Sample 60

10. Exa isple of Safe Ceometry for Pipes or Cylinders . . . 67

11. Interaction Effects in Adjacent Containers..... 


\section{LIST OF TABI.ES}

No.

Title

Page

1. Physical and Chemical Properties of Plutonium. . . . . . . . . 14

I1. Decay Features of Selected Isotopes . . . . . . . . . . . . 22

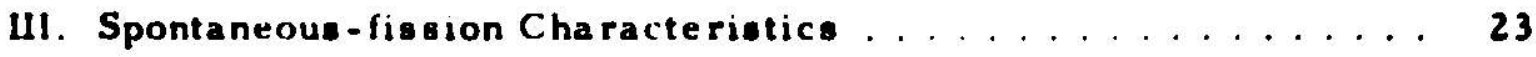

IV. Fast-neutron Emission from Selecied Compounds . . . . . . . 24

V. Thermal Cross Sections of Plutonium Isotopes . . . . . . . . 26

VI. Ignitıon Characteristıcs of Plutonium Metal . . . . . . . . . 28

VII. Selected Transplutonium Nuclide Properties Relative to ${ }^{239} \mathrm{Pu}$. . 28

VIII. Practical Quality Factors .................. 33

1X. Represencative Dose-effect Relationships in Man for Wholebody Irradiation. . . . . . . . . . . . . . . . . . . 34

X. Radiation-protection Standards for External and Internal Exposure for Individuals in Controlled Areas . . . . . . . . . 38

XI. Photon Surface Dose Rates. . . . . . . . . . . . . . . . 39

XIl. Body Burdens and Maximum Permisuible Concentrations . . . . 45

XIU. Basic Nuclear Parametere for ${ }^{239} \mathrm{Pu} \ldots \ldots \ldots$

XIV. Occupational MPC andi Body Burden for Solected Nuclides . . . . 56

XV. Transmisuion of $X$ and Gamma Raye in Selected Materials . . . 64

XVI. Averare $Q$ Values, and Neutron-fux Densities That Delivar a Maximum Dose Equivalent of 100 mrem in $40 \mathrm{hr} \ldots \ldots 66$ 



\title{
PLUTONIUM SAFETY TRAINING COURSE
}

by

H. J. Moe

\begin{abstract}
This course seeks to achieve two objectives: to provide initial safety training for people just begınning work with plutonium, and to serve as a review and reference source for those al ready ongaged in such work. Numerous references have been included to provide information sources for those wishing to pursue certain topic more fully.

The first part of the courece content deals with the general safety approach used in dealing with hazardous materials. Following is a discussion of the four properties of plutonium thet lead to potential hazards: radioactivity, toxicity. nuclear properties, and sontaneoue ignition. Next, the various hasards arising from these properties are treated. The relative hazards of both interna' and external radiation sources are discused, as well as the epecific hazards when plutonium is the source. Similarly, the general hazards involved in a criticalitv. fire. or explosion are treated. Comments are mads concerr ". the specific hazards when plutonium is involved. A brief summary comparioon between the hazards of the transplutonium nuclides relative to ${ }^{239} \mathrm{Pu}$ follows.
\end{abstract}

The final portion deals with control procodures with reepect to contamination, internal and external exposure. nuclear cafety. and fire protection. The philosophy and approach to emergency planning are also discussed.

\section{INTRODUCTION}

Since the diecovery of the man-made element plutonium in 1941, the importance and usefulness of this olement has eteadily increased. ${ }^{1-1}$ In addi. tion to ite application in nuclear weapone, plutonium ie en important source of nuclear fuel for the production of electric power in resctors. Lightweight plutonium-fueled power units produce electricity to run devices such a pacemakere and epace experiment packages. Plutonium is uued with certain other materials to produce a source of neutrone. This element is also useful in the detection of noutrons. The element is used as a source material for the production of other substences called traneplutonium elemente. A number of these elemente have al ready been produced. 
The first pluionium was produced from uranium in a cyclotron. Since then, much greater amounts have been produced frorn uranium used in reactors. Reactors using uranium of low enrichment as fuel produce large amounts of plutonium. However, much of this plutonium is also used up as the reactor fuel before it can be recovered. The net content of plutonium in discharged fuel runs about $0.5-1.0 \%$. This can then be recovered for reuse when the spent fuel is reprocessed. ${ }^{4}$ Since existing power reactors generate so much plutonium, the recycling of this plutonium for use as the fuel of the power reactor is an attractive concept.

The special features of plutonium that increase its utility require that this substance be handled most carefully. This need for safety arises from four main features of the element. First, plutonium is an unstable substance, whose decay results in the release of radiation. This radiation may present a hazard, even if one is distant from the source. Second, the element is toxic. Intake into the body may reoult in long-term deposition in bore with severe local damage at these sites. Third, the substance is fissile. When enough of this material is present in the proper setting, a fission chain reaction can oc-

cur. Such an event would release large amounts of energy and radiation. Fourth, some forms of plutonium are pyroploric; that is, they ignite spontaneously. Once started, a fire could spread rapidly and result in great damage. To reduce the hazard potential and to achieve safety in handling plutonium, control of these fiatures is required.

\section{A. General Safet/-design Approach}

Through the years, the safety-design philosophy for plutonium has evolved into the central theme "confinement and containment." Confine the process to ensure a barrier exists between the worker and the toxic substance. The barrier then protects the worker from the hazards of the material. A source enclosed in a capsule would be a simple means of confining s enclosing the material. Sometimes, both the substance and the process need to ie confined, and enclosures such as hoods, gloveboxes, hot cells, and other structures a re us ed. $5-13$

Containment refers to preventing the release of a confined substance. A release should not result in the discharge of a hazardous amount of the confined substance from the facility. ${ }^{14}$ This requires the presence of other systems to contain any release of confined material when an accident occurs. Proper design of airflow patterns and tandem exhaust filtering provide a multiple barrier to releases. Airflow patterns are directed from clean areas toward those in which hazards may develop, as shown in Fig. 1. Air in these areas flows from offices through corridors into the laboratory to pass through the et:closed system. The enclosure (hood, glovebox, etc.) atmosphere is dis charged through the filter system. The flow pattern is always into the enclosure, which reduces the chance of material escaping. The room, the airflow, and the filter system provide the containment. Other more detailed ventilation syatems may also be devised. ${ }^{15-16}$ 


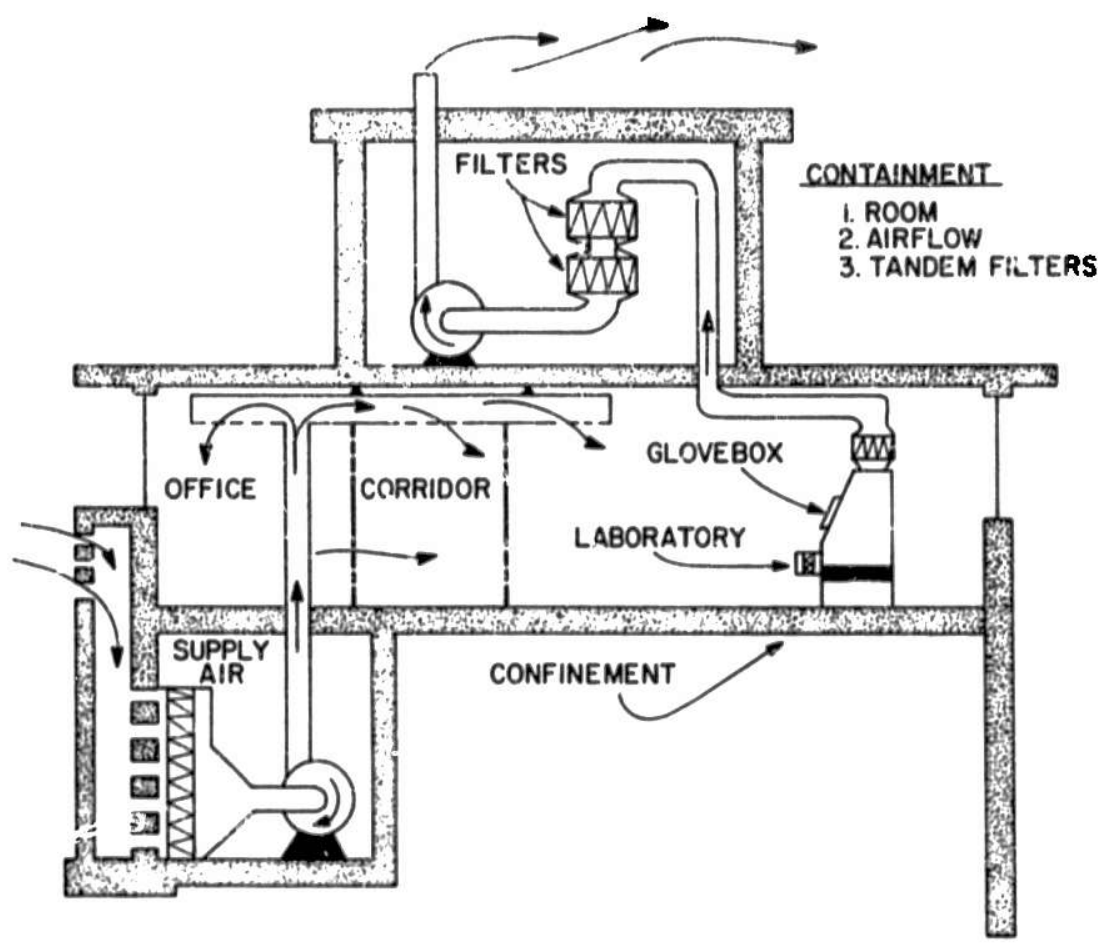

Fig. 1. Confinement and Containment for a Plutonium Laboratory

B. Safety-design Philosophy

The purpose of the safety design in all cases should be to achieve these goais:

3. Ensure that personnel radiation exposure is kept as low as reasonably achievable under normal operations.

2. Control effluent release to ensure no increase in present environmental background levels occurs. Ensure that any radiation exposure to nearby population groups is kept as low as reasonably achievable. Design systems to prevent the release of hazardous levels of material in the event of accidents.

3. Include features that will prevent or reduce the severity of incidents. The impact of the event in regard to personnel injury and threat to life should be the prime concern. Damage to property and program delays should also receive some thought. ${ }^{14}$

Bocause of the apecial hazards that are present in work with plutonium. many design features must be treated. The type of functions to be carried out will affect the degree of safety needed. Banic atudies of the site, plant layout, ventilation patterns, waste-handling needs, fire-control approach, radiationcafety problems, and nuclear-safety aspects will dictate many design goals. ${ }^{7,17-20}$ Structure design, process flow, confinement, and containment through glovoboxes or other devices will also call for a certain level of engineered safety. ${ }^{11,12,19,20}$ The form, amount, and composition of the plutunium handled are also factors. These aspects modify the extent of hazards expected from the radiative, biological, nuclear', and ignition properties of plutonium. 


\section{Operational Safety Measures}

The design of safety features into the plant or process is but part of the effort needed to attain safety. Since workers must still perform certain required tasks, human error can be a factor that cancels any gain made by built-in safety. For this reason, a proper administrative approach to safety is crucial. Policy must require and promote safety as an integral part of proper work methods. Such an approach demands that instructions, procedures. or manuals stating the correct sequence and safe methods of performing the work be prepared in detail. ${ }^{5,7,12,21}$ Responsibility for safety, as well as work responsibilities, should be pointed out at each level of job function. Included in the writeup should be safety procedures in regard to waste disposal, fire control, accident prevention, initial decontamination, radiation safety, a:ıd emergencies. 5,7 The material should be reviewed and updated on a $r$ equent basis.

Employees should be instructed in the proper procecures and made aware of their safety responsibilities. The worker has primary responsibility for his own safety, since he performs the work. The worker should be welltrained not only in regard to proper work methods, but also in regard to safety measures. Frequent review and training in regard to safety aspects should be provided. Drills and reviews of the proper action to be taken during emergencies should also be conducted.

The employee should be made aware of whatever hazards are involved in the process. He should be trained in measures to avoid fires, accidents. explosions, and injuries. Workers should know what emergency plans exist and the functions of the emergency groups. They should be instructed in how to obtain help quickly from the proper support p.oup. Training should cover the alarm systeriss, what they signify, and the proper response to the alarms.

\section{Hea:th-physics Measures}

Even though design seeks to prevent accidents, and work is done in a safe manner, one cannot overlook the potential for acciclents to occur. These events may result in the release of radioactive matter. Thus safety measures should be backed up by an active health-physics program.

Enclosing the process excludes the toxic substance from the worker's environment. This measure protects him from the toxic effects that result from intake into the body. By proper shield design, external radiation exposure to the worker can be controlled. However, when a breach in the system occurs, this control is lost and serious hazards may result.

The term "contamination" may be used to denote the presence of unwanted radioactive matter. The control of the spread of contamination is one of the functions of the intact enclosure. Alarm devices that respond to a preset 
radiation level or to the presence of radioactivity in air denote on a gross scale when contamination control is lost. A health-physics program provides personnel and area-monitoring services that help control the spread of contamination. Frequent surveys of an area or personnel with instruments allows early detection of any contamination. Air sampling allow s mall amo'unts of radioactivity to be found. These measures point out small defects in the control system before major hazards occur. In this way, the spread of contamination is limited and measures to locate the defect can be undertaken.

Other aspects of a health-physics program will be discussed later. These include such things as personnel monitoring, bioassay programs, instruments, surveys, remote monitors, and emergenc' planning.

\section{E. Safety Achievernent}

A certain degree of safety can be iesigned into a plant or process. Over and above this, safety practices can be written up, presented, and promoted. Workurs can be instructed, trained, and retrained in safe practice and in recognizing hazards. A health and safety program can augment these featuree by maintaining the safuty control achieved by these measures. In the final analysis, the achievement of safety requires a balanced effort which involves the planning and cooperation of many groups. When the concept that safety is a shared responsibility is accepted, then the goal of a safe program can be realized. 


\section{PROPERTIES OF PLUTONIUM}

Although more research has been devoted to methods of producing and using plutonium, much knowledge of the properties of this substance has also been collected. ${ }^{2,2,22,23}$ Plutonium, an unstable element of atomic number 94 , is a heavy metal. This substarce (given the symbol Pu) is artificially produced during fuel burnup in reactors. The metal has many unique properties. Some of these affect the degree of hazard involved in plutonium work. Some make this substance very hard to work with under certain conditions. Others make this metal very useful. No other metal has such diverse properties. In this section we discuss some of these features to provide a background for later treatment of plutonium hazards.

\section{A. Chemical and Physical Properties}

Plutonium metal, which has a bright, silverlike appearance, quickly tarnishes in air. ${ }^{2}$ It corrodes faster in moict air than in dry air. Plutonium is highly reactive. It combines with oxygen to form $\mathrm{PuO}_{2}, \mathrm{PuO}$, and $\mathrm{Pu}_{2} \mathrm{O}_{3}$, reacts with some acids, and forms stable compounds with most nonmetallic elements. The metal exists in six distinct crystal forms (phases) within certain temperature ranges. At room temperature, the metal is normally in the alpha phise. Upon being heated, the metal will expand in some phases and contract in others. When unalloyed, it is hard and brittle: as an alloy, it may become soft and ductile. Although a metal, it is not a good conductor of heat or electricity as most metals are. Because of its radioactive decay. it will self-heat, and this may damage the metal or compound. As decay occure, a change in the chemical makeup takes place as the plutonium changes to other substances. ${ }^{2}$ Table I. adapted from Ref. 7, contains a brief summary of come of the satures of this metal.

TABLE I. Physical and Chemical Properties of Plutonium ${ }^{2,1,22}$

Density

Melting point

P.sre metal

Alloye

Boiling point (pure metal)

Oxidation rate

Action of acide and bases
15.9-19.9 $\mathrm{g} / \mathrm{cm}^{3}$. depende on metal phase.

$640^{\circ} \mathrm{C}$.

Up to $2000^{\circ} \mathrm{C}$, varies with alloy.

$3327^{\circ} \mathrm{C}$.

Slow. Ir. dry air.

Rapid under moist conditione or when heated.

May result in a low spontaneous ignition temperature.

Dissolves readily in concentrated hydro. chloric, hydrolodic, and perchloric acide.

Attacked by most dilute ecide: not readily attacked by concent -ated sulfurte and ni. tricscids or sodiun. inydroxide culut!: ne. 
B. Radiologic Properties

1. Int roduction

The basic structure of all matter consists cf the union of one or more of the atoms of certain elements. Air, water, and ualt a re matter composed of nore than one element. Lead, silver, and gold are matter composed of only one element. Each element has a symbol by which a compound may be expressed. Plutonium dioxide may be written $\mathrm{PuO}_{2}$; that is, one atom of plutorium (Pu) and two atoms of oxygen (O).

Of the more than 100 known elemenis, 90 have been found in nature and the reat have been artificially produced. Some natural elements and all man-made ones are unstable. This mans that these ubstances undergo changes to become other elemente untii a stable form is reached. This change may be quite rapid or may require millions of years to achieve the final atable state.

\section{Atomic Structure}

The changes in unstable elements reflect adjuetments in the structure of their atoms. An atom is thought to consist of nucleus surroundec by

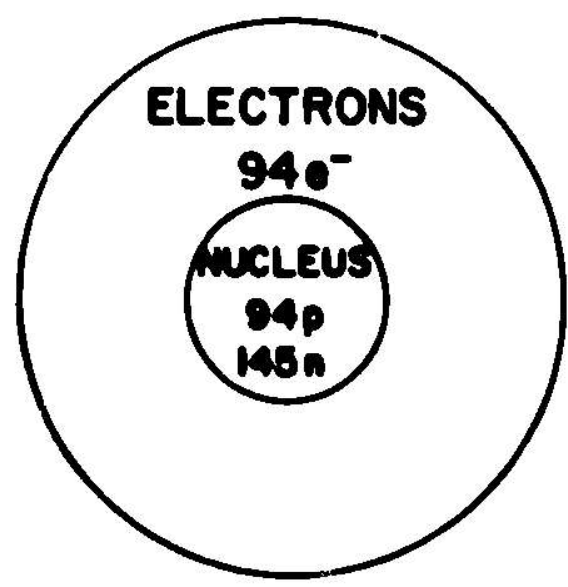

Fis. 2. Atomic structure of $20 \%$ hy enough electrons to produce no net cherge. The nucleus is the maseive, central, positively charged portion of the atom, composed of neutrone and protons (eee Fig. 2). The neutron and the proton are particles of about equal mase. The neutron is electrically neutral: the proton had a unit posi. tive charge, and the electron carries a unit negetive cherfe. The etructure of an atom of an element may be denoted by $\$ X$. where $X$ etands for the element symbol. The mase number. $A$. aives the total number of neutrons and protons in the nucleus. $Z$ is called the atomic number and aives both the number of protons for poeitive che rees) in the nucleus and the number of elec. trone (or negative cherzee) outelde of the nucleus. The noutron number is obteined by oubtracting $Z$ from A. On the batic of atomic welghte. both the noutron and the proton have about unit mase. 0 the mase number ts the closest whole number to the stomic weight. The emall electron mase odde little to the atomic waight.

The chemical mature of any elemeat is a function of ite atomic number. If the $Z$ number changes. the eubstence becomes some other element dencted by the new $Z$ number. However. the eame element mas hase atome that differ in mase number. The term "lectope" le uead to dencte atoms with the oame atomic nur' or tut with different atonite mase. Since 2 is the same, lectopes have equel numbere of protone, but the number of neutrone vertee. 
The stability of an atom is related to the mass of that atom. The lighter elements, in which the neutrons and protons are about equal, are usually stable. For those of larger mass, an excess of neutrons is required for an atom to be stable. For very large atoms $(Z>84)$, the mass seems to be. come too larke to maintain a stable state. When this occurs, all the isotopes of a given element will be unstable and will adjust their structure until a stable state is attained.

\section{Radioactive Decay}

To alter the structure of an unstable atom requires a change in the composition of thi nucleus. This can be done if the atom undergoes a change in the number o: neutrons or protors. One way in which the atom brings about this change is called radioactive decay. In this decay or disintegration process. the nucleus of an unstable atom spontaneously emits certain radiations, which alter the nuclear structure. For a given lubstance, the rate of decay of its atoms is characteristic of that isotope of the element. The half-life, wi:ch expresses the tim? for one-half of the atoms in a given sample to decay, is related to the rate of decay.

\section{Types of Radiation}

The term "natural radioactivity" is applied to unstable or radioactive substances that are found in man's natural environment. These emit one or more of three types of radiations: alpha, beta, and gamma rays. Radioactive substances can als 4 be produced by artificial means. such as reactor irradiation, accelerator sombardmert, and other ways. These processes also produce other radiations: $X$ rays, positrons, and neutrons.

Radiations are emitted with various amounts of energy, which can be related to the specific source. As they move thrighh matter, this energy will be lost. The rate of loss depends on the type of emission, the nature of the interaction. and the kind of substance involved. The transfer of the energy to matter resultn in the release of electruns from the atoms of the substance. The process whereby electrons are removed from a neutral atom is called ionization. For this reason. the radiations mentioned above are called ionizing radiations. Sometimes. no electrons are removed during energy transfer to the atom and the procese is called excitation.

- Alpha Rediation. Alpha particles (a) are helium nuclei $\left({ }_{2}^{4} \mathrm{He}\right)$ emitted with a discrete energy and a characteristic half-life of emission. Most naturally occurring alpha sources (atomic weight $>200$ ) emit particles in the energy range $4.9 \mathrm{MeV}$. (The $\mathrm{MeV}$ is a ueful energy unit used in nuclear physice and stands for million electron volte.) Alpha particles lose ener.y mainly by direct ionization and excitation. An alpha particle carries a druble posilive charge and has a relatively large maes so that it forme a large num. ber of lons along its track and hence quickly loses onergy. An alpha particle 
is easily absorbed by a few sheets of paper or the outer (dead) skin layer of the body. For alpha particles from natural sources, the range in air is only a few inches.

b. Beta and Positron Radiation. Beta particles (sometimes called negatrons) and positrons aresimilar and possess many of the same features:

(1) Beta particles $\left(\beta^{-}, e^{-}\right)$are electrons emitted at high speed from the nucleus of the radioactive atom. The electron is a small particle (mass about 1/7300 of that of an alpha particle) with a single negative charge. Buta particles are emitted with a continuous energy spectrum up to some maximum energy, which is characteristic of that nource. Natural beta sources emit particles with maximum energy up to about $4 \mathrm{MeV}$. Low-energy beta particles lose energy mainly through direct ionization and excitation. Some of the energy loss may be through a conversion process called bremsitrahlung (braking radiation), which gives sise to $X$ rays. This conversion process becomes increasingly important as the energy of the beta particle increases and may be the major process at high energies.

Because of the single charge and small mass, beta particles lose energy les 3 rapidly than alpha particles. Ionization by beta partirles is roughly 100 times less than that for alpha particles. Beta particles have ranges up to many feet in air and will penetrate a few millimeters of body tissue. $X$ rays are produced in stopping beta particles, and these may also lose energy in the medium.

(2) Positrons $\left(\beta^{+}, e^{+}\right)$a re positive electrons having the same rest mass as an electron but with a positive charge. They are omitted from certain artificially produced radioactive substances with a continuoue energy spectrum up to some maximum energy characteristic of the source. Ponitrons and electrons may also result when high-onergy gamma rays interact with matter. The positron lones its energy by the same procesese that electrone do. However. a positron that has lust its energy of motion existe for only about $10^{-9} \mathrm{sec}$. It then isteracts in a process called annihilation, which re. leases a pair of gamma rays. The gamma rays may then aloo looe erergy in the mediuns.

c. $X$ and Gamma Raye. $X$ and gamma raye a re electromagnetic radiation simila $r$ to light, but of shorter wavelength. They are called photone and possess similar properties. A photon has an effective morrentum, but no mass or charge. Gamma ray in a term usually applied to photions emitted from the nucleus, $X$ rays to those produced cutside the nucleus of the atom.

The gamma raye that often accompany alphe- and beta. particle emiseion are emitted with diecrete onergies. Thie eneray indicates a transition of an excited nucleus from one level to a more atable one. 
$X$ rays (bremsetrahlung) produced when high-energy charged particles are stopped in matter have a spectrum of energies the spectrum varying from ze ro up to the particle energy. Characteristic $X$ rays (discrete energy) are emitted when an excited atom returns to a normal energy state.

Photons lose energy to matter by three main processes: photoelectric effect. Compton effect, and pair production. ${ }^{24}$ Other processes such as photofission and nucleas reactions occur only for very-high-energy photons. In the three main processes, the photon is eithe $r$ absorbed or scat tered and energetic electrons are released. These secondaries $\left(e^{-}\right.$and $\left.e^{+}\right)$ produce most of the ionization that results in the substance. Thus, $X$ and gamma rays ionize in an indirect manner.

$X$ and gamma rays can travel great distances in a medium before losing any energy. As the photon proceeds onward. it loses no energy until an interaction takes place. The chance of a photon interaction along its path remains constant until one occurs, but only a fraction of all available photons interact at any given point. The rest of the photons move on without any energy loss. The discontinuous feature of photon-energy transfer gives $X$ and gamma rays great penetrating power. Even in dense media, such as lead, the penetration 18 gignificant. Photons can enter deeply into the body or even pase through it without interacting.

d. Neutruns. Neutrons $\left(\begin{array}{l}1 \\ 0\end{array}\right)$ are uncharged particles of atomic weight slightly greater than a proton or hydrogen nucleus ( $\mathrm{H} H$ ). They are found in the nucleus of every elsment heavier than hydrogen and in all bist one hydrogen isotope. Outside of the nucleus. neutrone are unstahle and are transformed to protons after beta decay.

Neutrone are not emitted from natural sources. They result from fistion in reactors and ; ce emitted when certain heavy clemente undergo epontaneoue fiseion (see Sec. 7 below). Accelerators produce neutrons when high-energy particles strike euitarle targets. Radionctive cources. combined with the proper turget substanco. yield neutrons through reactions of the tar. pet nucleus and the omitted radiation. These are referred to as (o. $n$ ) or $(i, n)$ reactions. The iission procese and $(0, n)$ reactions produce neutrons with a epectrum of energien. Accelerator and $(v$. $n)$ procosece yield nearly monoenergetic neutrons.

Ae they traverse matter. neutrona lose eneruy through nuclear interactions with the membe: elements of the medis. A number of proceseos niay take plere: olestic ecattering. inelastic ecattering. and absorption leadink to radiative capture. fiesion. charped-particle reactione. or $(n$. $2 n)$ reactione. 24,24 In those proceseses. nuutrons. cherped perticles (recoil nuclet or omitted par. ticles). and remma raye are reloased. The ionization that takes place result:

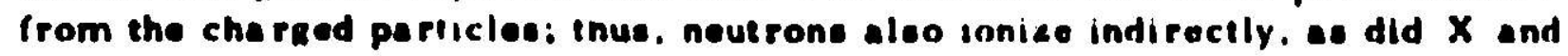
nemme rey. 
As with $X$ and gamma rays, neutrons can penetrate to great depths in a substance. Necitrons lose no energy until one of the competing processes occurs at some point. This means that neutron energy transfer is a discontinuous process as was the case for photons. Since energy is not lost continuously along the path, neutrons can enter deeply into the body or may even pass through without being absc bed.

It is customary to categorize neutrons in terms of the energy ranges in which certain effects predominate. The NCRP ${ }^{26}$ uses the following scheme: the rmal $(0.025 \mathrm{eV})$, intermediate or resonance $(1.0 \mathrm{eV}$ to $10 \mathrm{keV})$. and fast (>10 keV).

\section{Plutonium Formation}

In Sec. 3 above, it was mentioned that the structure of an unstable atom can be altered by changing the number of neutrons or protons. In radioactive decay, the atom ejects matter, so that the trend is to refuce the size of the nucleus. On the other hand, changes in the nuclear structure may also be caused by adding neutrons or protons. 27 Such was the manner in which plutonium first came into being. ${ }^{2,27}$ The unstable element uranium was bombarded by deuterons $\left({ }_{1}^{2} H\right)$ to form a new substance:

$$
{ }_{92}^{238} \mathrm{U}+{ }_{j}^{2} \mathrm{H} \rightarrow{ }_{93}^{238} \mathrm{~Np}+{ }_{0}^{1} n+{ }_{0}^{1} n .
$$

In this case, the deuteron enters the uranium nucleus, giving an already unstable atom much more than it can handle. The new excited nucleus "opits" out two neutrons, leaving what remains a new element, ${ }^{230} \mathrm{~Np}$. However, this new element is alco unstable and decays by beta emission:

$$
{ }_{9}^{23} \mathrm{~Np}_{\mathrm{P}} \rightarrow{ }^{23} \mathrm{Pu}+\mathrm{B}-
$$

Shortly after thic first isotope of plutonium was found, the isotope ${ }^{239} \mathrm{Pu}$, which is valuable in the nuclear-weepons progrem, was produced.1,2,27 Although the cyclotron was used to produce the firet plutonium, this method could not be used to make large amounte of the metal. A method that would - upply useful amounte of the subetance wat developed when the first selfeustained chain reaction was achleved.

In the early reactors, natural uranium, compoed mostly of ${ }^{230} \mathrm{U}$ with about $0.7 \%{ }^{23} \mathrm{U}$ and $0.005 \%{ }^{234} \mathrm{U}$. wae ued ae the fuel. The ${ }^{239} \mathrm{U}$ leotope was the actual fuel that kopt the chein reaction going. However. neutrone ro. leased in the liseion or eplitting of ${ }^{235} \mathrm{U}$ could be captured by the ${ }^{213} \mathrm{U}$. Thie capture procees changes $231 \mathrm{U}$, which decaye very elowly. to ${ }^{210} \mathrm{U}$, which decaye quickly. The product of ${ }^{239} \mathrm{U}$ bete decay is ${ }^{209} \mathrm{~Np}$. which aloo bete decays fairly quickly to form ${ }^{210} \mathrm{Pu}$. In thie manner, the eupply of ${ }^{210} \mathrm{Pu}$ could be butlt up. ince the half-life of ${ }^{210} \mathrm{Pu}$ is about 24,400 yeare. 
Not only is the 239-isotope formed in the reactor, but other plutonium isotopes are also produced (see Fig. 3). Further capture of neutrons converts some of the ${ }^{239} \mathrm{Pu}$ to ${ }^{240} \mathrm{Pu},{ }^{241} \mathrm{Pu}$, or even higher isotopes. The relative amounts of the isotopes formed depend upon the type of reactor, the length of irradiation time, and the composition of recycled fuel. ${ }^{7}$ With the advent of power reactors fueled by plutonium, the radiologic properties of the spent fuel are subject to the influence of more isotopes than ${ }^{239} \mathrm{Pu}^{28-30} \mathrm{Fig}$ ure 4 shows an estimate of how the plutonium isotopic composition varies with burnup in uranium-fueled boiling water and pressurized water ieactors. Reference 28 contains estimates of plutonium isotopic composition from plutoniumfueled reactors and a liquid-metal fast breeder reactor.

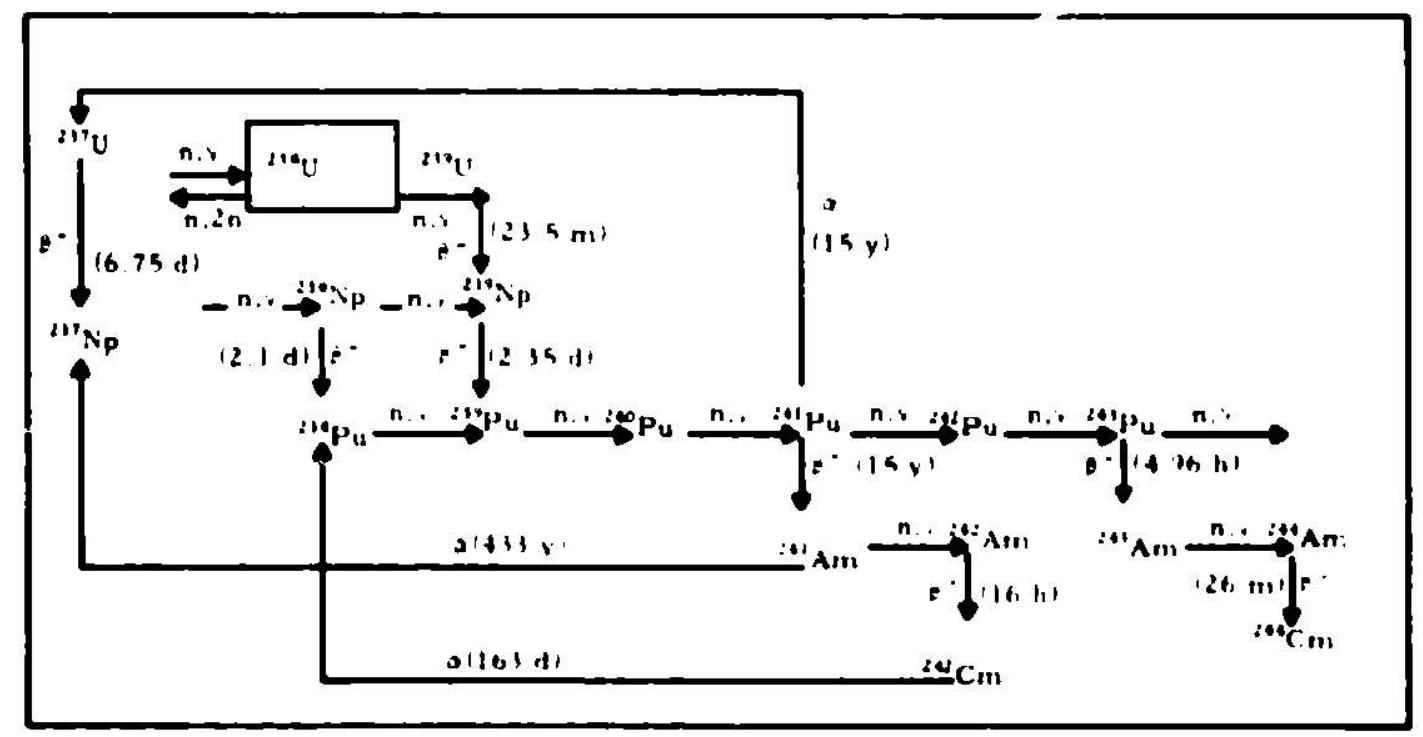

Fig. 3. Formation of Plutunium isotopes and Daughters (Adapted from Refs. 28 and 29)

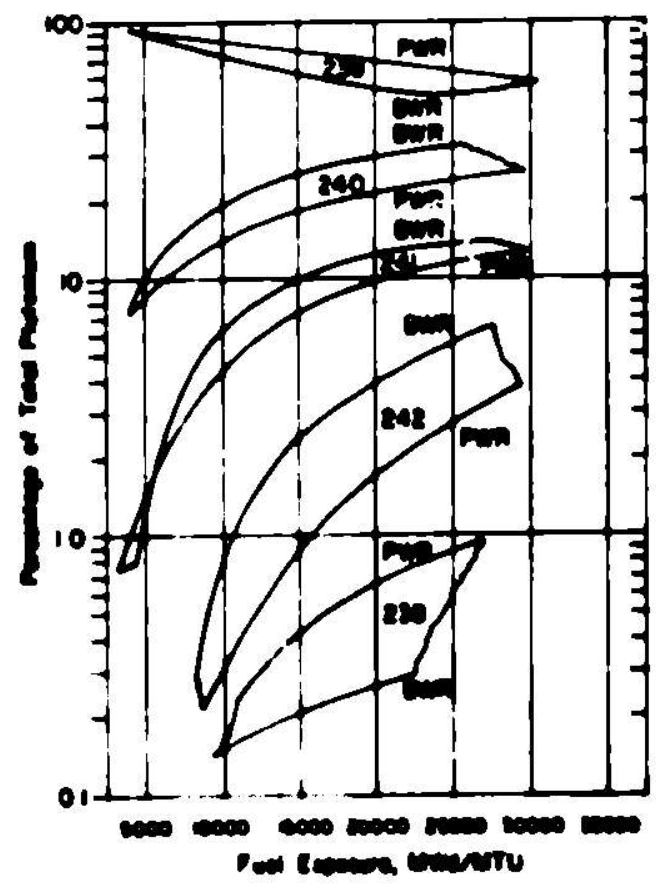

Fig. 4

Plutonium leotople composition as

- Function of Urenium umup 
The la rgest amsunt of plutonium has been produced in reactors. both research and power types. Some plutonium, as well as transplutonium substances, has been produced in accelerators and also has resulted from the rmonuclear-weapons tests.

\section{Radioactive Decay of Plutonium}

The unstable nature of some elements reflects the failure of the forces that bind neutrons and protons in the nucleus. Since like charges repel, protons repulse each other. To balance this, it is assumed that neutrons and protons are attracted by short-range forces. As the mass of the atom increases, though, more neutrons are needed to overcome the repulsive force. If the ratio of neutrons to protons becomes too great, the atom will also be unstatle and will favor beta decay. If the ratio is too low, positron decay would be expected.

In the heavy elements with the large content of protons, the degree of instability is such that alpha decay begins to occur. That is, the nucleus begins to eject larger particles in an attempt to reach a more stable structure. As the mass numbers and proton content go even higher, the imbalance in the forces increases.

\section{A!1 15 known isotopes of plutonium (mass numbers 232-246) are} radioactive. iMnst of these decay by alpha emission. However, ${ }^{241} \mathrm{Pu}$ is a notable beta emitter. For the most part, only the isotopes of mass number $238-242$ and some of their dicay nr daughter products need be discussed here. In this reapect, the product. ${ }^{23} \mathrm{U}$ and ${ }^{211} \mathrm{Am}$ require attention, since they inc rease the amount of gamma radiation as the plutonium ample ages. These products are the only ones from the decay of the $238-242$ group with half-lives short enough to affect the ample activity.

A number of compilatione of the decay fentures of plutonium isotopes and their daughter products have appeared. 1,22,29-15 Table II, adapted p.imarily from Ref. 30 and updated, summarizes some of these festures.

\section{Sponteneous-fission Neutron Rediation}

Fur the heaviest elemints, the atome became so unstable that still additional processes act to change the structure to a more stable one. The unetabla atom may oplit into two large fregmente in a procese called fiesion. Since the atom breake apart in a random procees much like redioactive decay. the procese ie termed "eponteneous" fiseton. As with redioective decay. one can oseign a half-life for epentaneoue fiselon. The chanre of epontaneous fiseion occurring incroeses at the 2 number increases, and those atoms with even $Z$ and even $A$ eeam to heve the shortest eponteneous flesion half-lives." 
TABLE II. Decay Features of Selected lsotopes ${ }^{30.34-17}$

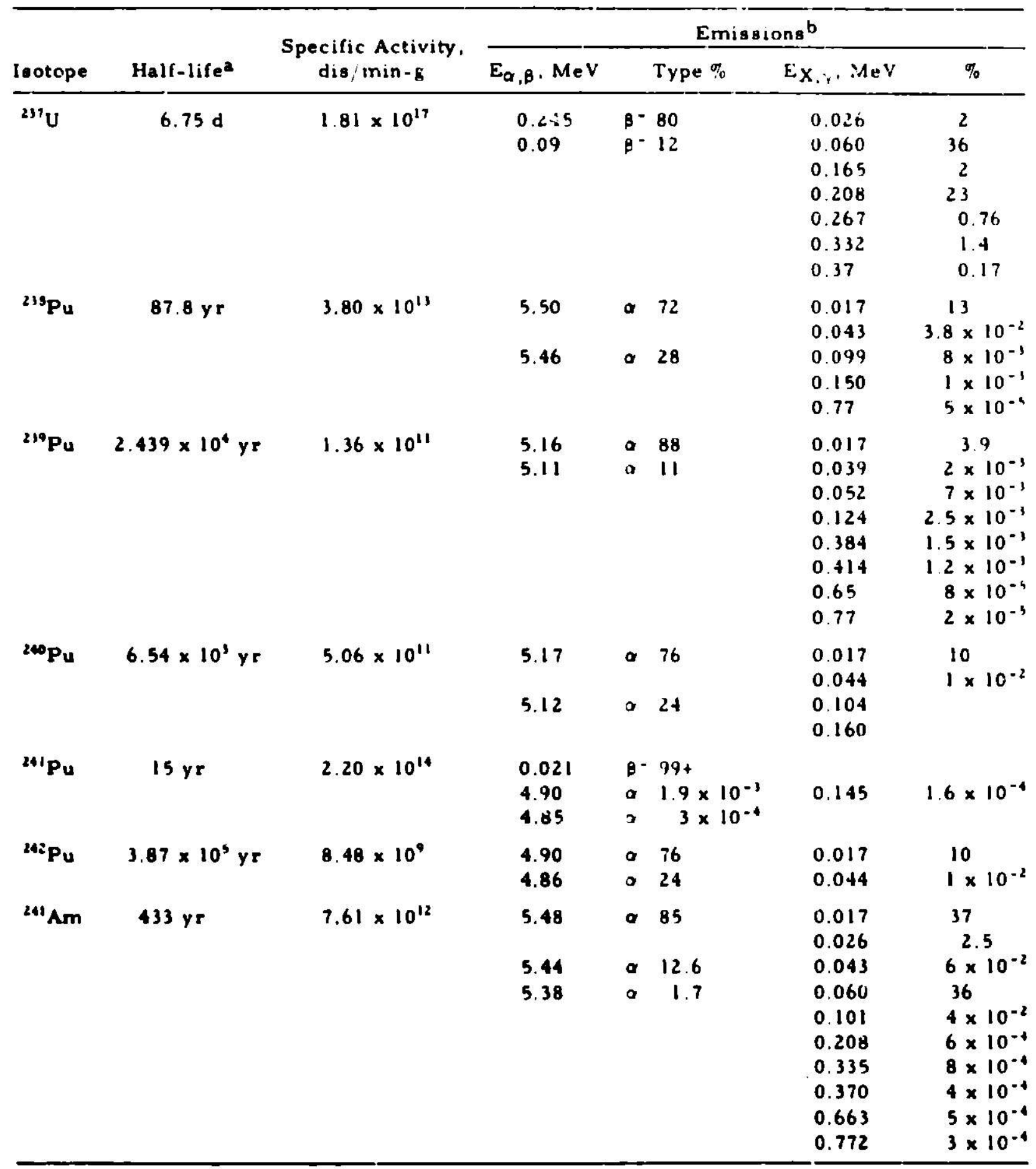

Half-life values were obtained from The Chart of the Nuclidee, April 1972 edition.

bFiguree for the X-ray abundence (0.017 MeV) lieted lor ${ }^{26} \mathrm{Pu}$ and ${ }^{241}$ Am were obtained from

Ref. 39. For a more detalled lieting of $X$ and gamme raye. eee Ref 38 . 
In the fission process, both fast neutrons and gamma radiation are emitted. The number of neutrons per fission is a function of both the atomic weight and the atomic number of the isotope. The neutrons which are emitted in this process will add to the total radiation which must be dealt with. The rate at which these neutrons are emitted will be a function of the isotopic compusition of the plutonium. Table III gives information in regard to the spontaneous firsion aspects of some isotopes.

TABLE III. Spontaneous-fissicn Characteristics

\begin{tabular}{lccc}
\hline Isotope & $\begin{array}{c}\text { Spontaneous Fission } \\
\text { Half-life, years }\end{array}$ & $\begin{array}{c}\text { Neutron Emission, } \\
\text { avg n/fis }\end{array}$ & $\begin{array}{c}\text { Calculated } \\
\text { Emission Rate, } \\
\text { T/P, } / \text { sec-g }\end{array}$ \\
\hline${ }^{238} \mathrm{Pu}$ & $4.9 \times 10^{10}$ & 2.04 & $2.32 \times 10^{3}$ \\
${ }^{239} \mathrm{Pu}$ & $5.5 \times 10^{15}$ & $2.15^{\mathrm{a}}$ & 0.02 \\
${ }^{240} \mathrm{Pu}$ & $1.34 \times 10^{11}$ & 2.23 & $9.22 \times 10^{2}$ \\
${ }^{242} \mathrm{Pu}$ & $7.1 \times 10^{10}$ & 2.32 & $1.79 \times 10^{3}$ \\
${ }^{241} \mathrm{Am}$ & $2.0 \times 10^{14}$ & $2.3^{\mathrm{a}}$ & 0.62 \\
\hline
\end{tabular}

$a_{\text {Not from Ref. } 40 .}$

\section{Neutron Emission from Compounds}

Neutrons produced from plutonium by spontaneous fission may not be the only source of neutrons to contend with. The alphac emitted from plutonium are all emitted with rather high energy (see Table II). These alpha rays are able to enter the nuclei of light elements ouch as aluminum, beryl lium, lithium, oxygen, fluorine, and eodium. Such a process results in a compound product which is in an excited or unstable state. This compound then emite a neutron in an effort to return to the ground or stable state for the new element. These $(\alpha, n)$ reactions result in fast neutrons. The neutron yield and the maximum neutron energy for $(\alpha, n)$ processes are function of the alpha energy and the nature of the target inaterial. There is no simple method by which one can arrive at either the neutron energy or yield.

Although exact neutron-emission ratas from plutonium compounds are not well known, some useful estimate have been made. 30,41 Neutron emiasion from certain compounds should not be neglected, since they can greatly increase the neutron problem. ${ }^{29}$ Table IV liste the rates calculated by Steindler ${ }^{30}$ for plutonium tetrafluoride and dioxide. 
TABLE IV. Fast-neutron Emission from

Selected Compounds

\begin{tabular}{lc}
\hline Compound & $\begin{array}{c}(\alpha, \mathrm{n}) \\
\mathrm{n} / \mathrm{sec}-\mathrm{g} \mathrm{Pu}\end{array}$ \\
\hline${ }^{238} \mathrm{PuF}_{4}$ & $2.1 \times 10^{6}$ \\
${ }^{239} \mathrm{PuF}_{4}$ & $4.3 \times 10^{3}$ \\
${ }^{240} \mathrm{PuF}_{4}$ & $1.6 \times 10^{4}$ \\
${ }^{242} \mathrm{PuF}_{4}$ & $1.7 \times 10^{2}$ \\
${ }^{238} \mathrm{PuO}_{2}$ & $1.4 \times 10^{4}$ \\
${ }^{239} \mathrm{PuO}_{2}$ & 45 \\
${ }^{240} \mathrm{PuO}_{2}$ & $1.7 \times 10^{2}$ \\
${ }^{242} \mathrm{PuO}_{2}$ & 2.7 \\
\hline
\end{tabular}

C. Nuclear Properties

In the section above, our attention was directed to the unstable nature of plutonium isotopes. For spontaneous fission and decay, the events are random, not subject to outside influences. The $(\alpha, n)$ processes, however, show that the radiations from plutonium can affect the nuclei of other atoms. In this section, we will discuss some of the processes that bring about certain effects in plutonium atoms. For the purposes of this discussion, only the actions of neutrons on the nuclei need be treated.

\section{Neutron Reactions}

$A$ number of neutron interactions with matter were mentioned in Sec. II.B.4.d. These types of interactions also occur in plutonium. Some of these processes are more likely to occur with slow neutrons; others are more likely to occur with fast neutrons. Some may hardly occur at all in certain energy ranges, and others may occur to some degree regardless of energy range. For slow neutrons, the three reactions--elastic scatter, rariative capture, and fission--are those most likely to occur. In the fast-neutron region, the proresses of inelastic scattering and $(n, 2 n)$ reactions become possible. Of all these processes, those of capture and fission are of main concern. Radiative capture, i.e., the $(n, y)$ reaction, results in the buildup of the higher isotopes of plutonium in a reactor (see Fig. 3). Because the fission process takes place in plutonium, this substance can be used as the fuel in power reactors.

\section{Fisoion}

The fission process was first detected in the isotope ${ }^{235} U$ and re-ulted from attempts to produce a transuranic element. ${ }^{24,25}$ In studies using 
neutrons to bombard uranium, slow-neutron capture led to beta emitters that were difficult to identify. In the process, a thermal neutron, $n_{\text {th }}$, is captureci by the ${ }^{235} \mathrm{U}$ nucleus (see Fig. 5). This produces a compound nucleus which is

in an excited state. The result is

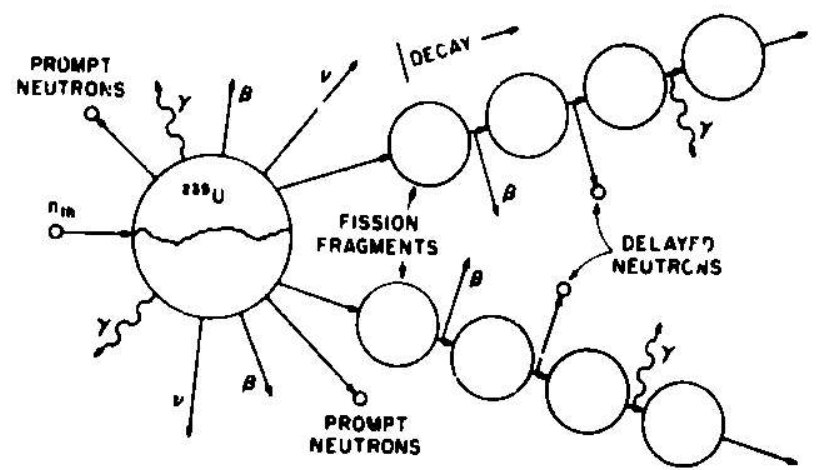

Fig. 5. Fission Process in $235 \mathrm{U}$ due to a Thermal Neutron that the compound nucleus fissions or breaks apart and the two fission fragments carry off most of the energy given up in the process. At the time of the fission, gamma rays, beta particles, and neutrinos $(v)$, are cmitted. as well as neutrons. The beta particles and gamma rays are referred to as prompt. The neutrino is a particle of zero mass which carries off some of the released energy. About $9 \mathrm{MeV} /$ fission of prompt beta par ticles and about $7 \mathrm{MeV} /$ fission of prompt gamma rays are emitted in ${ }^{235} \mathrm{U}$ fission. ${ }^{40}$ The fission fragments corne off with velocities of about $10^{9} \mathrm{~cm} / \mathrm{sec}$ and may have ranges up to $l \mathrm{in}$. in air. Since these fragments have too many neutrons to be stable, they eject one or more neutrons. Most of the neutrons (>99\%) are emitted at fission or slightly after the fission occurs; these are known as prompt neutrons. These neutrons a re emitted almost isotropically with a spectrum of energieg from 0 to $17 \mathrm{MeV}$. The average energy is about $2 \mathrm{MeV}$. Some neutrons (called delayed neutrons) a re released over a period of minutes. The delayed neutrons are emitted at times $>10^{-3} \mathrm{sec}$ after the atom splits. For ${ }^{235} \mathrm{U}$ fission, about 2.5 neutrons a re emited per fission, on the average.

During the decay phase of the fission fragments and resulting fission products, more beta particles and gamma rays a re also given off until stable nuclei are formed. The entire fiseion process results in a release of about $200 \mathrm{MeV} /$ atom fissioned. Of this, fission fragments carry off about $165 \mathrm{MeV}$. Note that this is the energy released in only one fission. This implies that we can obtain a tremendous amount of energy from just a small amount of uranium because it would contain so many atoms. The energy released in the fission of $1 \mathrm{~g}$ of ${ }^{235} \mathrm{U}$ is equivalent to about 21 tons of TNT. ${ }^{24,25}$ The large amount of energy released per fission makes this process very useful as an energy source.

We can distinguish between those substances that can be fissioned and those in which a chain reaction can be sustained. Under the proper conditions, fission has been produced in many substances with $Z \geq 73$. The release of neutrons in the fission process is a vital feature necessary to allow a chain reaction to proceed. The released neutrons may in turn strike other nuclei and lead to more fissions, etc. However, before the chain reaction can maintain itself, a certain amount of the fissile substance nust be present. Other processes compete with fission events for neutrons; therefore the supply of neutrone must be large enough to keep the chain going. Part of the reason is that many neutrons are lost while being slowed to thermal onergy. 
This effect depends upon other substances in the system. Those that slow down neutrons without absorbing them a re called "moderators." Those that tend to aiosorb neutrons are called "poisons." The amount of fissile material needed to sustain fission is called the critical size or mass. For any system the process will be self-sustaining when the number of neutrons lost is balanced by the number produced. In many substances, though, the fission process cannot be made self-sustaining. For this reascn, only ${ }^{233} \mathrm{U},{ }^{235} \mathrm{U},{ }^{239} \mathrm{Pu}$, and ${ }^{241} \mathrm{Pu}$, in which the chain reaction can be maintained, a re of value for present thermal-reactor use.

The fission process is not restricted solely to thermal-neutron captures in fissile substances. Some of these materials may be fissioned by fast neutrons or other agents as well; e.g. ${ }^{238} \mathrm{U}$ is fissioned by fast neutrons, but not by thermal neutrons. In Sec. II.B.7 we saw that some substances even undergo spontaneous fission.

\section{Fission in Plutonium}

All the odd-mass isotopes of plutonium can be fissioned by thermal neutrons, but the short half-life of some of these substances limits their practical value. In essence, ${ }^{240} \mathrm{Pu}$ and ${ }^{242} \mathrm{Pu}$ are nonfissile at low neutron energy. For even-mass products of $A<240$, thermal fission becomes more probable. The probability of fission at any neutron energy may be expressed by the

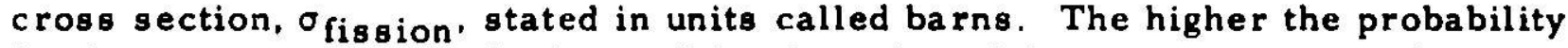
for fission to occur, the higher will be the value of the cross section in barns. The cross-section concept also applies to other processes which compete with fission. Table $V$ gives values of the cross sections for thermal neutrons $(0.025 \mathrm{eV})$ for those processes likely to occur in plutonium isotopes.

TABLE V. Thermal Cross Sections of Piutonium Isotopes ${ }^{42}$

\begin{tabular}{|c|c|c|c|c|}
\hline Isotope & $\sigma_{\text {absorption barns }}$ & ${ }^{o}$ fission barns & ocapture barns & Neutrons/fission \\
\hline${ }^{29} \mathrm{Fu}$ & - & $16.8 \cdot 0.3$ & $403 \cdot 10$ & - \\
\hline${ }^{239} \mathrm{Pu}$ & 1008 & $754 \cdot 9$ & $254 \cdot 11$ & $2.89 \cdot 0.05$ \\
\hline${ }^{2+0} \mathrm{Pu}_{\mathrm{u}}$ & $281 \quad 10$ & $0.030 \cdot 0.045$ & 281 & - \\
\hline$\therefore \mathrm{Pu}$ & $1370 \cdot 15$ & $1030 \cdot 8$ & 340 & $3.03 \cdot 0.05$ \\
\hline${ }^{2+2} \mathrm{Pu}$ & 30 & $<0.2$ & $30 \cdot 2$ & - \\
\hline
\end{tabular}

From the table, it is clear that both ${ }^{239} \mathrm{Pu}$ and ${ }^{241} \mathrm{Pu}$ can be fis sioned oy thermal neutrons. These isotopes may also be fissioned by resonance neutrons, and in that energy iange, the cross-section values do vary dramatically in the region of a resonance. 42 
For fast neutrons above about $1 \mathrm{MeV}$, all the plutonium isotopes are fissile. The cross sections for ${ }^{239} \mathrm{Pu}$ and ${ }^{241} \mathrm{Pu}$ decrease from the high thermal values, but level off to a value of about 2 barns. The fission cross sections for ${ }^{240} \mathrm{Pu}$ and ${ }^{242} \mathrm{Pu}$ rise abruptly in the range $0.4-1.0 \mathrm{MeV}$ to values comparable to those of ${ }^{239} \mathrm{Pu}$ and ${ }^{241} \mathrm{Pu}$. This "fast-fission" feature of plutonium, coupled with the thermal-fission aspect, makes this substance useful as the fuel in both thermal and power reactors.

D. Pyrophoric Properties

Throughout the past years, studies have been conducted on the ignition properties of plutonium. ${ }^{4-47}$ These were undertaken because the metal has proven to be quite pyrophoric under certain conditions. ${ }^{46-50}$ Spontaneous ignition of plutonium metals has resulted in severe fires in which great damage has occurred. ${ }^{51-53}$ Plutonium fires can occur in air with massive forms of the metal, but are more likely to occur when the metal is in a more diepersed form.

The threat cf fire arises mainly in these instances: $:^{49}$

1. In work that involves turnings, chips, powders, or other finely divided forms of the metal.

2. In moist atmospheres, which allow unstable compounds such as plutonium hydride and hydrated plutonium oxide to form.

3. In processes forming certain alloys and metallic compounds that may be pyrophoric.

4. From impure residues, such as partially oxidized crucible skulls. which may ignite spontaneously.

Plutonium metal, in the massive and unalloyed form, oxidizes very slowly in dry air. From Table I, we see that the rate becomes rapid in a moist condition or when the metal is heated. Bolow the ignition temperature, the metal will not support combustion; above this temperature, oxidation occurs quickly. Factors that affect the ignition temperature include the rate of temperature rise, form of the metal, and previous exposure to oxygen. ${ }^{46}$ In studies with small samples, temperatures in excess of $300^{\circ} \mathrm{C}$ have been reported. Recent data support a value of about $500^{\circ} \mathrm{C}$ for large samples of the metal. ${ }^{43,44}$

In the form of the pure metal. plutonium is hard to ignite but when this does occur, it burne without name to form inert $\mathrm{PuO}_{2}$ in air. ${ }^{\text {is }} \mathrm{A}$ plutoniummetal fire is aleo difficult to maintain on a heat-conducting eurface. The peak temperature reached during burning ie directly related to the ratio of surface area to maes. Thus, when a given maes of metal is dispersed as turnings, these will reach a much higher peak temperature during burning. Table VI, prepared from the data of Felt, ${ }^{43}$ containe come ignition features of plutonium metal. 


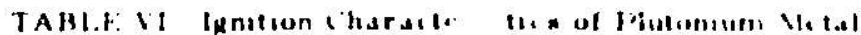

Material
Metal
Metal turning:
Skulls
Hood wotes loak filings
and drill turning:

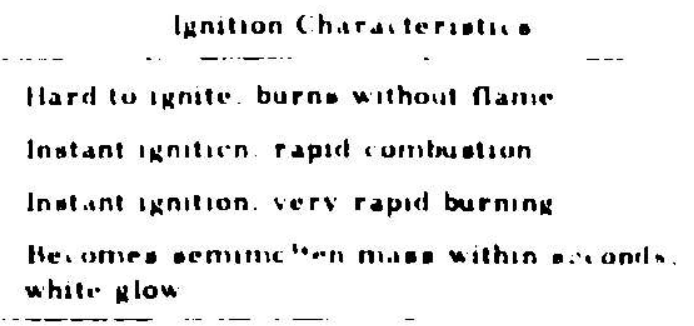

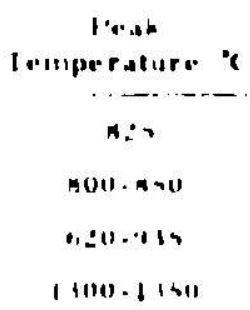

Studies have shown that to completely prevent plutonium ignition and burning requires an inert atmosphere. ${ }^{43,45}$ Teste with argon-air, nitrogen-air. and carbon dioxide-air system reveal that ignition does not occur for oxygen concentrations $<5 \%$ unles finely divided plutonium is involved. ${ }^{4}$

E. Properties of Transplutonium Nuclides

The element plutunium is the sixth member of a series of elements known as the "actinides." 2 The series extends up to element 103 and so includes inany of the transplutonium elements. This series of atoms is 10 grouped because of the oimllar nature of their chemical properties. Mluch of our previous material in regard to plutonium can be applied to these cement: with certain muitable modifications.

No known lootopes of the transplutonium group are atabls. Most decay by alpha emiesion, although beta decay, electron capture, and epontaneous fiesion also occur. ${ }^{39.34}$ In general. the higher $Z$-number products have shorter half-lives, and this means greater decay rates. As the $\%$-number of the isotope increases. the amount or mass of the product that can be produced declines. For this reason, large quantities of these leotopes are not readily found.

The major differences between the tranaplutonic elemente and ${ }^{239} \mathrm{Pu}$ are higher decay rates, shorter spontaneous-flseion half-lives, and more photone emitted per disintegration. ${ }^{30,30}$ Table VII, adapted from Denhain, ${ }^{39}$ compares some of these features with those of ${ }^{239} \mathrm{Pu}$.

TABLE VII Selected Tranoplutonium Nuclide Propertioe Relative to "Pu

\begin{tabular}{|c|c|c|c|c|}
\hline Isotope & $\begin{array}{c}\text { Redioective } \\
\text { Helf-Jife. } \\
\text { years }\end{array}$ & $\begin{array}{l}\text { Activity. } \\
\mathrm{dpm} / \mathrm{E}\end{array}$ & $\begin{array}{c}\text { Spontaneous Fiesion } \\
\text { Hall-dife. years }\end{array}$ & $\begin{array}{c}\text { Calculated } \\
\text { Emiecion Rete. } \\
n / \text { ece }\end{array}$ \\
\hline${ }^{20} P_{11}(0)$ & 24. 3100 & $136 \times 10^{11}$ & $5.5 \times 10^{14}$ & 002 \\
\hline${ }^{\prime \prime 1} A m(n)$ & 411 & $7.61 \times 10^{12}$ & $20 \times 10^{14}$ & 062 \\
\hline "Al Am (e) & 7.170 & $444 \times 10^{11}$ & • & $\cdot$ \\
\hline${ }^{204} \mathrm{Cin}(n)$ & 171 & $1.22 \times 10^{14}$ & $11 \times 10^{\prime}$ & $12 \times 10^{\prime}$ \\
\hline${ }^{34} \mathrm{Cl}(0)$ & 263 & $120 \times 10^{13}$ & 85 & $21 \times 10^{12}$ \\
\hline${ }^{20 *}$ B) $10^{\circ}$ ) & 1). 45 & $375 \times 10^{15}$ & $6 \times 10^{\circ}$ & $27=10^{\circ}$ \\
\hline${ }^{2 N} E=(n)$ & 076 & $+12 \times 10^{16}$ & $7 \times 10^{\prime}$ & $29 \times 10^{\circ}$ \\
\hline
\end{tabular}




\section{IIAZARDS OF PI.U TONiLis}

The hazarda that are present il plutonium handling may be traced to sorne of the leatures discussed in Sec l!. These hasards ariec from the radia. tion. tuxic. nuclear. And ignition leatures of plutoniums. The extent of these hazardo depends upon many factor. among shich are the form. amount, and isotopic composition of the plutunium and the type of operations porformed.

\section{A. Radiation Hazerds}

\section{Relative Hazards}

Tlie relative hazards that radioactive ubstances present can be related to the nature of their emissions. For this reason. the nature of tonizing radiation was diacuseed in Sec. II. I3. t. With rogard to asseseing the hazerd. major fector is the rate of energy lowe in matter. In peneral. radiations with - high rate of energy loss a re more offective in producing biological damage. On the other hand, radiation. that quickly lose onergy do not iravel very lar in any medium. By knowing the properties of the emission. one may refer to it as an internal or external hazard. If the emiseion has a short range in most materials. it will be uf concern mainly os en internal hazerd. If it has a long range in most substances, il will be significant as an external haserd.

a. Rolative Hazerd of Alphe Particles. The very short range of an alpis, particle ín any dense substance maken it ol little concern a in external hazerd. The most energetic alphe particle cmited by natural cources will just penetrate the outermost "dead" layer of skin. Thus, lattle living tiseue will be affected. With the source on the okin surface, an alphe particle needs $-7.5 \mathrm{MeV}$ to get through the dead layer. For most alpha emittere then, no living tisure will be damaged when the source is external to the body.

Once inside the body, the short range and high specific ionization (ion pairs produced per unit path length) of the alphe particle are cause for concern since it then becomes an internal source and may deposit ite energy in localized living tissue. Any damage will be highly localized in a small volume about the deposition site. The more dense energy deposition along the alpha's path is known to be more sffective in procucing damage than that of lesn dense energy deposition frum other radiations." These factore make alphe radiation of vital concern as an internal hazard.

b. Relative Hasard of Beta Particles. Depending upon the particle energy, a bets or poeitron source may constitute an external hasard. Because of their greater range, beta particles of $70 \mathrm{keV}$ are able to penetrate the doad layer of okin and runce depoelt their energy in living tieoue. Since most vital organe are at a depth of $5 \mathrm{~cm}$ ur more, they will be unaffected by beta particlee from sources having tiseue ranges lese thas, this, which is the case for most betu emittere. This source reduces en external bete source to primerily a ekin-exposure problem. Since moet beta particlee a re easlly abeorbed by a emall amount of metal cir plectic, the hesard will usually exiet only vory near the source. 
An external hazard may result from $X$ rays produced when a high-energy beta particle is stop! ed in an absorber (bremsstrahlung radiation). The amount of such $X$-ray production can be minimized by using low- $Z$-number absorbers. For positron emitters, the annihilation gamma rays reguire thicker absorbers tu reduce the external hazard.

As an internal hazard, beta particles are not as significant as alpha particles. The greater tissue range of beta particles means that damage will not be as locaized as for alpha particles. A much larger tissue volume about the deposited beta source will be involved. Some of the energy may actually be lost outside the small organ of concern. Annihilation gamma particles or bremsstrahlung may not even interact in the tissue mass, which mesns that some of the available energy will not be absorbed by the tissue. Also, the less dense energy deposition along the path of beta particles is less effective in producing damage than that for alpha particles. Nevertheless, damage may still be significant, so that beta emitters are of concern as an internal radiation source.

c. Relative Hazard of $X$ and Gamma Rays. X - and gamma-ray sources are significant as external hazards. The great range of photons in air means the hazard may be significant at large distances from the source of radiation. To reduce the hazard, extensive absorbing matter (shielding) is often required. Also, scattered photons may contribute to the hazard. Directsource radiation may be absorbed to ensure no hazard in one direction, while cattered photons may cause a hazard to exist in adjacent areas.

Because $X$ and gamma rays do penetrate to $s$ uch a high degree, the damage to tissue will extend throughout the body as photons pass through it. The deeper and more radiosensitive tissues will be exposed in an external gamma field. These tissues are more vital than skin, resulting in damage that affects the well-being of the body to a greater extent. This makes $X$ and gamma rays of greater concern as external hazards than either alpha or beta particles.

From the standpoint of internal hazards, $X$ and gamma rays are not as significant as alpha or beta particles. The longer tissue range of photons means less energy loss in a small tissue volume than for either alpha or beta particles. Since photon-energy loss occurs only at interaction sites, energy few interactions occur, since the path is small. For those that do occur, the density of energy deposition is similar to that for beta particles. Photons that do not interact in the organ carry away energy that is thus not deposited and therefore not effective in producing damage.

d. Relative Hazard of Neutrons. Neutron sources are significant as external hazarda. Since the neutron moves rather freely through air and other matter, the neutron field may still be hazardous far from the source. Absorbing material can reduce the hazard, but the required amount is often 
large. Scattered neutrons produced in the shielding material can also create concern in adjacent a reas. In addition, radiative capture and inelantic ocattering in the shield may result in enough gamma radiation to cause concern.

As neutrons travel through the body, tissue interactions extend throughout the body. The deeper, more radiosensitive tissues a re exposed to the external neutron field. The amount of damage done is related to the neutron energy. Fast neutrons give up about $80-95 \%$ of their energy in elastic 8 cattering processcs with hydrogen in tissue. The recoil protons from these processes ionize atoms of the tissue. Intermediate and thermal neutrons lose their energy mainly in the absorption reactions: ${ }^{1} H(n, y)^{2} H$ and ${ }^{14} N(n, p){ }^{14} C .{ }^{26}$

Since neutron interactions produce recoil particlea, protons. and gamma rays, the transfer of neutron energy to tissice will vary. The energy deposition from protons and recoil nuclei is more dense than that of electrons. This means that neutrons should be more effective in producing tissue damage than gamma rays. Depending upon the neutron energy, neutrons a re 2-10 times more effective. On this basis, neutrons a re more hazardous than gamma rays, although both are significant external hazards.

Neutron sources are not normally considered as an internal hazard. The lack of natural sources that emit neutrons and the physical properties of neutron sources make the chance of a neutron source being fixed in the body quite remote. This view could change if substances with high spontaneous fission rates become more readily available in larger quartities.

\section{Biological Effects of Radiation}

The harmful effects of radiation are due essentially to their ionizing effect on living tissues. ${ }^{56}$ These tissues, composed of similar cells, perform special body functions. The cell, which is the basic unit of tisoue structure, is composed of many elements, hydrogen, oxygen, carbon, and nitrogen being the main ones. Radiation passing through living cells ionizes or excites the atoms or molecules (groups of atoms) in the cell structure. This action may cause the molecule to break up into charged fragmente called radicals and ions. These can produce further effects in the cell so that damage is caused in both a direct and an indirect manner. The total effect on cell processes will depend upon the type and amount of radiation absorbed. Eells will be affected in vary ing degrees up to cell death. If the extent of damage is large, tisene functioi: may be impaired or even disabled.

a. Cell Mechanisms. The cell is usually composed of a nucleus surrounded by cytoplasm; both are encased in membranes. The nucleus ie considered the control center of the cell. It initiates cell divieion (mitosis) and controls the repair of cell damage. The cytoplaem is a liquid eubstance, which is a functional participant in such cellular activities as absorption and excretion. Many types of body cells have a limited life span and divide at a certain stage of their life. This allows the daughter cell to take over the 
paront-cell functions. As a cell divides, threadlike structuras (chromusumes) appear in the nucleus. These contain the genes that deternine hereditary cheracteristics. During coll division. the daughter cell reccives a duplicate set of chromosumes and identical genes from the parent. If the procase is normal, no alteration or changes occur in the chromosomes or genen. If change or damage does occir. mutation results that can affect either the daugh. ter cell or future-generaticn cells. Sone damage may be repaired by the action of the cell itself. If the cell is too bedly injured. repiacement can occur through mitosie of other heulthy calle.

In man, cell types or li:les are referred to as comatic or germ (gametes). The germ line gives rise to gametes or cells which can unite to reproduce the epecies. The somatic lines develop into the tissues of the individual. Stance only the germ-line celle can be transmitted to future generations, damage to soniatic cells le limited to the individual. Damage to the offepring of an individual may occur when there is damage to the cells of the gerrin line.

b. Radiosensitivity. All tissues of the body are susceptible to radiation damage. However, the cells that make up these tiseues differ in appearance and function as well as in their rusponse to radiation. For this reason, the radiosensitivity (response to radietion) of the body ussues also differs. To produce a specific biological effect, the necessary dose varies inversely as the relative sensitivity of the given tissue. Some factors that affect the response of tissue celle are: etage of development, metabolic activity, and division rate. "ss Bone marrow, lymphoid tissues, and the reproductive organa rank among the most radiosensitive. Muscle and bone mineral are among the least radiosensitive. 56

c. Relative Biolorical Effectiveness and Quality Factor. Although the types of damage produced by all radiations will be the same, the degree of response for an equal absorbed dose will differ, depending on the type of radiation, i.e., alpha verous gamma, etc. The absorbed dose $D$ is defined as the the energy imperted per unit mass of matter by ionizing radiation at the point of interest. The characteristic degree of response due to equal absorbed doscs from different types of radiation (0.8., alpha vereus gamma) is called the rela. tive biological effectivenese (RBE). As used in experimental work, the RBE is often defined $a$ the inverse ratio of the absorbed doses of two kinds of radiation that produced the same effect. To determine the RBE for a given type of radiation, one must define the exposure conditions a well as the effect studied. For this resson, the use of the RBE concept is generally reotricted by convention to experimental radiobiology. ss

An important factor in ar:-iving at the RBE of a given radiation is the linear energy transfor (LET). The LET expresses the rate of energy deposition measured along the track of en ionizing particle. $X$ and gamma rays produce electrons that give low-LET tracks; alphe particles and noutrons. which produce protons and recoil particles, give high-LET tracks. It is generally bolieved that the more denee energy deposition from high-LET radiations is responsible for their usual greater effectivenese in producing damage. 
In health-physics work, a factor is used to account for the variation in effectiveness to enable a comparison of the different radiation types in a mixed-radiation field. This quantity is called the quality factor (Q). It denotes that the effect of an absorbed dose is modified by the LET of the radiation. The $Q$ is an asigned value. it is not arrived at by experiment. The factor applies to cases of normal radiation protaction work. It is not applicable in the case of acute exposures at high dose rates, such ss occur in accidents." It provides a grose quality correction so that one may use a common scale for all types of radiation. The practical values of $Q$. suggested by the NCRP."s are thown in Table VIII.

TABLE VIII. Practical Quality Factor.

\begin{tabular}{lc}
\hline \multicolumn{1}{c}{ Radiation Type } & Rounded $\mathbf{Q}$ \\
\hline X rays, gamma rays, electrons, & \\
or positrons & 1 \\
Neutrons, $E<10 \mathrm{keV}$ & 3 \\
Neutrons. $E>10 \mathrm{keV}$ & 10 \\
Protons & $1-10^{\star}$ \\
Alpha particles & $1-20$ \\
Fiseion fragments, recoil nuclei & 20 \\
\hline
\end{tabular}

Use the higher value for round-off, or calculate by the methods of Ref. 58.

The common scale used to compere all types of radietion is called the dose equivalent $(H)$. This may be defined st the product of an abcorbed dose and other modifying fectors. One of these factors is the quality factor. Another modifier, the distribution factor (DF). may be used to correct for nonuniform distribution in the case of internal sources. The rem to the unit used for dose equivalent and is aumerically equal to the absorbed dose in rads times the appropriate modifying lactors. The rad is a unit of absorbed dose equal to the absorption of 100 erge of energy per gram of matter. The erg is a much larger energy unit than the MeV (by a factor of roughly one-hall million).

d. Somatic Effecte. Since damage to the eomatic celle is limited to the individual, somatic effecte include eny types of damage thet affect only the individual. A number of factore combine to make the effecte differ for verious conditions. The type of radiation is important, since come typee are more effective in producing damage than others, so was discused previously. The age of the individual is also a factor; children are more sensitive to radiation than adulte. The absorbed dose to important because the tolal energy aboorbed per gram of tiseue can be related to the effecte produced in the tiecue. The time distribution of the exposure will aiso modify the effect: $\bullet .8 .$. a "lethel does" received over a relatively short period of time may not be lethal if protracted over a long time. The dietribution of the dose is also important; 
1. e. the effects are greater if the total body is irraciated rather than just a specific organ. In thi caee. a lethal whole body radiation dose may be far from lethal if it is limited to one pecific organ.

Those effects that are observed may be loosely divided into early and late effects." Early, or acute, effecte occur at very high exposure levele and can be directly related to radiation as the cause. A broad picture of expected effects in man has been prepared by the NCRPss and is shown in Table IX.

IABL.E IX. Pepresenta: Ve Wuse-Elfecl Kelationstips in Man for Whois-body Irradiation

\begin{tabular}{|c|c|}
\hline Nature ol Elfect & $\begin{array}{l}\text { Representative Absorbed } \\
\text { Dose of Whole-body } X \text { or } \\
\text { Ciamnia Radiation. rade }\end{array}$ \\
\hline $\begin{array}{l}\text { Alinimial dose delectable by chromosome } \\
\text { anslywi or otf er epecialized analyees. } \\
\text { but not by hemogram }\end{array}$ & 5.25 \\
\hline 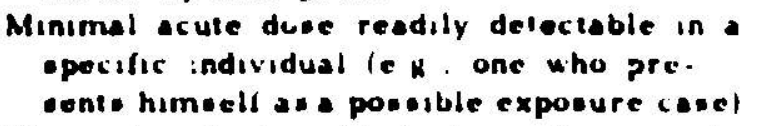 & 40.75 \\
\hline $\begin{array}{l}\text { Minimal ecute does likely to produce voliul. } \\
\text { ins in about } 10^{\circ} \text {. of people to expoesed }\end{array}$ & is.125 \\
\hline $\begin{array}{l}\text { Acute does likely to pruduce traneient dis. } \\
\text { ability and clear hemeloiogical chenges in } \\
\text { a majority of peuple so exposed }\end{array}$ & $131) \cdot 200$ \\
\hline Medien lethal dose for ungle nhort exposure & 100 \\
\hline
\end{tabular}

From the table it is seen shat, without special techniques, it is difficult to fint any immediate effects for acute doses of loss than 50 rads. The absorbed dosec shown a re called midline absorbed dosen. (An average absorbed dose of 1 rad of photons near the body midline would equal a dose about 1.5 times as high when meatured in (ree air.) As dose increases, damage increaces and, for large enough doses, death becomes more probable. In the dose range where eurvival may be the concern, the concept of the median lethal dose $\left(L D_{y n}\right)$ is used. This expresses the dose at which $50 \%$ of those exposed would die. As seen from the table, LDso is estimated a 300 rade (about 450 rads free air dose). For partial body irradiation, much higher doses a re required to bring about early or acute effects. These effects are rare, except following radiation therapy to localized portion. of the body. ${ }^{35}$

These effects, whether from partial or whole-body ir radiation, are the result of unusual exposure conditions. Thet is, one would expect to encounter these exposure levele in an accident situstion or single short incident. not under normal operations. Correct radiation-safety practice limite the exposure levels and duration so that none of these effects would be observed.

- Lete Effects. The problem in the study of late effecte is that the elepsod time may be many yeare and may sipond on the isse, making it 
hard to relate the cause to the effect. Since the late effects may be caused by many other agents besides radiation. there can be no positive assignment of the cause in most cases. At best, it is known that radiation increases the incidence of these nunspecific injuries. The main effects are neoplasms (tumors), cataracts, life shortening, and effects on growth and developinent. ${ }^{35}$

\section{f. Hereditary Elfects. Hereditary effects refer to those traits} that can be transmitted from one generation to another in a given opecies. Inherited iraits are determined by genes, and any mutation of a gene can result in an altered trait. Mutations occur spontaneously, and they also can be induced. Radiation (as well as other agents) produces the same effecta, so that radiation only serves to increasc the frequency of these effects. Even for high doess. increases in the rate are small.

Genes may be dominant or recessive. When a trait is determined by one of the genes, this is called the dominant gene. Mutations in dominant genes affect the offepring in the first generation. When genes a re recessive, the usual result is some intermediate trait. Damage occurs only if the same altered gene is received from each parent. Unless the same type of mutation occurs in a large population, damage due to recessive genes will not show up readily for generations.

Some hereditary effects in man are caused by chromosome damage. These effects are early embryonic mortality, neonatal deaths, and certain diseases that are eliminated in the first generation. ${ }^{55}$

Dominant mutations have a high probability of producing effects serious enough to terminato the line. On the other hand, recessive mutations have a small effect, but add to the number of mutations carried by the offepring. Added to this burden is the number of mutations caused by other agents. Thus, the total effect from the recessiva genes may be greater than that of the dominant genes because recessives a re eliminated less quickly. Recessive genes may not be eliminated for many generations.

\section{External and Internal Exposure Aspects}

The effects produced by radiation are the same, whether the exposure is internal or external, provided the absorbed dose and its distribution are the same. ${ }^{\text {ss }}$ The total organ dose is the sum of that from both types of exposure.

Radionctive matter may enter the body through inhalation, ingestion, abosption in wounds or punctures. and diffusion through skin. Once inside, these internal sources can end up in vital or critical organs. While they remain in the body, the irradiation is continuous. The amount in an organ decreases with time, due to radioactive decay and biological elimination. Each procese has a half-life or time in which one-half of the initial amount decays or is eliminated, respectively. Both processes act to reduce the amount, but for long half-lives, the total elimination rate is slow. Thus, living tissue may be irradiated for a very long time. 


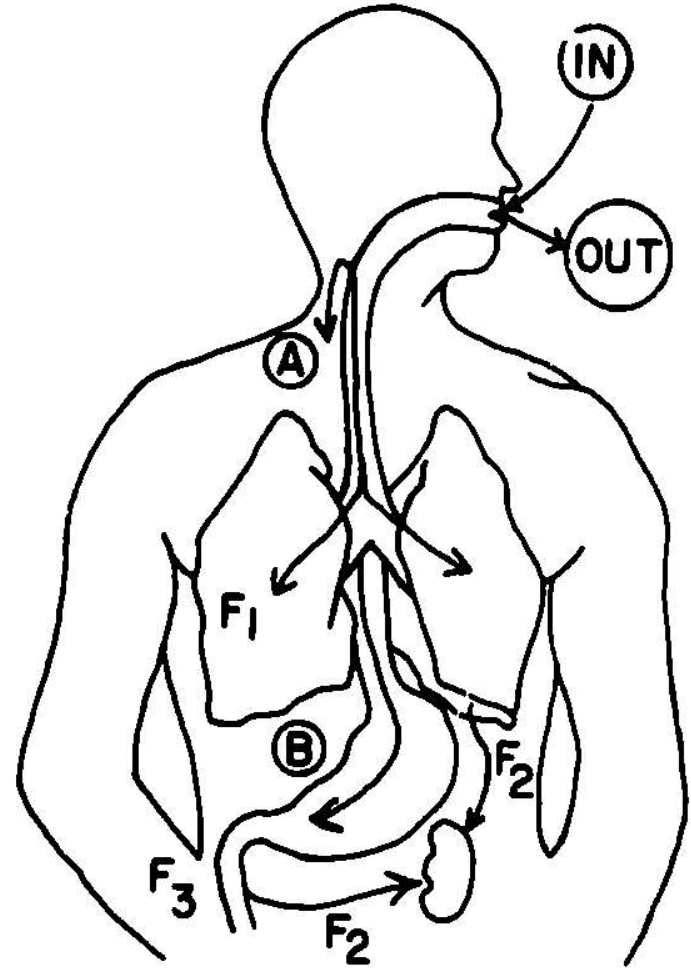

Fig. 6. Mechanisms of Inhalation and Ingestion of Radioactive $\mathrm{M}$ atte:
Consider the process of inhalation (see Fig. 6). Some of that taken in is $\mathrm{tm}$ mediately exhaled (out). Part of the inhaled matter is trapped by portions of the upper respiratory tract, and swallowed (A). This material is eliminated through the feces. During passage through the gastrointestinal tract, some of the material may be absorbed into the bloodstream $\left(\mathrm{F}_{3}\right)$ and transported to certain organs $\left(F_{2}\right)$.

Some radioactive matter reaches the lungs and leads to direct lung ir radiation while it is being retained $\left(F_{1}\right)$. Some of this material may also be absorbed into the bloodstream and end up in certain organs $\left(F_{2}\right)$. If the material is basically insoluble, part of the inhaled matter will be worked up from the lungs and swallowed (as in $A$ ). Some of the material will be retained in the lung and slowly taken up by body fluids.

Turning to ingestion, radioactive substances enter by eating, drinking, or by transfer of contamination from objects to the mouth. When such a substance is swallowed, the gastrointestinal tract (B in Fig. 6) receives direct irradiation during the time of passage. Again, if some of the material is soluble, part may be absorbed from the tract $\left(F_{3}\right)$ and transferred to an organ $\left(F_{2}\right)$. If insoluble, all will be eliminated.

The fractions $F_{1}, F_{2}$, and $F_{3}$ depend upon many variables, including the chemical properties of the material and its solubility in body fluids. In general, these fractions are not well known in humans. Data from animal experinents are used when applicable, but this information is not always available and sometimes not appropriate.

If radioactive material enters through open wounds or is transported through the skin, it may also pass to all portions of the body via the bloodstream. Little is known of the transfer fractions that appiy in these instances. However, it is known that the solubility of the substance influences the transfer that occurs. ${ }^{59}$ A larger fraction will translocate if the substance is soluble.

For internal exposure then, one must deal with continuous irradiation usually involving only limited parts of the body. In general, a substance deposits nonuniformly in tissue, leading to an uneven dose distribution. In terms of the potential for producing biological damage, short-range, high-LET radiation is the most important. Because of the fixation of the material in the 
body, internal exposure cannot be readily controlled. It is there:ore necessary to direct a conscious effort toward eliminating any intake.

In the case of external sources, exposure can be more readily controlled. One can limit the time of exposure and reduce the magnitude of the radiation field through distance and/or shielding. Source intensity and, hence, exposure rate decrease rapidly with distance from the source. When the source dimensions are quite small, this decrease varies inversely as the square of the distance. A shield is a dense substance which reduces the radiation field for those cases in which the worker must be close to the source. The dense substance provides a large amount of closely packed matter, which increases the number of radiation interactions. This increase tends to remove radiation more quickly and hence results in 1 ess intensity. Any one or all of these three factors may be used in the control of external exposure.

On the other hand, certain external sources can deliver a very high dose in a very short time. Often the whole body, not just part of it is exposed. These features are usually absent in internal exposure, but require attention in the case of external sources.

Accelerators, $X$-ray devices, and reactors require special care in their use to reduce the chance of external exposure. When charged particles such as electrons and protons are accelerated, they become more hazardous as they gain energy. This is due to the increased penetrating power and the nuclear reactions they are able to cause at high energies. Reactors are a potent source of both neutrons and gamma rays. Moreover, samples placed in the reactor become radioactive and require special care in handling during removal. The spent fuel removed from a reactor will contain gross amounts of fission products which will be highly radioactive. A serious whole body dose can be received in a very short time from any of the above sources.

\section{Radiation-protection Standards}

The task of setting safe radiation limits is a vital and yet, very difficult, undertaking. It is vital because workers must be protected from the harmful effects of ionizing radiation. It is difficult because 80 many factors enter into the effects that radiation produces. Though considerable data have been gathered and studied, many complex areas need more work before firm conclusions can be reached. ${ }^{55}$

Since some unknowns still exist, the setting of limits involves judgments that cannot be wholly based on scientific knowledge. This process depends upon the concept of an "acceptable risk." That is, the benefits are weighed against the potential harm, and limits are set at some level at which the most benefit to mankind will accrue. From time 10 time then, limits are revised as new knowledge is gained. This reflects an attempt to replace as sumption by fact in order to arrive at a better value judgment. 
The present radiation-protection standards for internal and external exposure that govern ERDA Contractor operations ${ }^{60}$ are shown in Table $\mathrm{X}$.

TABLEX. Radiation-protection Standards for External and Internal Exposure for Individuals in Controlled $i$ reas

\begin{tabular}{lcc}
\hline \multicolumn{1}{c}{ Type of Exposure } & Exposure Period & $\begin{array}{c}\text { Dose or Dose } \\
\text { Commitment, rem }\end{array}$ \\
\hline $\begin{array}{l}\text { Whole body, head and trunk. } \\
\text { gcnads, lens of the eye, red } \\
\text { bone marrow, active blood- }\end{array}$ & $\begin{array}{c}\text { Cear } \\
\text { forming organs }\end{array}$ & 5 \\
$\begin{array}{l}\text { Unlimited areas of the skin } \\
\text { (except hands and forearms). }\end{array}$ & Calendar quarter \\
Other organs, t1ssues, and & Year & 3 \\
organ systems (except bone). & Year & 15 \\
Bone & Calendar quarter & 5 \\
Forearms & Year & 10 \\
Hands and feet & Calendar quarter & 30 \\
\hline
\end{tabular}

The standards shown in the table set the limits that should not be exceeded. However, the goal is to keep all exposure as low as reasonably achievable: thus, operational guides may need to be imposed. These guides are used as signals when the exposure level approaches ur reaches a certain value. This permits an awareness that control may be breaking down before the limits are exceeded. Also, the guides and standards serve as yardsticks for evaluat ing the relative hazards of a radiation field. That is, if no controls are imposed, a certain dose rate from a given source may deliver a dose in excess of the limits. Depending upon what this excess is, the relative hazard and the necessary controls will vary. For this reason, a measure of the radiation field from is given source is needed for the purpose of evaluating the radiation hazard.

\section{External Dose Rates from Plutonium}

The external dose rate from plutonium includes contributions from $X$ rays, gamma rays, and neutrons. Electrons (beta particles) have been ignored since they are of low energy and will 18 ually be absorbed by the gloves of the handling enclosure. The actual dose rate from a sample of high-exposure recycled plutonium vill be a function of the isotopic composition. From Fig. 4, it can be seen that such a sample will contain a fairly large total fraction of ${ }^{238} \mathrm{Pu},{ }^{240} \mathrm{Pu},{ }^{2+1} \mathrm{Pu}$, and ${ }^{242} \mathrm{Pu}$. Also, the daughter products ${ }^{237} \mathrm{U}$ and ${ }^{241} \mathrm{Am}$ contribute to the gamma dose rate as these products build up. The net effect of the isotope content is to increase the expected dose rates as the total fraction present in the sample increases. ${ }^{61,62}$ The calculations of Roesch, ${ }^{31}$ Birchall, ${ }^{32}$ and Arnold ${ }^{+1}$ have provided a basis for estimating external dose rates from 
plutonium. These r.sults have been summarized ${ }^{29,38}$ and have been adapted for use in this section. The advent of high-exposure plutonium has greatly increased the external radiation hazard, especially in regard to extremity exposures. Not treated here is the impact of fission-product contamination on the external dose rates from recycled plutonium.

a. Surface $X$ and Gamma Dose Rates. X rays from plutonium occur as the result of the internal conversion process. This process is an aliernative mode of gamma decay. An excited nucleus that may emit a gamma ray transfers this energy instead to one of the outer electrons of the atom. This ejects the electron, and this $108 \mathrm{~s}$ leaves the atom in an excited state. When the atom returns to the $g$ round state, a discrete-energy $X$ ray (fluorescent $X$ ray) is emitted. Fluorescent $X$ rays also result from gamma absorption in high-Z-number substances and these add to the $X$-ray total.

Gamma rays from alpha decay, spontaneous fissior, and the fission products of a fissioned atom are sources that increase the gamma contribution. In addition, $X$ and gamma rays are emitted by ${ }^{237} \mathrm{U}$ and ${ }^{241} \mathrm{Am}$, which will increase the total dose rate as time goes by.

The surface dose rate can be divided roughly into two portions, that from photons below about $40 \mathrm{keV}$ and that from those above. Table XI gives the surface dose rate through a layer of about $50 \mathrm{mg} / \mathrm{cm}^{2}$ of tissue equivalent material from massive plutonium metal. ${ }^{31}$

TABLE XI. Photon Surface Dose Rates $8^{31,38}$

\begin{tabular}{lcl}
\hline & \multicolumn{2}{c}{ Surface Dose Rate, rad $/ \mathrm{hr}$} \\
\cline { 2 - 3 } Isotope & \multicolumn{1}{c}{$<40 \mathrm{keV}$} & $>40 \mathrm{keV}$ \\
\hline${ }^{238} \mathrm{Pu}$ & 980 & 2 \\
${ }^{239} \mathrm{Pu}$ & 0.61 & 0.056 \\
${ }^{240} \mathrm{Pu}$ & 14 & 0.62 \\
${ }^{242} \mathrm{Pu}$ & 0.19 & 0.11 \\
${ }^{241} \mathrm{Am}$ & $0.09 \mathrm{t}^{\mathrm{a}}$ & $0.10 \mathrm{t}$ \\
${ }^{237} \mathrm{U}$ & $0.56\left(1-e^{-0.102 t}\right)^{\mathrm{b}}$ & $23\left(1-\mathrm{e}^{-0.102 t}\right)$ \\
\hline
\end{tabular}

a Time $(t)$ in days since plutonium was purified; valid for times $<<14$ yr.

b Time $(t)$ in days since plutonium was purified; valid for times $<14$ yr.

From Table $X I$, the tota! dose rate from $X$ and gamma rays at the surface becomes

$D(\mathrm{rad} / \mathrm{hr})=982 f_{230}+0.67 f_{239}+14.6 f_{240}+0.3 f_{242}+0.19 f_{241} t+24 f_{241}\left(1-e^{-0.102 t}\right)$. 
in which the symbol $f_{A}$ stands for the fraction by weight of the is otope of mass number A. By only using the dose rates for $>40 \mathrm{keV}$, we can obtain an expres sion for the gamma or "hard" portion of the surface dose rate. As fuel exposure increases the isotopic composition, the photon surface dose rates from the recycled fuel also increase.

b. Neutron Dose Equivalent Rates at Emitter Surface. Neutrons arise from two sources: spontaneous fission and $(\alpha, n)$ reactions in light elements. Both of these processes produce fast neutrons. For the fission neuirons, the mean energy is about $2 \mathrm{MeV},{ }^{42}$ and for $(\alpha, n)$ reactions the mean energy is estimated as between $0.75-1.5 \mathrm{MeV} .^{30}$ If we assume a mean energy in the range 1-2 MeV, the dose equivalent rate would be $1.28 \times 10^{-4} \mathrm{rem} / \mathrm{hr}$ per neutron $/ \mathrm{cm}^{2}-8 e c{ }^{26}$ Roes $\mathrm{ch}^{31}$ has derived the expression for the neutron flux density at the surface of a metal sphere. With his result, and the above conversion factcr, the dose equivalent rate at the sphere surface is

$$
\mathrm{H}_{\mathrm{n}}(\mathrm{rem} / \mathrm{hr})=2.82 \times 10^{-4}(\eta / \mathrm{p}) \mathrm{M}^{1 / 3},
$$

in which $\eta / \rho$ is the number of neutrons emitted per gram per seconc and $M$ is the mass of plutonium in grams. Using the data from $\Gamma$ able III for $\tau_{i} / \rho$, the expression becomes

$$
H_{n}(\mathrm{rem} / \mathrm{hr})=\left(0.65 \mathrm{f}_{238}+0.26 \mathrm{f}_{240}+0.5 \mathrm{f}_{242}\right) \mathrm{M}^{1 / 3}
$$

for the neutron component from spontaneous fission. For the $(\alpha, n)$ reactions,

$$
H_{n}(\mathrm{rem} / \mathrm{hr})=\left(609 \mathrm{f}_{23 \theta}+0.12 \mathrm{f}_{239}+4.5 f_{240}+0.05 f_{242}\right) \mathrm{M}^{1 / 3} \text { for } P u F_{4}
$$

and

$$
\mathrm{H}_{\mathrm{n}}(\mathrm{rem} / \mathrm{hr})=\left(3.95 f_{238}+0.01 f_{239}+0.05 f_{240}\right) \mathrm{M}^{1 / 3} \text { for } \mathrm{PuO}_{2}
$$

From the two expressions above, it is seen that the 238 isotope greatly affects the total neutron emission. Estimates of the ${ }^{238} \mathrm{Pu}(\alpha, n)$ neutron activities for other light-element compounds have been derived. ${ }^{34}$ The neutron contribution from a plutonium sample does not change with time as does the photon portion. However, in light element compounds, the ing rowth of ${ }^{241} \mathrm{Am}$ will increase the $(\alpha, n)$ output.

c. Other Dose Rates. Not only may the surface dose rate be of concern, but also that at a given distance from the source. According to Roesch, ${ }^{31}$ for photons, the dose rate at some distance $r$ is related to the surface dose $D_{B}$. The expression involves the projected area $A$ of the plutonium sample and is given by

$$
D(\mathrm{rad} / \mathrm{hr})=\frac{D_{8} A}{2 \pi r^{2}}
$$

where $D$ is the absorbed dose rate at somedistance $r(\mathrm{~cm})$ from the surface of the oample. 
For neutrons, the estimate of the dose equivalent rate, at some distance $r(\mathrm{~cm})$, may be obtained from

$$
H(\mathrm{rem} / \mathrm{hr})=\left(0.024 f_{238}+0.010 f_{240}+0.018 f_{242}\right) \frac{M}{r^{2}},
$$

in which $\mathrm{H}$ is the spontaneous neutron dose equivalent rate. This should be valid when the distance $r$ is roughly six times the largest sample dimension.

B. Toxic Haza:cis

\section{Toxicity of Internal Emitters}

The toxic aspects of an internal source are governed by a number of factors. Among these are the type and energy of the emitted radiation, since these features alter the biological effectiveness of a given organ dose. The physical and chemical forms enter in because these influence the uptake and distribution patterns in the body. Even the age and species of the subject, as well as the mode of entry, modify the toxic effect.

One problem is to pick out the organ that is most affecteri by the given radioisotope. In many cases, a substance will be taken up by a number of body organs. The concept "critical organ," or that organ of the body whose damage by the radiation results in the greatest damage to the body, is used to deal with this groblem. A number of factors affect the choice of a critical organ. Some organs are more 48 sential to the body than are others, and slight damage to these may affect the body more than heavy damage to some others. Other factors, such as the radiosensitivity of the organ and the fraction of the radioisotope accumulated in the organ, are also important. When little uptake by the body occurs, the greatest harm may be produced in the organ of entry.

From the standpoint of absorption into the body, the solubility of the substance in body fluids plays a major role. It is not so easy to tell whether a given substance will be soluble in body fluids. However, as a mode of entry, ingestion is of concern only for the soluble form of the isotopes. In the case of elements not normally required by the body, uptake by ingestion is minimal.

When uptake occurs, one is concerned with the transfer of the material to some organ. Only a fraction of the ingested matter will go into the bloodstream. Of this, only a fraction will go into the organ of concern (see Fig. 6). To add to the problem, almost equal portions of the substance may end up in a large number of organs. This increases the problem of choosing "the" critical organ, since several organs may be essential to proper body function.

For the problem of inhalation, both ooluble and insoluble matter must be treated. Other factors are perticle size and density, as well as the 
physiology of respiration. ${ }^{63,64}$, he movement and retention of matter in the respiratory tract are sensitive functions of the particle size ${ }^{65}$ In general, for $B i z e$ in the range $5-10 \mu \mathrm{m}$, these particles are trapped and easily removed from the upper respiratory tract. For sizes below this, the chance of the particle reaching the deep portions of the lung increases. The mechanism is quite complex so that estimates of the transfer of matter by this mode of entry a re poor.

One must also treat the matter of elimination. Even though the substance is deposited in an organ, the time of stay in the organ is not indefinite. A fraction of the substance is eliminated from the organ as time passes. For a radioactive substance, a certain fraction decays per unit time, but some of the material leives the organ because of biological processes. One must have knowledge of the net growth in a certain organ to assess the effect of the radioisotope deposit. The ICRP ${ }^{66}$ assumes that each organ can be $t$ reated as a separate comparment in which a substance is eliminated at a constant rate. This means that each organ has a half-life for biological elimination of a given substance. This model provides a simple means of obtaining a rough estimate of the retention in an orgas.

Given the amount of a radioisotope in an organ, one can then estimate the dose equivalent $(H)$ rate. If one has a $s$ tandard for the allowed $H$ rate, then one can arrive at a permissible amount or organ burden. This will be the amount of the radionuclide in the organ that delivers the allowed $H$ rate.

A much greater problern is to estimate the amount of a substance in an organ that results from intake into the body. Given certain intake rates, one can estimate values for the permitted concentration in air and water for the radioactive materials. This concentration would not result in an arcumulation greater than the organ burden for an assumed daily intake. Of course, to make this estimation requires the use of many of the above-mentioned factors. At any rate, the ICR $P^{66}$ has made recommendations in regald to concentration values (MPC) and organ burdens (MPBB). The MPC (maximum permissible concentration) gives the allowed concentration in air or in water for a given radioisotope. Intake at the MPC rate for $50 \mathrm{yr}$ will not result in an organ ccumulation greater than the organ burden. The term maximum permissible body burden (MPBB) denotes the amount of the radioisotope in the total body such that the critical organ burden is not exceeded.

\section{Toxic Features of Plutonium}

There are many reasons why plutonium ranks among the more toxic radioactive materials once absorbed in the body. The alpha particles emitted by this substance have relatively high energy (see Table II). Not only is their range in air short $(-3.8 \mathrm{~cm})$, but the tissue range is extremely short $(35-40 \mathrm{\mu m})$. The dense, highly localized energy loss from the plutonium alphas means a greater biological effectiveness in tissue. Once inside the body, the beta and electron contributions also take on added importance. 
Soluble plutonium enters the body $\mathrm{fl}$ inds and is transported throughout the body, ending up in liver and bone. Bone is presently taken as the critical organ in the case of soluble plutonium. ${ }^{66}$ Plutonium is found both on the bone surfaces and in the bone-marrow spaces. ${ }^{67}$ The uneven, initial surface deposits result in high alpha exposure to the sensitive, active bone-lining cells. Bone growth and other processes remove the uneven surfacc plutonium and redeposit it at other sites or bury it under new bone. ${ }^{68}$ During these processes, an uptake of plutonium in the marrow occurs. ${ }^{67}$ In man, plutonium is tightly bound in the bone so that the excretion rate is slow. In the past, the biological half-life has been taken as 200 yr, ${ }^{66}$ but recently the ICRP has suggested a new value of $100 \mathrm{yr}^{59}$ Since the radioactive half-life is also long for ${ }^{239} \mathrm{Pu}$, only a small portion is removed during a life span.

The body burden for ${ }^{239} \mathrm{Pu}$ with bone as the critical organ is only $0.65 \mu \mathrm{g}$. This means that only a very small amount of ${ }^{239} \mathrm{Pu}$ need get into the body to give a significant deposit. This also increases the risk, since high dose rates may result from relatively small intakes, in term. of the mass of material.

The lung is the organ of interest when one considers insoluble plutonium. Much of the initial portion taken into the lung is cleared rapidly. That which is retained after about the first day is in the deep regions (pulmonary) of the lung.

Some of the insoluble material will be slowly worked back up the throat and swallowed (see Fig. 6). The remainder is cleared by movement into the lymph nodes. ${ }^{64}$ If the intake is soluble, the material will be taken up by blood and deposited in bone and liver. Deposition of matter in the lung is seldom uniform. ${ }^{69}$

In the past, the half-life of insoluble plutonium in the lung was taken as one year, ${ }^{66}$ but recent evidence suggests that 500 days or more may be more appropriate. ${ }^{59}$ In terms of mass, the lung burden is $0.26 \mu \mathrm{g}(0.016 \mu \mathrm{Ci})$. Even a small intake of insoluble material then represents an important quantity with respect to the lung burden. Also, material that moves to the lymph nodes tends to accumulate there. This long-term retention may require further evaluation of lymph-node damage, but presently the lung remains as the critical organ. ${ }^{59}$

Most human exposure to actinide elements has occurred either from inhalation or absorption through wounds. Animal experiments have yielded estimates of absorption from lung to the critical organ of $1 \%$ to $10-15 \%$. In the case of wounds, some remains at the site of entry, some is transported, if soluble, to the skeletal system, and some may migrate to the lymphatic system. For wounds, deposition is assessed through the use of instruments that measure the intake amount at the site. However, no model has yet been worked out to relate the amount at the site to that which is eventually deposited elsewhere. 
Ingestion is not considered a major mode of entry, since absorption through the gastrointestinal tract is very low. ${ }^{63,70}$ Diffusion through intact skin is negligible, ${ }^{63}$ whereas injection is not a very likely mode of entry. However, plutonium in organic solvents or acids may enter the body when in contact with skin. Regardless of the mode of entry, though, plutonium is rapidly cleared from the bloodstream and fixed in tissues.

\section{Toxic Effects of Plutonium}

The toxic effects of plutonium in humans must be deduced from animal studies. In large animals, with life spans of several years, lung cancers, tumors of the lung capillaries, bone tumors, nasal tumors, and liver tumors have been observed. ${ }^{68,71,72}$ These late effects in general are produced by large doses.

Lung cancer in doge has been noted at levels about 30 times the present lung-burden value for man. ${ }^{73}$ Bone cancer occurs in dogs for levels about 25 times the present bone burden. ${ }^{67}$ No leukemias were reported in dog studies, but have been observed in rats. The high levels of exposure used in these studies may produce a spectrum of cancers that would differ from that found at low levels. ${ }^{7}$ For this reason, present long-term dog experiments are underway at low levels. These levels are in the range from 1 to 30 times the present body burden. In small animals, changes in the lungs were observed for low and high doses; this was attributed to uneven distribution of plutonium. ${ }^{72,74}$

Langham ${ }^{63}$ has discussed acute effects of plutonium. The basic mechanism seems to be a breakdown of the blood-forming system. These effects were observed only when massive amounts of plutonium were given to the animals. No dat 1 exist for man, but it is estimated that to observe acute effects would require an ingesion of pounds of plutonium or the inhalation of gram amounts.

For late or delayed effects, studies that compare radium to plutonium toxicity have been made. Like plutonium, radium also concentrates in bone. Because of its early use in dial-painting industry and in medicine, human exposure data are available for direct study. ${ }^{75}$ The data on the delayed toxicity of ${ }^{226} \mathrm{Ra}$ in man has allowed a direct evaluation of the body burden for radium. For this reason, radium is used as the standard for bone seekers. The results of the comparative studies indicate that plutonium is 5 to 10 times as hazardous as radium on the basis of the absorbed dose in bone. ${ }^{76}$

Turning to human data on plutonium effects, no specific injuries have been noted. ${ }^{77}$ The largest group studied has been 25 workers exposed during 1944-1945. A recent follow-up study showed estimated bone burdens of 0.1-10 times the currently used level. ${ }^{78}$ Although no injuries have yet appeared, the long latent period associated with some late effects of radiation makes it prudent that such studies continue. 


\section{Toxic Index}

One may use the body-burden value as a toxic index to arrive at the relative hazard of a given amount of material. That is, the relative hazard is assessed by comparing the given amount of the substance to its body-burden value. Table XII contains these values for selected nuclides with bone as the critical organ. For the microcurie values $\left(1 \mu \mathrm{Ci}_{\mathrm{i}}=2.22 \times 10^{6} \mathrm{dpm}\right)$, the relative hazard varies little. However, using microgram values, the relative hazard may differ by several orders of magnitude. This points out the difficulty in control, since the release of the same mass of each nuclide gives vastly different activities. The table also shows the ICRP concentration values (MPC). These are used to assess the relative hazard of measured airborne plutonium concentrations.

TABLE XII. Body Burdens and Maximum Permissible Concentrations ${ }^{66}$

\begin{tabular}{lccc}
\hline & \multicolumn{2}{c}{ Body Burden } & $\begin{array}{c}\mathrm{MPC} \text { in } \mathrm{Air}^{\mathrm{a}} \\
\mu \mathrm{Ci} / \mathrm{cm}^{3}\end{array}$ \\
\cline { 2 - 4 } Radioisotope & $\mu \mathrm{g}$ & $\mu \mathrm{Ci}$ & $2 \times 10^{-12}$ \\
\hline${ }^{238} \mathrm{Pu}$ & $2.3 \times 10^{-3}$ & 0.04 & $2 \times 10^{-12}$ \\
${ }^{239} \mathrm{Pu}$ & 0.65 & 0.04 & $2 \times 10^{-12}$ \\
${ }^{240} \mathrm{Pu}$ & 0.18 & 0.04 & $9 \times 10^{-11}$ \\
${ }^{241} \mathrm{Pu}$ & $8.0 \times 10^{-3}$ & 0.9 & $2 \times 10^{-12}$ \\
${ }^{242} \mathrm{Pu}$ & 13 & 0.05 & $6 \times 10^{-12}$ \\
${ }^{241} \mathrm{Am}$ & $1.5 \times 10^{-2}$ & 0.05 & 6 \\
\hline
\end{tabular}

a These values are similar to the Concentration Guides (CG) of Ref. 60 .

\section{Criticality Hazards}

The mere presence of any fissile material does not mean that a criticality haza rd will exist. For such an event to occur, given the proper setting, a certain amount of the substance must be present. As discussed in Sec. II.C.2. this amount is called the critical mass. This term should not be taken to mean that only the mass of the fissile substance is a factor. Indeed, many other factors such as the shape, form (solid or solution), nature of the surroundings, and neutron absorbing features of the system enter in. Given a favorable set of parameters, there is then a minimum critical mass, which does refer to the total amount of the fissile matter. If this value is not exceeded, no criticality will occur. TableXIII presents some minimum critical values for the isotope ${ }^{239} \mathrm{Pu}$ and points out the influence of some of the factors. iNote that the presence of other lsotopes in the sample will modify the values obtained for ${ }^{239} \mathrm{Pu}$ alone. The values in the table under the column marked "recommended value" include safety factors. Use of these values will provide an extra measure of safety in plutonium-handling operatione. 
TABLE XIII. Hasic Nuclear Parameters for "Pu (Ref. 79)

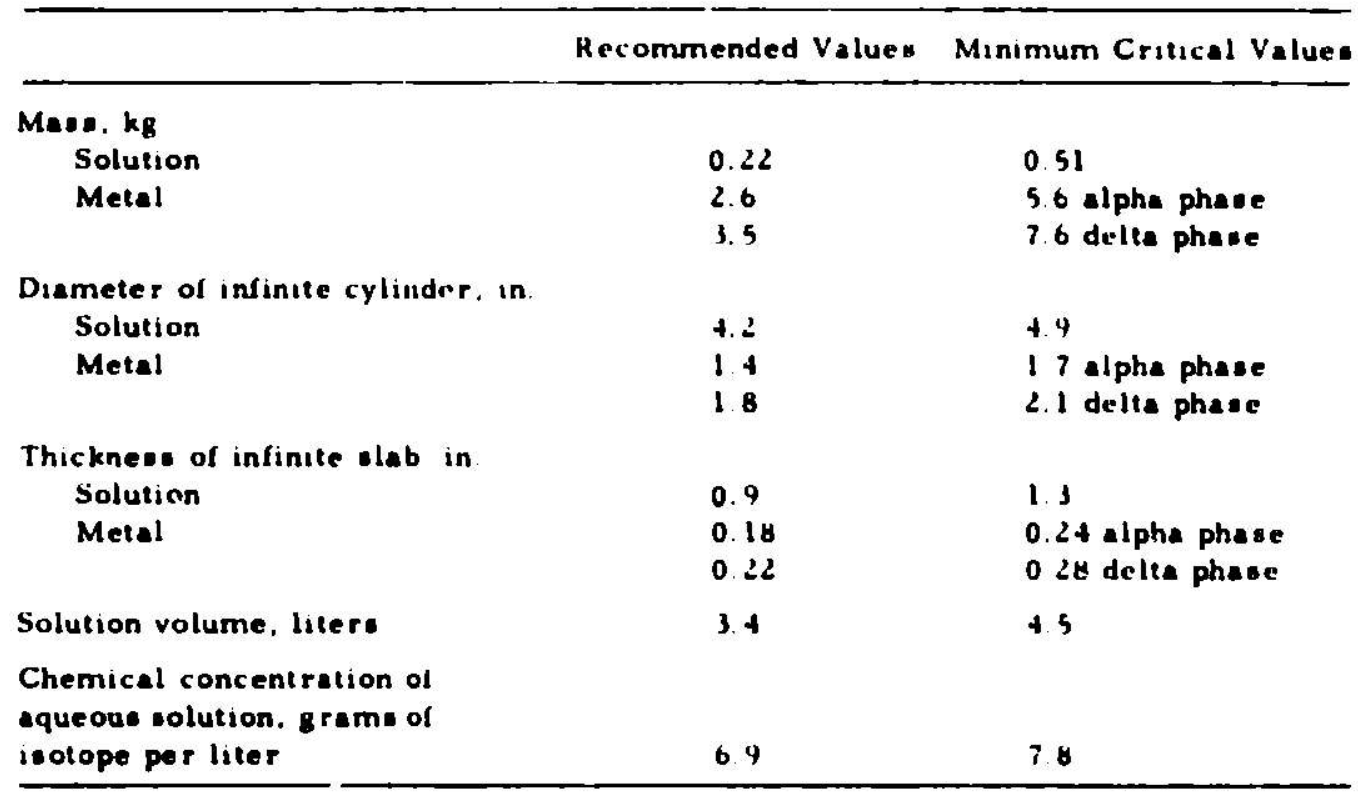

Despite care in handling and safety i,l design, an unwanted criticality can result. The incident occurs with no warning, so that there is no time to invoke safety messures. That is, the systern is subcritical one instant and then, suddenly, critical. When one of these accidents begins, nothing otops the process until the system returns to the subcritical state. In most cases, a single -hort burst of radiation occurs in a fraction of a second and the process is not sustained. In other cases, a sustained self-controlled reaction for a rather indefinite time period may result. Both types have occurred on occasion, but the more likely event is a burst type.

In the burst type of incident, these effects can result: (1) high radiation levele, both $n$ and gamma, which can be lethal for a considerable distance: (2) the release of enough heat to melt metals in some parts of a contained eystem: and (3) contamination of the nearby area severe enough to present a haz. ard to personnel for perheps monthe; ${ }^{\infty}$ and (4) high gamma residual radistion levele from fiesion products.

Such a buret-type event may occur in an unehielded oyetem of low initial radionctive content. It ma also occur in highly radiosctive eystems such as reactors and processing plants. In the latter case, the presence of large amounte of thielding would greatly reduce the initial radiution exposure. However, the release of airborne radionctive material would result in extensive contamination. In the case of the former, the contamination would be high only in the local ares of the event. The minimum value for the buret size in a ey tem mey be estimated as $10^{15}$ fissione for alarm purposes, $10^{16}$ flesions for dosimetry application. " For a water-moderated anembly, one may expect $10^{17}-10^{10}$ fiscione in a short-burat incident. For metal asemblies, eccidental bursts of $10^{17}-10^{19}$ fiestons a re eseumed poselble." 
From the data on the mockup experiment of the $\mathrm{Y}-12$ incident, ${ }^{83,04}$ it is possible to compute the prompt neutron and gamma doses as a function of dis-

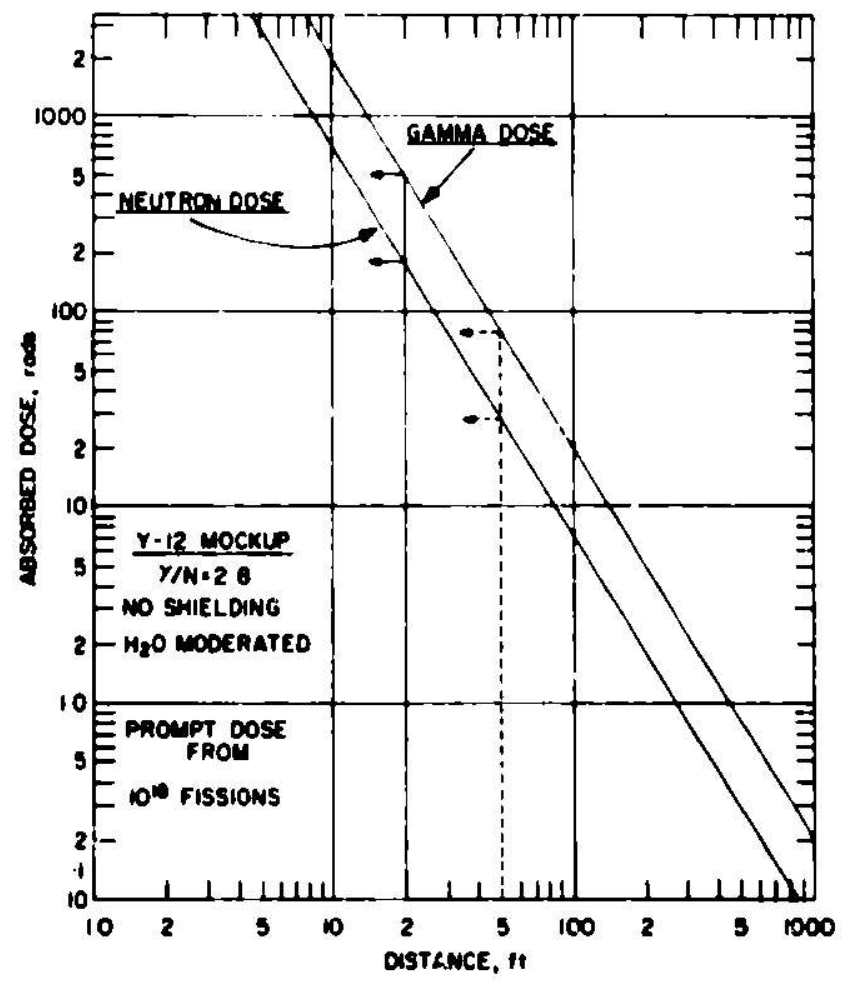

Fig. 7. Prompt Radlation Dose from \& Burst of $10^{18}$ Fissions. Total absorbed dose is $\geq 600$ rads up to $20 \mathrm{ft}$ : $\geq 100 \mathrm{rads}$ up to about $50 \mathrm{fl}$. tance from a burst of $10^{18}$ fissions. These are shown in Fig. 7. From the figure, one can obtain the total dose at some distance and scale this up or down for an as sumed number of fissions. No shielding effects have been taken into account nor changes in the $n / \gamma$ ratio for other types of critical asaemblies. The data may be used to obtain a rough estimate of the doses possible in an incident involving a moderated system.

To estimate potential doses from an incident in a metal system, the data from the Health Physics Research Reactor burst operations may be used. $^{\text {BS }}$ The $n / \gamma$ ratio of this system varies, but is in the range of 5-9. On the basis of data taken for $n / Y=$ 5.7 , a burst of $10^{18}$ fissions in a metal system would produce $4000 \mathrm{rad}_{\mathbf{n}}$ and 700 rady at $10 \mathrm{ft}$. Assuming no shielding, this would yield total doses of 2600 rads up to about $30 \mathrm{ft}$ and 2100 rads up to a round $70 \mathrm{ft}$.

Note that these estimates are tied to certain $\mathrm{n} / \mathrm{\gamma}$ ratios. These ratios may vary from system to system, as well as in a series of bursts using the same system. In general, for a moderated system, one would expect the gamma dose to be the higher; in a metal system, however, the neutron dose would be expected to be the higher one.

For a burst of about $10^{18}$ fiesione, dispersion of the fissile substance and the fission products would follow. Heavy local contamination would result, giving very high residual dose rite. This dose rate decreases very rapidly shortly after the burst, but nay still be on the order of tens of rad/hr one hour ofter the event. ${ }^{\text {II }}$ In addition, the dispersal of the plutonium would mean very h!gh alpha contamination levels.

The criticality incidents that have occurred in AEC operations are deac ribed briefly in Ref. 86.

D. Fire and Fixplosion Hazards

As in the case of a criticality incident, the hazerde from a fire or explosion exist only if the event occurs. For this reason, the emphesin is on 
prevention of the incident. Should the incident occur, the potential hazards would be personnel injury or death, property damage, and loss of equipment.

The components necessary to initiate and sustain a fire are: fuel, heat, oxygen, and a chemical chain reaction. ${ }^{87}$ That is, a substance (fuel), raised to the proper ignition temperature (heat) in the presence of air (oxygen), will ignite and continue to burn (chain reaction). So, to prevent the start of a fire (or to put out one already started), one must:

1. Remove one of the three elements: fuel, heat, ixygen.

2. Inhibit the chain reaction.

With respect to fire prevention, these efforts are directed at achieving the first goal. One may inert the system (r.move oxygen). If this is not practical, one may center efforts toward remuval of fuel sources or heat (ignition) sources. That is, analyze the process for conditions that allow fire to start and attempt to remove these. If one removes all fuel sources, or all ignition sources, the fire-prevention goal will be realized. However, sometimes the process itself and the type of enclosure used preclude removal of all fuel or ignition sources.

Many of the $z$ ources of fire and explosion have been treated in the literature. $5,7,11,44,88$ In Sec. II. D. we discussed the features of plutonium that make it a source of ignition at times. Among the other items that can be classed as ignition sources are chemical reactions, services and equipment that may produce heat or parks, and excessive heat from alpha and fissile material. ${ }^{5,11,34}$ Explosion sources include flammable gases and solvents, finely divided metallic dusts, compressed fluids, equipment, and chemical reactions. $5,11,88$

In addition to the ignition sources above, many fire hazards can be found within the enclosure. In the case of gloveboxes, the enclosure itself may be constructed of many combustible substances. ${ }^{13}$ Such items as the gloves, exhaust filters, plastic panels, and vinyl bags nay readily burn in a fire from some other source or even support combustion. ${ }^{44}$ Fires arising from ignition of oils, solvents, rags, and paper can lead to rapid heating in the system. ${ }^{89}$ Although the initial source of ignition moy be small, the fires that arise in the secondery materials can be very serious and difficult to control.

A fire or explosion in the enclosure may cause either a gradual or a sudden pressure increase, which can cause failure of the enclosed system. Based upon the sped of the ignition (or flame) propagation and the rate uf energy release, combustion explosions fall into two types. ${ }^{88}$ The usual type occurs because of the increased pressure from a thermal expansion caused by the propagation of ignition through the combustible mixture. This movement of the flame occurs at lese than the speed of sound. The peak pressure that is reached is low, seldom above 130 poi (pounds per square inch). Moreover, this presoure can be reduced to only few psi with pressure-relief devices. ${ }^{88}$ 
The other type is an extremely fast explosion. The flame advances at speeds much greater than the speed of sound, and the peak pressure may reach many thousand psi. This type is called a detonation and cannot be effectively vented. ${ }^{88}$

The ability of the enclosure to withstand the increased pressure depends upon the duration, rate, and extent of the pressure rise. In general, most combustion explosions start out as the first type, and a few are of the second type. This is fortunate, since in the case of a weak structure, such as a glovebox. the enclosure would rot be able to contain a detonation. Smaller gloveboxes a re more vulnerable than larger ones, since more of the volume may be involved in the explosion, and this increases the pressure load. ${ }^{88}$

Another type of explosion hazard of concern involves those that arise in experimental equipment and are rather anomalous in regard to pattern. These serve to point out that not every case of overpressure results from combustion processes. These types not only produce an operpressure, they also create missile hazards if the device or setup shatters into many pieces. Of course, many expiosions that breach the containment also produce missiles in the process.

In the case of plutonium fires or explosions, a number of hazards may arise. ${ }^{7}$ These are briefly discussed in the following sections.

\section{Personnel Hazards}

If the containment is breached, plutonium will be dispersed into the area. This presents an immediate hazard in regard to inhalation and a subsequent hazard due to widespread contamination. Because of the extreme toxicity of plutonium, the extent of the hazard may be severe, even if only a small amount of matter is involved. In addition, severe injuries due to the blast pressure or flying missiles may occur in explosion.l. Added to this, wounds caused by contaminated objects could result in internal plutonium contamination.

\section{Contamination Hazards}

A fire or explosion that results in the release of plutonium may contaminate large areas of a plant. This would require expensive and extensive decontamination. ${ }^{7}$ Present information suggests that, outside of the facility itself, little plutonium will be dispersed beyond the plant boundaries. ${ }^{90-93}$ This is attributed to two factors: Burning pluton: um produces large particles that tend to settle out quickly, and airborne plutosium particles become readily at tached to surfaces. ${ }^{91}$

\section{Plant Damage}

The damage to the plant from a fire or explosion can be quite extensive. ${ }^{51-53}$ This damage not only includes the physical damage, but also that caused by the 108 of items too badly contaminated to reclaim. To this must 
be added costly delays in vital programs. These arise out of the inability to replace crucial, damaged equipment and to use the area in which the incident occurred. Other areas may also be affected either by the event directly or by tracking of contamination following the accident.

\section{Criticality Haza rds}

A critical mass may be formed during an incident when a metal shape is changed by dispersal or by melting. The process of fighting a fire nay introduce moderators, such as water, which could enhance the chance of a criticality. An explosion could cause otherwise safe amounts to be blown together, thus creating a criticality. The hazards produced by this type of event are those discussed in Sec. III.C.

\section{E. Hazards of Transplutonium Nuclides}

In general, the same hazards are present in handling transplutonic nuclides as in handling ${ }^{239} \mathrm{Pu}$, except for degree. Because of higher decay rates in most cases, these substances are more hazardous on a mass basis. ${ }^{39,94}$ Hand exposures could be quite high and may be the limiting dose fartor for glovebox-handling operations. Neutron dose rates will be greater because of the shorter spontaneous fission half-lives (see Table VII). The self-heating and spontaneous-ignition effects in these substances are much greater than in ${ }^{239} \mathrm{Pu}$, and foils may even ignite in air. ${ }^{39}$ The threat of criticality is less than for ${ }^{239} \mathrm{Pu}$ because sufficient amounts of these substances have not been produced. However, they are fissioned mainly by fast neutrons, and the critical mass needed may be less than that for ${ }^{239} \mathrm{Pu}$. The biological patierns have been studied for some of the transplutonic elements, but no firm estimates of any differences in damage were made. ${ }^{75,96}$ In total, these factors combine to indicate that, as a group, the transplutonium nuclides may be more hazardous than ${ }^{239} \mathrm{Pu}$. 


\section{CONTROL PROCEDURES}

\section{A. Introduction}

The type and extent of control measures used in plutonium work will vary. Many factors enter in, and only some of these were briefly mentioned in Sec. I. B. In some cases, plutonium is handled in open-faced hoods, but in most instances, it is handled in semiremote units (gloveboxes) or remote enclosures (hot cells). ${ }^{6,7,11,18,89,97}$ The features of a particular handling operation may dictate special control measures, as does the state of the plutonium being used. Low levels $(<1 \mu \mathrm{Ci})$ of nondusty plutonium samples do not require the degree of control that higher levels do. Sealed or clad plutonium, regardless of amount, may be handled in hoods rather than gloveboxes for certain steps in the process. Several reports deal with both the hazards and control measures of certain programs. $34,54,61,64,98-102$

The laboratory handling of plutonium differs from that found in a plant or production facility. ${ }^{7}$ In general, on the order of $10 \mathrm{mCi}$ or les 8 of plutonium is handled in open hoods; gloveboxes are used for larger amount.s. In plants in which gram or kilogram amounts are used, gloveboxes are used almost exclusively. For dusty operations or for plutonium in other pyrophoric forms, these call for gloveboxes with inert atmospheres. In processes involving ir radiated plutonium samples that have not been separated from fission products, hot cells are used to provide shielding. In the future, glovebox handling of plutorium may be precluded.

In all these systems, the enclosure forms the primary confinement of the material. Added to this, the airflow design and filter placement, as discussed in Sec. I. A, will contain any releases. The module, room, or building it self will also ald a degree of containment.

Tranefer of items into and out of the enclosure must be done so as to preserve the barrier integrity. For a closed system, such as a glovebox, the design often includes slastic-bag ports or sphincter valves which allow such transfers. ${ }^{5,6}$ Plans for changing gloves as well 28 windows must also be thought up for glovebox procedures.

The probability of accidents such as spills, unexpected chemical reactions, small fires, or explosions should be considered. ${ }^{5}$ Safety design will attempt to overcome or misimize the effects of such incidents. However, since these events may still occur, it is extremely important that personnel be trained in methods of combating such episodes. Needless to say, plans must be formed that treat the problems arising out of such accidents.

Regardless of the design excellence, the worker must also follow cer tain approved, albeit regimented, practices, which should be spelled out in written work instructions. These measures should include such things as: 
1. Remove all unnecessary equipment from the enclosure before starting a new project.

2. Use absorbent matter or strippable paint on the surface to avoid contaminating the floor of the enclosure.

3. Limit or avoid the use of pointed tools, wire, or sharp objects, and quickly report any punctures, wounds, or scratches obtained while performing plutonium work.

4. Follow good housekeeping practices: Clean interior surfaces often, clean spilled matter at once, remove solid waste promptly, limit amount of solvents and other combustible material, and segregate pyrophorir matter. ${ }^{5}$ Do not let dust pile up!

5. Inspect gloves often for signs of rupture, wear, pin holes or deterioration. Be aware that acids and other mixtures attack the gloves. Also, gloves fail rapidly in work with oxides of high specific alpha activity. ${ }^{34}$ Change gloves frequently to avoid mishaps (preventive measure).

6. Remember that stored vessels that are not vented can result in pressure buildup leading to rupture and spillege. Also, the storage of highspecific-activity alpha emitters in solution may result in heat evaporation of the liquid. This process may occur in conjunction with breakdown of the liquid (radiolysis) in the solution, causing gas buildup. For a very high specific activity, such as for ${ }^{238} \mathrm{Pu}$, gas bubbles rising to the surface may burst and form a very fine oxide dust, which can grossly contaminate the enclosed system. ${ }^{34}$

7. Avoid splashing of liquids or spraying them during enclosure operations, and keep liquid containers in a secondary container.

8. Use latex or surgeon's gloves in addition to those that are part of the enclosure.

9. Do not perform plutonium work with open wounds or scratches unless you have obtained prior approval from medical authority.

10. Know what your responsibilities are in regard to work performance and safety procedures.

The above listing is not meant to be complete, nor should it be taken as such. It is provided as a guide to point out some areas of safe practice and perhape serve as a stimulant to enable the reader to reflect upon, and conjure up, other pertinent safety practices.

To supplement the efforts of the worker, as well as maintain the control achieved by the safety-design features, requires a program that can evaluate the effectiveness of the control mechanisms. This latter need is supplied by the health-physics program. Even though highly sophisticated instruments are used, and techniques are refined to the utmost detail, events that result in the loss of control will still occur. To mitigate the impact of 
these events by limiting the extent of the loss of control quickly is a function also supplied by the health-physics program. The features of such a program in regard to plutcnium work will be covered in this section. In addition, some aspects of fire and nuclear safety will also be discussed.

\section{B. Contamination Control}

The toxic nature of plutonium requires that this substance be kept out of the body. Since plutonium in air tends to form a finely divided, loosely held oxide, there is a danger of this material being dispersed into air and remaining airborne. ${ }^{5}$ The presence of such uxide in air creates an inhalation hazard. To prevent this, the plutonium is confined. However, the enclosure then becomes highly cont: minated with the loose matter, so that a negative pressure must exist in the enclosure to avoid contamination leaks. Then, the airflow in the area will pass through the enclosed system and out through the filters in the exhaust system. This arrangement prevents the spread of contamination. However, since no system is perfect, leaks may still occur.

Since one must have access to the plutonium in gloveboxes, rubber or neoprene gloves are provided. These gloves protect the worker from contamination, but are subject to breakdown. This is one reason why surgical gloves are also worn: They provide another means of protecting the individual from contamination. In the event of a slight breakdown of the rubber gloves, the individual may not know this merely from appearance. Some other means must then be used to detect the spread of contamination.

Besides the two examples given above, loss of control may also occur as the result of operator error. Then again, an incident may be due to some unforeseen reason or unknown cause, but loss of control will still be the result.

In hood work, surgical gloves are worn to protect the worker's hands from contamination. If at all possible, one should not handle objects within the hood with the gloves directly. Something else, such as tissues, should be used. Then, the tissue becomes contaminated first, and the gloves act as a second line of defense. Hands should not be pulled out of the hood unless gloves are removed, since this may cause a loss of control. Also, if the gloves pick up significant contamination, they should be changed and disposed of as waste. The use of highly contaminated gloves only dieperses the material throughout the hood and increases the chance of hand contamination if the glove fails.

\section{Philosophy of Contamination Control}

The goal of any contamination-control program is to limit the epread of contamination to as small an area as possible. ${ }^{5}$ This aids in reducing the exposure potential of the incident, eases the task of controlling the extent of the event (spill), and enhances cleanup of the area. One common approach is shown in Fig. 8: 
a. Set up zones or areas to isolate the more hazardous processes. Allow work with radioactive materials only in the laboratory area.

b. Control access. Set up a security guard (G) at the entrance, or require a special badge to actuate the door lock.

c. Direct traffic patterns. Permit access to the laboratory area only through the doors at either end of the area $(E)$ and past monitoring stations (M).

d. Set up monitoring (M) and/or decontamination stations (D) at zone interfaces.

e. Use protective clothing that is limited to the zone. Leave clothing worn in the laboratory area in the change room (CR) when leaving the laboratory area.

for radiation.

f. Insist that anything leaving the hazardous zone be surveyed

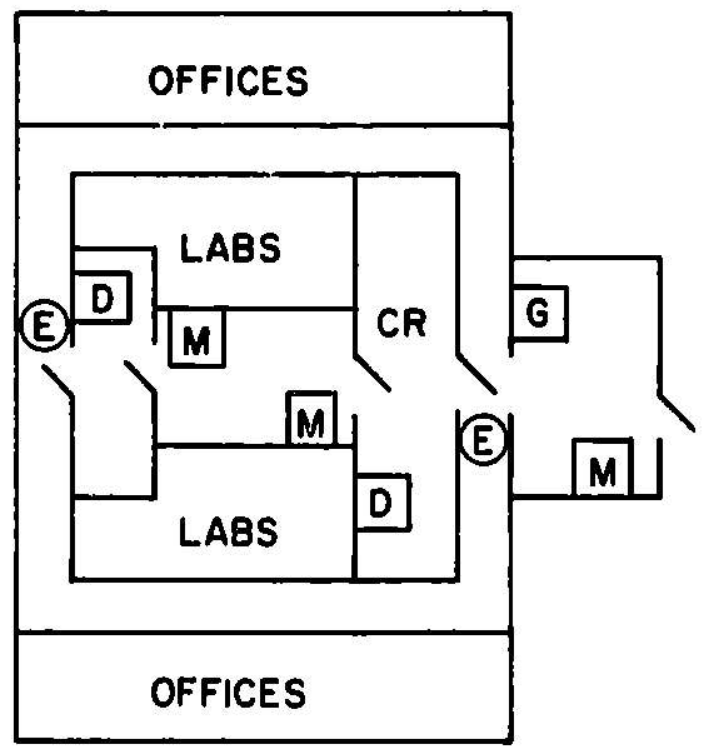

Fig. 8

Design for Contamination Control

The above scheme provides a means to detect and limit contamination that might otherwise be tracked or transferred to other areas. The entrance may also be marked with inetruction for use of monitoring devices and special protective equipment while in the radiation zone. Such devices or equipment may be provided there or in the change room. In some cases, decontamination stations located at the zone boundary may be desirable. All these features may be set up, but depend upon the good will of the workers if they are to succeed. That is, unless the workers, and the visitors to the area, realize the necessity for checking everything that leaves the hazardous area, the contamination-control concept will fail. The scheme to contain any contamination within the laboratory area in Fig. 8 works well only if the total cooperation of all personnel involved is obtained. When cooperation breaks down and exceptions to the control procedures begin to increase in frequency, 
then the probability of losing control is greatly increased. On the other hand, with strict adherence to the control procedures, the extent of any contamination can be limited to the hazardous zone alone. In addition, if frequent surveys of the laboratory area are performed, contamination incidents are picked up more quickly. This also aids in reducing the size of the area involved in a contamination incident.

\section{Contamination-control Practices}

In addition to the practices discussed in Sec. IV. A above, the worker should observe other control measures. These measures seek to reduce the hazard potential at the local level as well as prevent intake of contamination. The uss of shoe covers, laboratory coats, and surgical gloves that are not worn 0 : $t$ of the area will help contain the spread of contamination. Survey of surgical gloves for radiation each time the hands are removed from the glovebox permits early detection of loss of control. The forbidding of smoking, eating, or drinking in the radiation area will reduce the chance of radioactive matter being inhaled or ingested. Hands should always be washed following work with radiation. When leaving a radiation area, one should monitor his hands, shoes, and any equipment he is taking to further prevent the chance of spreading any costamination. Wounds or punctures should always be monitored for plutonium and promptly treated by a doctor.

Waste-disposal practices set up for different forms of contaminated waste should be observed. Dry waste is often put in metal containers, sealed in plastic bags, and removed through bag ports. ${ }^{5}$ This waste may then be placed in large, covered, metal drums, which can be sealed when filled, and removed for burial. Liquid waste is handled by piping to waste tanks or containers, by use of small bottles or other containers, and by treatment (evaporation or absorption in vermiculite) that changes the liquid waste to solirl waste. ${ }^{5}$ Gaseous waste is often planned for in the design feature 3 of the $1: x-$ haust system. ${ }^{5,7}$ Pyrophoric wastes are often burned within an conclosure before being disposed of.

Waste-handling rules ohould specify the correct method of disposal for items that do not fit standard containers. Also, the correct use of waste containers as well as proper waste segregation should be explained.

Plutonium storage practice involves nuclear-safety aspects that require special attention. ${ }^{79}$ For this reason, storage must be strictly controlled. Large amounts of plutonium are often stored in areas or vaults of special design, and under the control of a responsible individual. He must keep records of the amount on hand and be responsible for proper storage and movement of plutonium. For safety purposes, access to these areas should be restricted.

For omaller amounts, the user should submit a material-handling plan that should include otorage plans. He is responsible for the movement and 
storage of this material in his area. This plan should be reviewed for approval in regard to nuclear safety. For amounts below an established minimum, the threat of a criticality is no longer a problem. However, depending on the form of the plutonium, special storage precautions may need to be taken. Such things as proper containers or storage in an inert atmosphere will warrant some thought.

\section{Control Problems}

The previous discussion was concerned with the general design and administrative aspects of contamination control. However, the problems in degree of control are specific to the material which is involved. For ex-

TABLE XIV. Occupational MPC and Body Burden for Selected Nuclides

\begin{tabular}{|c|c|c|c|}
\hline \multirow[b]{2}{*}{ Nuclide } & \multirow{2}{*}{$\begin{array}{c}\mathrm{MPC} \\
-\mathrm{Ci} / \mathrm{cm}^{\prime}\end{array}$} & \multicolumn{2}{|c|}{ Body Burden } \\
\hline & & $-\mathrm{Ci}$ & $-\mathrm{g}$ \\
\hline${ }^{230} \mathrm{Pu}$ & $2 \times 10^{-12}$ & 0.04 & 0.65 \\
\hline${ }^{23} \mathrm{Pu}$ & $2 \times 10^{-12}$ & 0.04 & 0.0023 \\
\hline$\because \mathrm{Cl}$ & $6 \times 10^{-12}$ & 0.01 & 0.000018 \\
\hline $210 \mathrm{Po}$ & $2 \times 10^{-12}$ & 0.03 & 0.0000067 \\
\hline Nat. C & $7 \times 10^{-11}$ & 0.005 & $i 400$ \\
\hline
\end{tabular}
ample, see Table XIV. This table groups together a number of materials that are presently in use. Included in the table are the ICRP values of the MPC in air and the body burden values, in both microcuries and micrograms, for each of the nuclides. If one compares the MPC values, the relative control problems would be about equal for all but natural uranium. This is also true if one compares body-burden values in microcuries. However, on the basis of MPC values, natural uranium appears to be 35 times less hazardous than $239 \mathrm{Pu}$; and on the basis of body burden in microcuries, eight times more hazardr us. To assess the degree of control needed, one must look at the mass of material as well as the activity. That is, in a loss-of-control incident, the mass of any of the above materials that leaks out will be about the same, but the relative hazard this represents will differ greatly.

For example, assume $0.1 \%$ of a sample leaks out in an incident. If the sample were $650 \mathrm{\mu g}$ of ${ }^{239} \mathrm{Pu}$, the release would be $0.65 \mathrm{Hg}$ or one body burden. The same conditions involving natural uranium would result in $0.65 \mathrm{\mu g} / 7400 \mathrm{\mu g}=8.8 \times 10^{-5}$ body burden. If the incident involved ${ }^{252} \mathrm{Cf}$, then $0.65 /\left(1.8 \times 10^{-5}\right)=3.6 \times 10^{4}$ body burdens would be released! Clearly, the degree of control needed in each case is vastly different. So, with respect to design, one must be aware of the added confinement needed on the basis of mass considerations.

\section{Health-physics Control Measures}

Health-physics control measures may be grouped into two classes: (1) Provide fixed monitor for detection of hand, shoe, clothing, or air contamination; and (2) provide portable instruments and monitoring service on a routine basis to maintain contamination control. 
a. Fixed Monitors. A fixed monitor may be used to trigger an alarm when the measured radiation field exceeds a preset level. In this sense, the device indicates that the loss of control is significant. A fixed monitor may also be used to check the contamination status of an item. In this application, the device may indicate either no contamination or some level of contamination. Both types of devices may be used for certain operations.

(1) Personnel Monitor. A personnel monitor is an ac-operated device used to survey hands, shoes, and portable objects. ${ }^{103}$ It features a chamber in the form of a flat plate-type probe of large area through which the counting gas passes. Alpha particles enter the chamber through a thin Mylar window and ionize the chamber gas. The chamber output, which is proportional to the alpha activity, is displayed on a count-rate meter and indicated by audible clicking from an attached speaker. The same device may be used for beta monitoring if the operating voltage is shanged.

This type of rnonitor can be placed both at the enclosure and at exits to the work areas. When 2 hand is withdrawn from the enclosed system, it can be surveyed immediately without the risk of tracking any contamination. Upon leaving the work area, a worker is also able to survey his hands, clothing, and shoes. By making frequent surveys, he will quickly detect the presence of contamination. This action will limit the spread of any contamination.

Another type of pe-sonnel monitor, the hand-and-foot counter, is also used at the entrance to radiation areas. Such units may be designed to monitor both hands and shoes during the same counting period without requiring the use of a probe. ${ }^{104}$ At the end of a fixed counting time, an indication of contamination or no contamination is given. When contamination is indicated, the level can then be measured with portable health-physics instruments. These monitors are useful when a large number of people require hand-and-shoe surveys.

(2) Continuous Air Monitors. Continuous air monitors are used to maintain a watch on the level of air activity in the work area. These instruments are usually of homemade design and consist of some air-collecting device and a suitable detector for the radiation. ${ }^{105-107}$ For gases, a flowthrough chamber may be used to collect and detect the presence of the radioactive gas. For particulate $s$ or dust, filters are often used to collect the material, and the iype of radiation emitted will dictate a choice of detector. The device is often provided with an alarm, since the presence of an airborne toxic substance may represent a severe intalation hazard.

The presence of natural airborne radioactivity [see Sec. IV.B.4.b(4) 1 below] affects the ability of an air monitor to detect airborne plutonium. These radioactive products give rise to short-lived alpha and beta activities that tend to mask out any activity due to plutonium in an air sample. In the past, the sensitivity of air monitors has suffered because of this feature. 
The continuous air monitor, CAM-5, designed at ANL, ${ }^{105}$ counts both the beta and alpha activities built up on a fixed filter. The counting rates for each type of activity are then displayed on their own charts. Although the separate counting rates may vary up or down, the ratio of the se counting rates will remain fairly steady if no other $r$ adioactive substance is present. This ratio is balanced out by electronic means to give a nearly null reading, which is displayed on a third or center chart. Unless some other activity is collected on the filter, the ratio remains fairly constant. Hence, the presence of an alpha emitter deflects a needle to one side of the central chart, and the presence of a beta-gamma emitter deflects the needle to the opposite side. This design greatly increases the sensitivity of the air monitor in regard to plutonium. However, the detector is not shielded so that external beta-gamma fields can adversely affect its operation.

(3) Stack Monitors. This type of fixed monitor is used to estimate levels of radioactive substances which are released to the environs. In case of an accident, it also serves to denote if control by the filter system has been breached and what the extent of the release may be. These types of monitors are often homemade devices that are designed and assembled for specific jobs.

b. Monitoring Services. The monitoring services provided by an active health-physics program include routine instrument and smear surveys for surface contamination, personnel and item contamination surveys, and standby monitoring. Air sampling of the general work area, as well as special samples during certain operations, are also carried out.

(1) Surface-contamination $5 \lambda_{1}$ ays. Routine surface surveys should include both instrument and smear surve;s. The frequency of these surveys will depend upon the form of the plutonium and the type of operation carried out. In most cases, because of the degree of confinement used for plutonium, a positive survey result is cause for concern. I hat is, even a rather low level of contamination should warrant both cleanup a.d further investigation. For this reason, surface-contamination guides or levels are not readily found for plutonium. ${ }^{108}$ At any rate, the toxic nature of plutonium is such that any loss of control should mandate followup surveys. In some cases, certain contanination levels may be tolerated on the basis that proven control techniques are able to maintain contamination at or below these levels.

A number of portable or survey instruments are used to perform routine surface surveys. ${ }^{25,103,109,110}$ Normally, alpha survey instruments are used for surface surveys when plutonium is involved. If the sample contains fission products, though, a beta-gamma ourvey instrument may be used. Gas-flow proportional counter ${ }^{103}$ are used for all types of alpha monitoring. When humidity may vary greatly, these are preferred over air counters. The counter is a small, flat, platelike probe through which the gas flows. The alpha radiation enters the counter through a thin Mylar window and ionizes the 
chamber gas. The counting rate displayed on the instrument meter is proportional to the activity of the alpha source. Because of the short range of alpha particles, the probe must be used very near to the surface being surveyed $(<1 / 4$ in.). Earphones should be used with the counter to increase detection sensitivity. The lower limit of detection is about $250 \mathrm{dpm}$ in the area under the probe. ${ }^{103}$ This type of counter may be modified so that lowenergy beta particles can be detected. ${ }^{110}$ This latter capability is useful in monitoring for some of the transplutonic radioisotopes. Alpha scintillation counters using $\mathrm{ZnS}$ crystals are also used for alpha surveying. ${ }^{25,109,110}$ Gas flow and scintillation cointers both respond to neutron fields, so that extra care is needed when surveying for alpha surface contamination.

The smear survey consists of wiping a filter medium or other suitable material across a surface that is suspected of being contaminated. ${ }^{5}$ The smear can then be surveyed for activity with a portable instrument or counted for activity in a laboratory counter. This technique is easy to apply and allows quick spot-checking of areas for loose contamination. In many cases, one is concerned more about the presence of the contamination rather than its level. The qualitative result, cotained in smear surveys are most useful in these instances. The method is also used to check the integrity of clad or sealed sources to ensure that no leakage has occurred.

(2) Personnel and Item Surveys. In addition to the fixed monitors used for surveys in the work area, many other surveys of both personnel and items are made by survey instruments. These surveys are required when transfers into and out of enclosures are made. Surveys are also required for such things as skin punctures or wounds, glove changes on enclosures, decontamination of personnel or items, and repair work on potentially contaminated objects.

(3) Standby Monitoring. It some cases, the nature of the work may be hazardous enough to require the presence of a health physicist during the entir: process. This is called standby monitoring. This type of monitoring is also good practice each time a new echnique is being used. The advantage here is that the worker can devote full concentration to the job and the health physicist will take care of the necessary monitoring. Also, the worker has the benefit of health-physics advice at each step of the job.

(4) Air Sampling. Air sampling is carried out to ssess the condition of the work-area environment. It also allows a check on the effectivenes of the control design and/or work practices in regard to contamination control. Since internal dosimetry is difficult to perform, common practice has been to limit the concentration of radionuclides in air. Although the MPC value $\theta$ in Table XII are used as otandards that should not be exceeded, the goal is to keep airborne levels as low as possible. The MPC value (or CG value of ERDAM 0524) is used as an index of control, and airborne concentrations well below this level imply satisfactory control. To confirm that this is the case, 
routine air samples are collected. When air samples reveal levels above the standards, this is viewed as a potential iureakdown of the control system. Levels greatly above the MPC values for short periods do not constitute a severe hazard of themselves, but such levels over extended periods would be of concern. In the former case, it is not so much the level but the apparent loss of control that should be the major concern. Once control is lost, levels may go even higher as more material is released.

1. Natural Airborne Radioactivity. Airborne radioactivity has always been present as a part of man's environment. It arises largely because of the presence of uranium and thorium in soil throughout the world. ${ }^{25,55}$ The long-lived isotopes ${ }^{238} \mathrm{U}$ and ${ }^{232} \mathrm{Th}$ have long decay chains, which produce many daughter products. In each chain, a noble-gas daughter product is born: radon $\left({ }^{222} \mathrm{Rn}\right)$ in the ${ }^{238} \mathrm{U}$ chain and thoron $\left({ }^{220} \mathrm{Rn}\right)$ in the other. These inert gases migrate from the soil to the air, forming, along with their short-lived daughters, the major portion of natural airborne radioactivity.

The daughter products of these gases are particulate matter and attach to the dust in air. These are then captured by air sampling, and their activity often overwhelms that of the isotope of interest when the sample is counted shortly after sampling. This interferes with the proper interpretation of the air sample results.

2. First-count Factor. One scheme in use at Argonne to deal with the problem of natural airborne radioactivity is the "first-count factor" 25 or alpha-beta-gamma factor. ${ }^{103}$ This factor is obtained from the ratio of beta-gamma to alpha activities on the air sample, dete-"mined as quickly as possible after sampling ende. This factor is remarkably constant when only the radon-thoron daughter producte are present. ${ }^{25}$ If the ratio varies dramatically upward, the release of a beta emitter is signaled, and conversely, a major downward shift implies an alpha release. The actual value of the first-count factor is a function of many parameters and may vary from system to system. However, an air-sampling history of an area will quickly establish this number for a given system for the case of natural air activity. Once the factor is known, one can use the initial counting results of the air oample to estimate if an activity release has occurred.

3. Air-sampling Practices. The most common meane of eampling for particulates is to collect them on filters. ${ }^{2 s}$ The ampling technique lo to draw air at a known flow rate through a fllter for a known length of time. Figure 9 depicte a typical eystem.

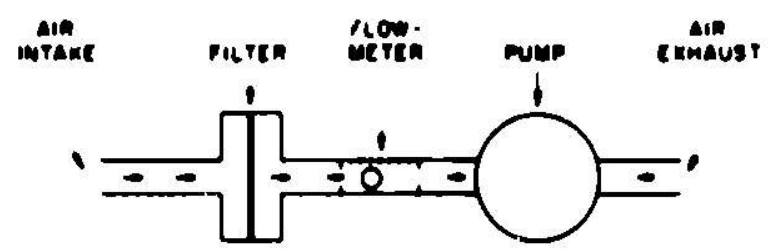

Fig. 0

Schematic Diagram of Typlcal Fllier Semple 
Once the sample is collected, the filter can be removed and counted for both alpha and beta activity on separate counter 8 . After the activity is measured, the concentration may be computed, since the air volume is also known.

Samplers may be located in the general work area to routinely monitor the overall operation. In other cases, samplers may be positioned close to a source of potential air contamination, such as hoods or gloveboxes. ${ }^{64}$ Personal air sampler ${ }^{111}$ have also been used to obtain air samples in the breathing zone of the individual. Thought must be directed to the type of sample needed in regard to sampler placement. Large differences have been obtained in the results of some of these methods for sampling a given atmosphere. ${ }^{100,111,112}$ The frequency of air sampling in an area will depend upon the form of the plutonium, the nature of the work, and the presence or absence of fixed air monitors.

\section{Internal Exposure Control}

\section{Personnel Monitoring Measures}

There are many problems in assessing the uptake, distribution, and retention of plutonium and the subsequest internal exposure that results. ${ }^{63.113-120}$ In Secs. III. B. 1 and III. B.2, many of these factors were briefly discussed. To estimate the internal-exposure rate, a measure of the organ burden is needed. Given the organ burden and excretion data, the total dose equivalent may be estimated. The control methods discussed attempt to exclude the entry of radioactive matter. Nevertheless, such entry may occur, so that methods are needed to estimate the burden and subsequent radiationdose equivalent.

A common method used to appraise internal exposures is a bioassay prugram. Routine urine and/or fecal samples are collected at some frequency, reduced chemically, and counted for the plutonium content. Soluble plutonium retained in the body is excreted mainly through the urine, whereas insoluble plutonium is found mostly in the feces. Data obtained from a number of samples can be used to estimate organ burdens. ${ }^{63,121}$ In the event oi a 848 pected intake, it may be necessary to collect all excreta for the first few days following an accident. ${ }^{113}$

In recent years, whole-body counters of special design have been used to detect plutonium in the body. ${ }^{114,115,117}$ These devices are able to detect the $17-k e V X$ rays from ${ }^{239} \mathrm{Pu}$ and the $60-k e V X$ rays from ${ }^{241} \mathrm{Am}$. Since these $X$ rays are easily absorbed in dense substances, the method is useful for lungburden determinations, but not for bone burdens. To correctly assese the lung burden by this method requires that the ${ }^{239} \mathrm{Pu} /{ }^{241} \mathrm{Am}$ ratio he known. 13,122 This method, used in conjunction with bioassay samples, has improved the estimate of intake in the case of inhalation eventa." 
Wound monitors have been developed that can be used to estimate the amount of plutonium in wounds. ${ }^{123}$ These instruments also count the lowenergy $X$ rays from the plutonium. These devices are useful for cases in which plutonium may be embedded in the tissue. Then, alpha radiation will be totally absorbed and not detectable, whereas the $X$ rays can still be seen. These monitors aid the physician treating the wound since the plutonium should be removed and may have to be excised. Normal skin cnntamination by plutonium can be detected by portable alpha survey meters.

On occasion, other samples such as nose swabs, sputum, or blood may be needed in order to help in assessing the intake.?

\section{Therapeutic Measures}

A number of substances have been found useful for increasing the urinary elimination of plutonium from the body. ${ }^{63,70,103,116,124}$ of the se, diethylene-triamine-penta-acetic acid (DTPA) has proven the most effective agent. ${ }^{70}$ However, treatment with this substance is most effective only in the early stages following intake. It is presumed that once plutonium is bound in bone, DTPA will have little effect. ${ }^{120}$ In the early stages, when the level of soluble plutonium in the blood is high. DTPA is able to increase the excretion rate. When plutonium is removed, the subsequent total dose may be greatly reduced. This feature is most important since soluble plutonium is so tightly bound in bone, ensuring long, continuous irradiation.

In recent years, pulmonary lavage (lung irrigation) has been tried as a means of removing inhaled matter from lungs. One application of this method to humans has been reported. ${ }^{25}$

\section{Protective Equipment}

Protective equipment should be supplied to the worker to increase the degree of protection afforded by othe: safety measures. Its purpose is to protert him from contamination and to aid in the control of contamination. ${ }^{126}$ The use of such equipment guards against pickup of external contamination on the worker's person or clothing and intake of contamination into the body. Also, the equipment is removed by the individual in the given area so that the contamination can be confined to that area.

Types of protective clothing used are laboratory coats, coveralls, and pants and shirts. ${ }^{7}$ Coveralls or pants and shirt are preferred, since these call for a change of personal clothing. This precludes loss of personal clothing in a contamination incident or spill. Gloves and safety shoes may also be provided to round out the basic scheme. In some cases, one may provide laboratory coats and shoe covers at the zone entry for use by observers or those not normally working in the area. Any handling operation with plutonium should be done with protective gloves on. Other more elaborate types of clothing may also be used. ${ }^{126}$ 
Other necessary protective devices include respiratory equipment. These may be needed for special operations, such as repair work or modifications, as well as for an emergency. The use of these devices on a continuing basis in place of proper source control of the plutonium work is undesiruble. One class of respirators, the full facepiece type, processes the air the worker breathes in from his surroundings. ${ }^{126}$ These are suitable for particulate matter, and some may provide protection up to 100 times the MPC in air. ${ }^{127}$ In the other class of respirators, which includes self-contained breathing units, the worker does not breathe the air from his surroundings. This type is suitable for both gases and particulate matter and should be used for particulate concentrations greater than 100 times the MPC in air. ${ }^{126}$ Here again, the function performed and the form of the plutonium used will affect the type and required use of the above protective equipment.

\section{External Exposure Control}

In Secs. III.A.5.a and III.A.5.b, the external dose rates from a plutonium sample were discussed. At that time, expressions were presented that showed that the external field is a sensitive function of the isotopic composition. For plutonium that contains less than $5 \%$ on a weight basis of isotopes other than ${ }^{239} \mathrm{Pu}$, the external field is not a great problem. ${ }^{61}$ Above this weight percent, the external exposure hazards increase and eventually require special controls, such as reduced work time, shielding, or semiremote handling. ${ }^{29,61,99}$ Of course, recently irradiated uranium capsules may contain fission products in amounts comparable to the plutonium content. These would present very serious external exposure hazards that would require extensive shielding and totally remote handling. such as in hot cells. This latter consideration also applies to handling large amounts of transplutonium matter. ${ }^{94}$

We saw, in the case of a plutonium sample, that the external field is comprised of low-energy $X$ rays, low- and high-energy gamma rays, and fast neutrons. Beta radiation is absorbed either by the enclosure itself or by the enclosure gloves. $X$ rays and gamma rays are reduced to some extent by the enclosure and by 11 sing leaded gloves. However, the photor dose rate increases with surface area of the plutonium. Thus, a thin layer of plutonium on the floor area of the enclosure may increase the photon dose rate. The presence of ${ }^{24 !} \mathrm{Pu}$ will mean a gamma-dose-rate $(>40 \mathrm{keV})$ increase for years due to ${ }^{241} \mathrm{Am}$ buildup. Neutron dose rates depend upon the mass of the sample in the case of spontaneous fission. The dose rate from neutrons may also be greatly increased if low-Z-number substances are used in the process. ${ }^{29}$

In the early handling of plutonium, extremity exposures were of little concern. With the advent of high-exposure plutonium, hand exposures as well as whole-body ones became important, and methods of reducing such exposures had to be provided. ${ }^{29,61}$ For transplutonium substances, dose rates are such that whole-body doses must be greatly reduced for all but small amounts of the se substances. ${ }^{94}$ 
1. Exposure-control Practices

Among the practices that may be used to limit the external exposure received by the worker are: 61,94

1. Limit the amount of material in the enclosed system.

2. Reduce the total work time allowed in handling plutonium.

3. Process the material as soon as possible after chemical separation.

4. Remove waste matter as quickly as possible so that surface deposits do not build up.

5. Use remote handling devices, such as tongs, as much as possible.

6. Rotate personnel for those jobs having the higher exposure rates.

2. Shielding

A number of substances have been used as shields to reduce the external radiation dose. Initially, the normal thickness of material on the enclosure provided enough shielding to reduce the low-energy $X$ ray to low enough levels. As the plutonium isotopic composition shifted, the use of leaded gloves became common practice. These gloves were used to limit hand exposure, but their thickness, in lead equivalents, was restricted since at some point handling operations berame too difficult. Common practice has been to limit thickness to $30-\mathrm{mil}$ leaded gloves $(0.1-\mathrm{mm}$ lead equivalent). As both gamma and neutron dose raes became larger, it was necessary to go to more potent shielding to achieve needed dose reduction. In the case of gloveboxes, only so much shielding can be included or added and still allow ease of manual handling. Therefore, at some point, hot cells and remole handling devices nust be used.

In the case of $X$ and gamma rays, high- $Z$-number substances are most useful as shields. However, a shield material does not absorb equally for all energies of the incoming photons. The transmission expresses the fraction of the incoming photons of a certain energy that pass through a shield of given thickness. Table XV gives photon-transmission values for some common materials used in gloveboxes.

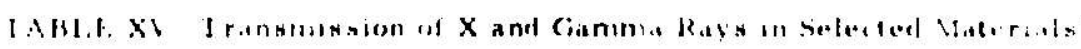

\begin{tabular}{|c|c|c|c|c|}
\hline \multirow[b]{2}{*}{$M 1,1+\cdot r 1 .+1$} & \multicolumn{4}{|c|}{ Iransminnnum } \\
\hline & $1 ;: 1.1$ & is $k+1$ & $+11+.1$ & $111) \mathrm{kal}$ \\
\hline 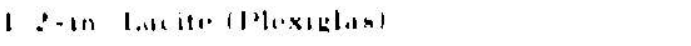 & $11 \therefore 4$ & $11 ; .1$ & $13 \times 1$ & 1142 \\
\hline (i) - & 11 & 11 is & $11:$ & " 14 \\
\hline $1.1 .11 . .1111 .1$ mum & $" 1$ & 111 & 11,1 & " : In \\
\hline $1 k=1 n+|1, \ldots|$ & 11 & 11 & $1 \cdots$ & $11+3$ \\
\hline
\end{tabular}


As may be noted from the table, as photon energy increases, the shield thickness must also be increased to retain the same shield transmission factor. For transplutonic isotopes, which have more photons in the range above $100 \mathrm{keV}$ than plutonium, the photon shielding problem becomes more troublesome. ${ }^{39}$

In the case of neutron shields, the choice of a proper shield substance is more complex. For a fast-neutron spectrum, the shield must quickly remove the neutrons, yet be thick enough to absorb photons produced in radiative capture. ${ }^{128}$ In very thick shields, the neutrons will be removed and still enough matter will be available to reduce the capture gamma ray hazard. In thin shields, one may reduce the neutron hazard but increase the gamma hazard.

For f3st neutrons, low-Z-number substances, such as hydrogen, are most useful as shield materials. ${ }^{26,89,129}$ One may compare neutronshielding substances on the basis of their hydrogen content. On this basis, polyethylene and water are among the better neutron shields, while concrete is one of the poorer ones. ${ }^{26,89}$ Reference 26 contains data on the shielding ability for some of these materials for fast neutrons. Transmission factors for thin neutron shields are difficult to obtain, sinc, one must deal with a spectrum of neutron energies. In thin shields, the spectrum changes rapidly over short penetrations, so that the shield effect may depend upon the initial spectrum assumed. In thick shields, removal theory for neutrons may be applied. ${ }^{26}$ Reference 130 contains shielding information useful for transplutonium material.

\section{Health-physics Control Measures}

Health-physics control measures cover monitoring services with survey instruments to define the radiation field and personnel monitoring programs to assess exposure. In addition to these features, fixed monitors that respond to external radiation fields above certain preset levels may also be used. The response may include visual and audible alarms to indicate acci.dent situations requiring prompt action.

a. Monitoring Services. A number of survey instruments are used to estimate the external radiation field. For photons, beta-gamma survey meters (Geiger counters) or ion chamber devices are most often used. ${ }^{25,110}$ Neutron fields may be evaluated by devices that measure the neutron-flux density (such as the long counter ${ }^{25}$ ) or approximate the dose equivalent rate (such as the neutron monitor ${ }^{110}$ ). Flux-density units may be related to the estimated dose equivalent rate by means of the relationships in Table XVI. These values have been adapted from Ref. 26.

For a fast-neutron spectrum, such as in fiesion or $(\alpha, n)$ processes, an average value for the flux density is used. The flux-density 
value for a mean energy of $1 \mathrm{MeV}$ is often used to estimate the dose equivalent rate. Any moderation of fast neutrons then provides a safety factor. This is particularly true when the field is measured after passing through hydrogenrich shields.

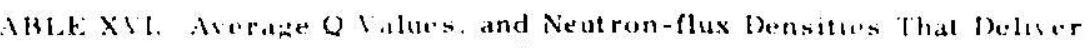
a Maximum Dess Fquisalent of 100 mrell in to he

\begin{tabular}{|c|c|c|c|c|c|}
\hline $\begin{array}{c}\text { Nevut ron finergy. } \\
\text { Ne. }\end{array}$ & $Q(a \times g)$ & $\begin{array}{c}\text { Neutron-llux Density. } \\
\text { n } \operatorname{cm}^{2}-50\end{array}$ & $\begin{array}{l}\text { Veatron Fineriss. } \\
\text { Mel }\end{array}$ & $Q(\omega n)$ & 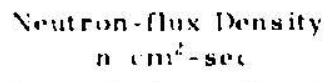 \\
\hline Thermal & 2 & 1,811 & $5 \times 10^{-1}$ & 11 & 27 \\
\hline $1 \times 11^{-7}$ & 2 & $n+40$ & 1 & 11 & 13 \\
\hline $1 \times 10^{-6}$ & $\therefore$ & ien & 2. 7 & it & $\therefore 0$ \\
\hline $1 \times 10^{-5}$ & 3 & $\overrightarrow{7 n t}$ & 5 & $s$ & I1. \\
\hline $1 \times 10^{-4}$ & 2 & 19 & $\vec{i}$ & : & $1:$ \\
\hline $1 \times 10^{-1}$ & I & $(N+)$ & 10 & e. i & $1 \vec{i}$ \\
\hline $1 \times 10^{-1}$ & $\therefore=$ & :1su & 11 & i. & 12 \\
\hline $1 \times 10^{-1}$ & 7.5 & 115 & 211 & $x$ & 11 \\
\hline
\end{tabular}

Estimates of the total dose rate from neutrons and gamma rays can be used to assess the hazard. If the dose rates greatly exceed the allowed standards, a severe hazard may exist. In these instances, actions that will greatly limit exposure during handling will have to be taken. For not so severe hazards, only minor changes may be called for.

b. Personnel Monitoring Devices. The most common type of device used to monitor the exposure of the worker is the film badge. These devices can be equipped with film that responds to beta, photons, and neutrons. After the badge is worn for a suitable period (2-4 weeks), the films are developed and the response can be related to the amount of exposure. A pocket dosimeter is often used with the film badge to allow visual checks of the exposure received. ${ }^{61}$ These devices can be read and recharged, and the reading recorded on a daily basis, if desired. Units can be used that respond to betagamma as well as to thermal and/or fast neutrons.

Film rings and wrist badges may also be worn for monitoring extremity exposures. In recent years, film has been replaced by thermoluminescent ( $T L$ ) dosimeters in the finger rings. ${ }^{61,94}$ One reason has been that the film has been subject to light leaks, which produce erroneous response. This is not a problem with $T J$ substances.

A problem in the use of film for neutron monitoring by track counting has been poor response in the intermediate-energy region. $25,61,94$ The NTA film in common use will not respond to neutrons below about $0.5 \mathrm{MeV}$. For moderated neutrons, this film may miss a large portion of the neutron dose. One method used to overcome this defect involves track-counting of fission-fragment tracks recorded in mica. ${ }^{131}$ The recoil tracks of fission 
fragments, which arise from neutron capture in ${ }^{235} \mathrm{U}$ foils, appear as pit marks in the mica. Following an etching process, the tracks may be counted under microscope and related to the total number of neutrons to which the foils were exposed. Since ${ }^{235} \mathrm{U}$ fissions for all neutron energies, this method will cover the intermediate-energy region. This method has been in use at Argonne National Laboratory and has resulted in more realistic neutron exposures being found. ${ }^{132}$ Other methods ${ }^{61,94}$ have been used to correct for any loss of response in using NTA film.

\section{E. Nuclear Safety}

Nuclear safety may be defined as the prevention of uncontrolled critical-mass reactions. ${ }^{133}$ For our purposes, this means preventing a criticality in any system meant to be subcritical. This task involves solving prohlems of a scientific, engineering, and administrative nature ${ }^{79,134}$ Scientific problems involve the setting of vaiues for the critical mass of the substance. Engineering problems involve process design to avoid conditions that favor a chain reaction. Administrative problems involve setting up practices, rules, and controls that attempt to preciude such occurrences due to errors in handling and processing. ${ }^{79}$

Using the data from critical-mass studies, the process and equipment can be analyzed to arrive at safe mass limits throughout the plant. Then, detailed rules to achieve nuclear safety can be drawn up, and an adninistrative system of checks can be set up to ensure that these rules are followed. ${ }^{79}$

\section{Control Methods}

The goal of nuclear safety is to minimize the chance that a criticality or excursion occurs. This goal is attained if a sufficiently large fraction of the neutrons released in fission are captured (nonfissile) or escape from the system (leakage). Then, fewer fissions occur in one generation than in the preceding one. A number of factors influence the neutron balance of the system so that several types of controls may be used. ${ }^{79,133,134}$ When these

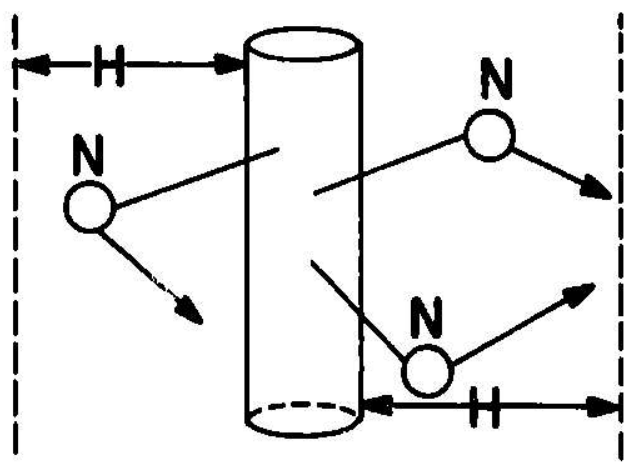

Fig. 10. Example of Safe cieometry for Pipes or Cylinders factors are applied, the principle used is that nuclear safety should depend as little as possible upon actions or decisions by personnel.

For solutions, safe geometry or "always safe shape" is the preferred method

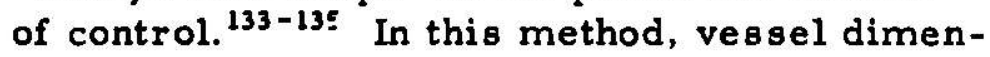
sions are such that enough neutron leakage occurs to prevent any excursion (see Fig. 10). The general approach is to limit one of the dimensions (such as the diameter of the cylinder in the figure) to ensure that enough neutrons will be permanently lost. Then, a chain 
reaction cannot be achieved in the isolated system, regardless of the amount of fissile material. That is, the cylinder in the figure could be of infinite length and contain any concentration of fissile matter in the solution without going critical.

In many processes, the absence of substances that may moderate and/or reflect neutrons cannot be guaranteed. For example, the human body contains a great deal of hydrogen. For this reason, the values assume that a thick hydrogenous reflector surrounds the material. The thickness, diameter, or volume of vessels can be designed so that criticality cannot occur. This method may also be used for metals in the form of slabs, cylinders, and spheres (see Table XIII, recommended values).

Mass control is often the method used for metals if safe geometry cannot be used. The "always safe mass" is that amount of the fisaile substance that cannot sustain a nuclear chain reaction, regardless of its shape or form and the nature of the surroundings. This mass, usually taken as slightly less than half the minimum critical value, is listed as the recommended value in Table XIII. This allows for one double-batching error, since two always safe masses will not cause a criticality. Mass control is often used for both glovebox and hot-cell work. "1,134 The posting of the mass limit on the enclosure is a common practice that aids proper control practices.

Other methods of control, such as concentration limits, use of fixed and soluble poisons, and $\mathrm{Pu} / \mathrm{U}$ ratio are discussed in the literature. ${ }^{134-136}$ In all cases, the limits used apply to iso-

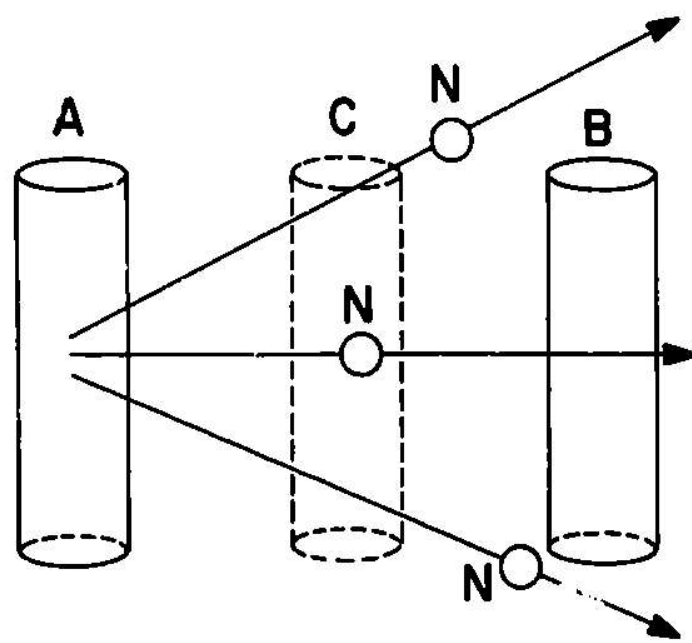

Fig. 11. Interaction Effects in Adjacent Containers lated systems.

In the use and storage of fissile substances, the spacing must be taken into account to nullify any interaction between two systems. ${ }^{79}$ In Fig. 11, containe $\mathrm{A}$ is separated from container $B$ by enough distance so that much of the n leakage from $A$ is not intercepted by $B$, or vice versa. In this case, both containers $A$ and $B$ could be geometrically safe, as isolated systems. In the setup pictured, those systems would also be safe by virtue of the sufficient separation. However, the probability of interaction occurring is proportional to the solid angle, which increases with the decrease in the distance of separation. Thus, if container $B$ were at position $C$ in the figure, more of the $n$ leakage would be intercepted. This could produce a situation in which enough neutrons would not be permanently lost from the system of two containers. That is, enough neutron leakage from the entire system to avoid an excursion may not be obtained if the spacing of fissile matter is close enough. These neutrons may 
cause fission in a nearby system, and neutrons from that system may do likewise. In this manner, two subcritical systems may be made critical if care is not taken. ${ }^{133}$ Storage in arrays or cubicles, which have posted mass limits. is one means of obtaining the proper separation.

\section{Administrative Controls}

Administrative controls may require that a written nuclear-safety statement or manual be prepared for review by competent individuals if more than safe amounts are to be handled routinely. ${ }^{62,137}$ These statements should describe the processes, facilities, and equipment to be used as well as the makeup, masses, and configurations of the fissile substance. ${ }^{62}$ Credible accidents must be treated as well as safe procedures for double-batching or two simultaneous, unlikely events occurring. ${ }^{79,134}$

For each approved statement, one individual should be responsible for seeing that only approved procedures are followed. Because of the importance of nuclear safety, the responsibility for nuclear safety must be clearly defined within the facility. ${ }^{79}$ Detailed controls that are set up must be arrived at by each facility through analysis of unique functions.

\section{Monitoring and Dosimetry Practices}

Although the risk of an excursion is very low, it cannot be entirely eliminated, so that these events may accidentally occur. ${ }^{86}$ For this reason, one should provide (1) a means of alerting workers to the threat of highradiation fields and (2) a plan for their quick evacuation. ${ }^{85}$ The exposures in such an event can be quite severe, so a delay of even a few seconds in leaving the area can be crucial.

The radiation alarm system should have a very rapid response and good reliability, give little or no false alarms, and emit a distinct, audible signal. ${ }^{81,85}$ This system should sound an immediate local alarm so that an area can be evacuated. It should also indicate the location and radiation level of the event at some central control station. The sensor, or radiation detector, may respond to either gamma or neutron fields. This is usually placed near the point where an excursion is a possibility. The alarm system, which may consist of a number of horns, may be distributed throughout the rest of the area. Personnel should be instructed so that they are aware of the alarm sound, the proper evacration route, and the vital need for immediate evacuation. Drills and periodic training should be carried out to ensure that this information is not forgotten.

If a criticality occurs, a system is needed to obtain data on the absorbed dose to which a worker has been exposed. Such data will be of value for a number of reasons. ${ }^{138}$ To obtain this information, we need a measure of both the neutron fluence and spectrum and the gamma-absorbed dose. Such 
information can be obtained by the use of one of a number of nuclear-accident dosimeters. ${ }^{138}$ Since placement of these fixed units may differ from the location of the exposed worker, a measure of the ${ }^{24} \mathrm{Na}$ activity induced in the person's body is a:so needed. With the ${ }^{24} \mathrm{Na}$ data, the dose at the dosimeter station can be relat $3 \mathrm{~d}$ to the dose the worker receives. ${ }^{84,139}$

The nuclear-accident dosimetry system in use at Argonne used a modified Hursi dosimeter package. ${ }^{140,141}$ The dosimeter is made up of a neutron section and a gamma section, which are physically tied to each other. The neutron section contains a bare gold foil, a cadmium-clad gold foil, a sulfur pellet, a cadmium-clad copper foil, and a ${ }^{237} \mathrm{~N},{ }^{235} \mathrm{U}$, and ${ }^{238} \mathrm{U}$ fissionfoil system in a cadmium and ${ }^{10} \mathrm{~B}$ shield. This unit measures neutron fluence in the thermal, intermediate, and fast regions to provide a rough spectrum estimate. This information allows the neutron dose to be estimated. The gamma dosimeter has chemical components and a TL dosimeter for measuring gamma dose.

To aid in dose determination, a "quick-sort" method is needed to roughly divide those exposed from the unexposed. ${ }^{142}$ A common method used is to provide the person with an indium foil. When exposed to thermal neutrons, the foil gives off beta-gamma radiation. This can easily be read with beta-garmma survey instruments if the check is made soon after the incident. An alternative method is to use a gamma-survey meter at the body midsection to measure induced radioactivity in the body. ${ }^{142}$

In addition to the fixed dosimeters, the worker may be provided with neutron-measuring components that are part of his film-badge unit. ${ }^{109}$ At ANL, these components include sulfur powder, an indium and two gold foils in a cadmium box, and a copper foil taped to the outside of this box. In addition to spectrum information, some information in regard to orientation in the ncutron field can be obtained.

In principle, nuclear-accident dosimetry methods are simple and easy enough to apply. In practice, an accident may be a complex affair in which many unforeseen obstacles can appear. ${ }^{143}$ These factors may delay or impede the dose determination in any given event. For example, a dosimeter may be destroyed or badly contaminated in the incident. Also, the radiation field may be so high that the unit cannot be readily retrieved. In these cases, other activated substances may be found that can be used to measure neutron activation. ${ }^{142}$

\section{F. Fire Safety}

\section{General Discussion}

The most effective means of preventing plutonium fires is to use a $d y y$, inert atmosphere, such as argon, helium, or nitrogen, in the enclosed system. Both moisture and small amounts of oxygen (see Sec. II. D) should be 
avoided when pyrophoric metal is involved. For some operations, dry air has been used with success. Room air is used for aqueous solution lines and where clad material only is handled. ${ }^{5}$

Such design features as the use of noncombustible materials, fire breaks in an enclosure line, wire-mesh fire screens for exhaust filters, firedetection systems, alarms and control for overpressures, fire-suppression systems, and other detection systems increase the degree of fire safety. $5,7,11,12,88,144,145$ Practices that control the sources of ignition and explosion treated in Sec. III. D will also help to prevent fires. Methods such as maintenance of airflow to prevent gas buildup, monitors for explosive mixtures, and control of inert-atmosphere purity aid in explosion control. ${ }^{11,12}$

Fire safety in areas outside an enclosed system should be designed to protect the exterior of the enclosure from damage. The construction and fire-protection design of rooms and areas in which enclosures are found is important. These should be constructed of fire-resistant or noncombustible substances and provided with fire walls that isolate the area from other areas of the plant. ${ }^{5}$ The module, room, or building should remain standing to provide containment in the event of a serious fire in which material may be released from enclosures. Automatic as well as manual fire-fighting systems should be available. ${ }^{5,12}$ Automatic water-sprinkler systems can be used in areas in which there is no danger due to criticality or the presence of reactive metals (for example, sodium). ${ }^{5}$ Other types of area systems have also been developed. ${ }^{146,147}$ Portable or manual fire extinguishers should also be provided. These may include dry powder, $\mathrm{CO}_{2}$ systems, fog nozzles, or foam devices, depending upon the nature of the fire hazard. ${ }^{5,12}$

\section{Fire Extinguishment}

Since fires in enclosures such as hoods and gloveboxes can be expected, one should prepare for them. In addition to automatic systems, manual systems for fire extinguishing should be provided. Quick-connect couplings have been used on gloveboxes $\mathrm{s}$ ease the task of discharging portable fire extinguishers. ${ }^{5}$ Piercing lances or nozzles may be attached to extinguishers to pierce a glove in order to combat fires. Storage of manual extinguishing agents within the glovebox may be provided when an inert atmosphere is not used.

A number of reports have discussed the methods of extinguishing plutonium fires. ${ }^{5,7,43,44,148}$ In this respect, it is important to distinguish between fires that threaten to involve plutonium and those in which the plutonium is actually burning. If no plutonium is burning, a number of extinguishers are effective. ${ }^{5,7,44}$ Carbon dioxide $\left(\mathrm{CO}_{2}\right)$ devices are effective for flammable liquids and electrical fires, but will often pressurize the system. ${ }^{5} \mathrm{~A}$ dry-chemical type will safely extinguish all but metal and filter fires. ${ }^{44}$ Water should be avoided for fires in which reactive or pyrophoric metals and/or fissile 
substances are present. However, it should not be totally ruled out, even where these problems exist, since it may be the only means of controlling the fire. ${ }^{53}$

For plutonium-metal fires, complete exclusion of oxygen and/or rapid heat removal to below the ignition temperature $\left(500^{\circ} \mathrm{C}\right)$ are the only truly effective means to extinguish plutonium fires. ${ }^{43}$ The work of $\mathrm{Felt}^{43}$ showed that applying argon locally was very effective in extinguishing fires in large amounts of plutonium metal. However, one could not attain oxygen exclusion merely by flooding an air box with the inert gas. Only with a somewhat reduced oxygen content $(<4 \%)$ could the argon stop the burning. This suggests either that an ine $t$ atmosphere be used or that some other method be available for extinguishing plutonium fires in an zir atmosphere.

The use of fusible salts or metal powders does not exclude oxygen, but these substances are effective in rersoving heat. Of course, when the temperature drops below the ignition point, the metal no longer supports combustion. Based on the heat-removal aspect, solid agents that were most effective were magnesium oxide ( $\mathrm{MgO}$ ) sand and copper powder. Other agents tested were graphite, ternary eutectic salts, lead powder, iron powder, foam, plutonium dioxide, and Halon 1301 gas. $^{43}$

Sometimes plutonium metal fires treated by the above agents may not be extinguished easily. The main concern is to contain the plutonium fire and prevent it from igniting other substances. Often the greater hazard occu:s when other combustible substances are ignited by the metal fire. ${ }^{43,44}$ When this happens, the fire can spread very rapidly throughout the system and great damage may occur before control can be regained. 


\section{EMERGENCY PLANS}

Much has been said in regard to preventing certain incident $B$, yet they still seem to occur. A number of causes can be assigned or postulated in each case, but the cogent feature is that, despite all that can be done, accidents still orcur. For this reason, one must accept the premise that certain accidents are going to occur. To properly deal with these situations at any level requires both a well-thought-out plan and trained individuals to execute the details. ${ }^{149}$ As one might expect, the more complex the incident, the more detailed will be the plan and the more substantial will be the group involved.

The philosophy that should apply in an emergency situation will reflect these goals: ${ }^{7}$

1. Protect personnel from injury and hazards, and quickly identify exposed personnel.

2. Avoid actions that might create greater hazards.

3. Bring the emergency under control.

4. Prevent property damage.

15. Limit the extent of any contamination.

To deal with an event and form a plan of action will require an initial analysis of the accident potential. Thought should be given to the type and nature of events likely to occur. These may include criticality accidents, contamination release in fires or explosions, or high-radiation fields. ${ }^{7,149}$ At this stage, extra precautions should be taken to reduce the likelihood of the event, if possible. One should ponder the extent of the area and estimate the number of people involved. Key areas should be identified, and photographs of the suspected trouble spots may be prepared. Other building data and plans to aid emergency response groups unfamiliar with the area may also be included.

Once the events are defined, written procedures for immediate actions in these emergency situations can be prepared. There may be many facets to the plan, depending upon the nature of the event. However, at every level these plans should (1) be easy to understand, (2) specify actions to be taken, (3) detail responsibilities, (4) define communication lines, and (5) denote sites of emergency equipment. The plans should cover such aspects as evacuation plans, reporting emergencies, and the types and meaning of alarm systems. Assembly points and decontamination centers, and the proper routes to these areas, should be detailed. Drills and training of personnel should be carried out to test response and farniliarize workers with their part in these plans. Review of these drills should be carried out to point out weak spots in the scheme so that these may be corrected. ${ }^{\theta 1}$ 
When immediate local actions are not able to cope with the event, a major emergency plan should be provided. This will require the response or assistance of many groups: medical people, health physicists, communications personnel, security forces, firemen, utility men, and others. The major plan should designate a director whose function is to coordinate the actions to ensure a team effort. He should be assisted by other designated personnel whose responsibility is to provide expertise in certain aspects of emergency control. Included in this group should be someone familiar with the area in which the emergency has taken place.

Among the functions that must be carried out in the event of a major incident are:

1. Evaluation of the situation in regard to degree of hazard.

2. Assistance in the evacuation or recovery of persons.

3. Surveying of persons for contamination and/or radiation.

4. Accounting of persons involved in the incident.

5. Formulation of procedures to bring the emergency under control.

6. Treatment and decontamination of any injured persolıs.

7. Provision of instruments, clothing, portable decontamination units, and other specialized equipment.

8. Collection of personnel data and preparation of public information.

Following any incident, a review of the event should be conducted with a view toward attaining greater safety in the future. In addition, the emergency measures and response of emergency groups should be evaluated. This may indicate methods of improving the handling of future emergencies.

Since facilities may be vastly different, the details of an emergency plan must be worked out on an individual basis. The intent here is simply to point out some of the aspects that must be treated in any actual plan. Reference 150 discusses several aspects in regard to emergency planning. 


\section{REFERENCES}

1. G. T. Seaborg, Progress beyond Plutonizm, USAEC Division of Technical Information Extension, Oak Ridge, Tenn. (1966).

2. W. N. Miner, Plutonium, USAEC Division of Technical Information Extension, Oak Ridge, Tenn. (1966).

3. G. T. Seaborg, "Plutonlum--Past, Present, Future," Commercial Plutonium Fuel.s Conference, CONF-6603C8, Pp. 60-68 (1966).

4. R. E. L. Stanford and C. R. Moore, "Commercial Plutonium--lts Availability and Composition," Commercial Plutonium Fuels Conference, CONF-660308, Pp. 77-85 (1966).

5. N. B. Garden, Editor, Report on Gloveboxes and Containment Enclosures, TID-16020 (1962).

6. M. J. Steindler, Comments on the Handling of Plutonium, ANL-6021 (June 1959).

7. G. J. Appleton and H. J. Dunster, Recommended Practice in the Safe Handling of Plutonium in Laboratories and Plants, AHSB (RP)-R-6, UKAEA, Harwell (1961).

8. L. R. Kelman, W. D. Wilkinson, A. B. Shuck, and R. C. Goertz, The Safe Handling of Radioactive-Pyrophoric Materials, ANL-5509 (Dec 1955).

9. J. H. Venables, "Remote Hendling of Irradiated Alpha Active Materials in the Metallurgy Division, AERE Harwell," Proc. Eighth Conf. Hot Laboratories and Equipment, TID-7599, pp. 78-92 (1960).

10. L. R. Kelman et al., "Gloveboxes for Plutonlum Metallurgy Research at Argonne National Laboratory," Pros. Ninth Conf. Hot Laboratories and Equipment, American Nuclear Society, Chicago, Ill., pp. 64-70 (1961).

11. L. N. Howell and E. E. Plerce, Glove-Box and Hot Cell Design Considerations, Nucl. Safety 3, 44-48 (1962).

12. L. N. Howell, Safety in Glove-Box Design and Operation, Nucl. Safety 5, 87-91 (1963).

13. "Glovebox Design and Operation," Section I, Proc. Rocky Flats Symp. Safety in Plutonizon Handling Facilities, CONF-710401, PP. 3-67 (1971).

14. M. B. Biles et al., "Safety Criteria for the Design of Facilities Processing Plutonium," Proc. Rocky Flats Symp. Safety in Plutonizm Handling Facilities, CONF-710401, PP. 438-453 (1971).

15. C. L. Taylor, "Filtration for the Exhaust Ventilation of Plutonium Recovery Fac1lit1es," Proc. Rocky Flats Symp. Safety in Plutonium Handling Facilities, CONF-710401, pp. 118-132 (1971).

16. P. J. Kleine, "Vent1lation Systems at Mound Laboratory "PP" Bullding," Proc. Rocky Flats Symp. Safety in Plutonizm Handling Facilities, CONF-710401, pp. 133-148 (1971).

17. C. J. Barton, Plutonium Handling, Nucl. Safety 1, 49-52 (1960).

18. R. E. Leuze, Safety in Plutonium Handling, Nucl. Safety 5, 392-396 (1964).

19. W. B. Cottre11, Safety in Hot-Laboratory Design and Operation, Nucl. Safety 2, 51-55 (1960). 
20. R. A. Robinsur, Sifety in Hot-Cell Design and Operation, Nuc1. Safety 6, 72-74 (1964).

21. C. J. Barton, A Review of Glove Box Constmation and Experimentation, ORNL-3070 (1961).

22. A. S. Coffinberry and W. N Miner, Editors, The Metal Plutonium, University of Chicago Press, Chicago, I11. (1961).

23. 0. J. Wick, Editor, Plutonium Handbook, Volume I, Gordon and Breach, Science Publishers, New York (1967).

24. R. E. Lapp and H. L. Andrews, Nuclear Radiation Physice, Prentice-Hall, Inc., New York (1954).

25. H. J. Moe, S. R. Lasuk, M. C. Schumacher, and H. M. Hunt, Radiation Safety Technician Training Course, ANL-7291 Rev. 1 (May 1972).

26. NCRP, Protection against Neutron Radiation, Report No. 38, NCRP Publications, Washington, D.C. (1971).

27. E. K. Hyde, Synthetic Transuranium Elements, USAEC Division of Technical Information Extension, Oak Ridge, Tenn. (1967).

28. C. A. Erdman and A. B. Reynolds, Radionuclide Behavior During Normal Operation of LMFBRs. Part 1: Production, Nuc1. Safety 16, 43-59 (1975).

29. C. M. Unruh, Radiation Hazards with Recycle Plutonium Fuels, Nucl. Safety 5, 378-382 (1964).

30. M. J. Steindler, Radiation Froblems Associated with the Handling of the Actinide Elements, ANL-6540 (Apr 1962).

31. W. C. Roesch, "Surface Dose from Plutontum," Proc. Second United Nations Int. Conf. Peaceful Use of Atomic Energy, Geneva, 23, 339-345 (1958).

32. I. Birchall, Radiation Dose Rates from Plutonizon Isotopes, AHSB(S) R-10 (1960).

33. L. G. Faust, Measured and Calculated Surface Dcse Rates of Plutonium and Plutonium Oxide, BNSA-22 (1965).

34. A. H. Case, "Problems Assoclated with Plutonlum-238 Processing," Proc. Rocky Flats Symp. Safety in Plutonium Handling Facilities, CONF-710401, pp. 300-306 (1971).

35. E. A. Putzler, Data Used in Health Physics Considerations for Plintonium and Americium, RFP-795 (1966).

36. C. M. Lederer et al., Table of Isotopes, 6th Edition, John W1ley and Sons, New York (1967).

37. S. S. Yaniv et al., Analysis of Pu-Am Spectra in a Xe Proportional Counter: Effect of Characteristic X-Rays, Health Phys, 23, 705-714 (1972).

38. H. V. Larson, "Factors in Controlling Personnel Exposure to Radiation from External Sources," Plutonium Handbook, Volume II, Gordon and Breach, Sclence Publishers, New York, pp. 845-857 (1967).

39. D. H. Denham, Health Physics Considerations in Processing Trans-Plutonium Elements, Health Phys. 16, 475-487 (1969).

40. Reactor Physics Constants, ANL-5800, Second Edition (July 1963). 
41. E. D. Arnold, "Radiation Limltations on Recycle Power Reactor Fuels," Proc. Second United Nations Int. Conf. Peaceful Uaes of Atomic Energy, Geneva, 13, 237-258 (1958).

42. B. R. I.eonard, Jr., "Nuclear Reactions," Plutonizm Handbook, Volume I, Gordon and Breach, Sclence Publishers, New York, Pp. 9-30 (1967).

43. R. E. Felt, Burming cond Extinguishing Characteristics of Plutonizm Metal Fires, IS0-756 (1967).

44. R. R. KIng, "The Prevention and Control of Fires in Glove Boxes Containing Plutonium," Proc. Ninth Conf. Hot Laboratories and Equipment, American Nuclear Society, Ch1cago, pp. 71-77 (1961).

45. L. E. Musgrave, "Plutonfum Ignition In Inert Atmospheres," Proc. Rocky Flate Symp. Safety in Plutonizm Handling Facilities, CONF-710401, pp. 106-117 (1971).

46. K. Stewart, "The Particulate Materlal Formed by the Oxidation of Plutonium," Progress in Nuclear Energy, Technology and Engineering, Series IV, Pergamon Press, New York, 5, 535-579 (1963).

47. J. G. Schnizlein and D. F. Fischer, "Plutonium Oxidation and Ignition Studies," Chemical Engineering Division Semiannual Report, July-December 1963, ANL-6800, pp. 359-383 (May 1964).

48. USAEC, Accident and Fire Prevention Information, Number 21 (Oct 28, 1955).

49. A. B. Shuck, Safety Aspects of Working with Plutonizm, Nucl. Energy Eng. 13, 411-414 (1959).

50. F. H. Ellinger et al., "Alloying Behavior of Plutonlum," Plutonium Handbook, Volume I, Gordon and Breach, Sclence Publishers, New York, Pp. 191-247 (1967).

51. USAEC, Serious Accidents, Number 264 (May 13, 1966).

52. USAEC, Serious Accidents, Number 293 (Aug 26, 1968).

53. USAEC, Serious Accidents, Number 306 (Dec 1, 1969).

54. D. H. Denham, "Health Phys1cs at the LRL-LIvermore Transuranfc Processing Fac1lity," Proc. 15th Conf. Remote Systems Technology, American Nuclear Soclety, Hinsdale, I11., pp. 179-186 (1967).

55. NCRP, Basic Radiation Protection Criteria, Report No. 39, NCRP Publlcations, Washington, D.C. (1971).

56. R. E. Barblere et al., A Radiobiology Guide, WADC 57-118(I) (1958).

57. Report of the RBE Comittee to the ICRP, Heal.th Phys. 9, 357-384 (1963).

58. ICRP, Recommendations of the Intermational Commission on Radiological Protection, Report of Committee IV (1953-1959) on Protection against Electromagnetic Radiation above $3 \mathrm{MeV}$ and Electrons, Neutrons and Protons, ICRP Publication 4, Pergamon Press, Oxford (1964).

59. ICRP, The Metabolism of Compounds of Plutonizm and Other Actinides, ICRP Publication 19, Pergamon Press, Oxford (1972).

60. ERRA Manual, Stansiards for Radiation Proteation, Chapter 0524 (1975).

61. T. A. Steele et al., "Radiation Protection Requirements for Fabricating Recycled Plutonium Reactor Fue1," Proc. First Int. Congress of Radiation Protection, Pergamon Press, Oxford, pp. 949-960 (1968). 
62. A. B. Shuck and J. H. Handwerk, "Plutonium Management at Argonne National Laboratory," Commercial Plutonizon Fuels Conference, CONF-660308, pp. 159168 (1966).

63. W. H. Langham, Physiology and Toxicology of Plutonium-239 and Its Inciustrial Medical Control, Health Phys. 2, 172-185 (1959).

64. B. Holl1day et al., Radiological Protection of Workers Exposed to Airborme Plutonizm Particulate, Health Phys. 18, 529-540 (1970).

65. Deposition and Retention Models for Internal Dosimetry of the Hwman Respiratory Tract, Health Phys. 12, 173-207 (1966).

66. ICRP Report, Report of Committee II on Permisaible Dose from Intermal Radiation, Pergamon Press, London (1959).

67. W. S. S. Jee, Vistribution and Toxicity of ${ }^{239}{ }^{2} u$ in Bone, Health Phys. 22, 583-595 (1972).

68. R. C. Thompson, "Biological Factors," Plutonium Handbook, Volume II, Gordon and Breach, Sclence Publishers, New York, pp. 785-829 (1967).

69. NCRP, Alpha-Emitting Particles in Lungs, Report No. 46, NCRP Publications, Washington, D.C. (1975).

70. J. I. Stara et al., Comparative Metabolism of Radionuclides in Mamals: A Reriew, Health Phys. 20, 113-137 (1971).

71. G. W. Lolphin, Problems Associated with Setting Safe Levels for wioring with Plutonizm, Health Phys. 22, 937-942 (1972).

72. Y. I. Moskalev, ${ }^{239}$ Pu: Problems of Its Biological Effect, Health Phys. 22, 723-729 (1972).

73. J. F. Park et al., Progress in Beagle Dog Studies with Transuranium Elements at Battelle-Nointhest, Health Phys. 22, 803-810 (1972).

74. C. L. Sanders and T. A. Jackson, Induction of Mesotheliomas and Sarcomas from "Hot Spots" of $2{ }^{2} \mathrm{PuO}_{2}$ Activity, Health Phys. 22, 755-759 (1972).

75. R. D. Evans, Remarks on the Maximum Permissible Deposition of Plutonium in Man, and the Safety Factors in the Pivot-Point Radiation Guide of 0.1 ue of Radium in Man, Health Phys. 8, 751-752 (1962).

76. W. J. Bair and R. C. Thompson, Plutonizm: Biomedical Research, Sclence 183, 715-722 (1974).

77. G. L. Voelz, What We Have Learned About Plutonium from Human Data, Health Phys. 29, 551-561 (1975).

78. L. H. Hempelmann et al., Manhatton Project Plutonium Workers: A TwentyBeven Year Follow-up Study of Seleoted Cases, Health Phys. 25, 461-479 (1973).

79. American Standards Assoclation and Amerlcan Nuclear Soclety, Nuclear Safety Guide, TID-7016, Rev. 1 (1961).

80. C. R. McCullough, "React or Safety," Reaotur Hondbook, Second Edition, Volwo IV, Engineering, S. McLain and J. H. Martens, Ed1tors, Interscience Publishers, New York, N.Y. (1964).

81. K. W. Bahler et ai., Prevention and Handling of Radiation Emergencies, K-1436, Office of Technical Services, Department of Comerce, Washington, D.C. (1959). 
82. American National Standard, Dosimetry for Criticality Accidents, ANSI N13.3-1969 (1970).

83. Accidental Radiation Excursion at the Y-12 Plant, Y-1234, Office of Technical Services, Department of Commerce, Washington, D.C. (1958).

84. G. S. Hurst et al., Accidental Radiation Excursion at the Oak Ridge Y-12 Plont--III. Determination of Radiation Doses, Health Pinys. 2, 121-133 (1959).

85. American National Standard, Criticality Accident Alarm System, ANSI N16.21969 (1969).

86. USAEC, Operational Accidents and Radiation Exposure Experience, WASH-1192 (1971).

87. National Safety Council, "Fire Protection," Chapter 43, Acrident Prevention Manual for Industrial Operations, Seventh Edition, National Safety Couric1l, Chicago (1974).

88. C. Yao et a1., Evaluation of Protection from Explosion Overpressure in AEC Gloveboxes, FMRC 16215.1 (1969).

89. J. W. Lindsay, "Glovebox Design and Operation/Glovebox Materials Study," Proc. Rocku Flats Symp. Safety in Plutonium Handling Facilities, CONF710401, Pp. 26-43 (1971).

90. J. Mishima, A Review of Research on Plutonizm Releases During Overheating and Fires, HW-83668 (1964).

91. C. D. Hunt, Restricted Re?ease of Plutonium--Part 1. Observational Data, Nucl. Safety 12, 85-89 (1971).

92. C. J. Barton. The Hazard of Dispersed Plutonizm Particles, Nucl. Safety ?, 468-473 (1966).

93. C. E. Cuthrie and J. P. Nichols, Possibilities and Consequences of Major Accidents in Radiochemical Plants, Nucl. Safety 6, 57-65 (1964).

94. R. A. Moyer, Savannah River Experience with Transplutonizon EZements, Health Phys. 15, 133-138 (1968).

95. D. M. Taylor, Interaction Between Tranouranium Elements and the Components of Cells and Tissues, Health Phys. 22, 575-581 (1972).

96. J. C. Nenot et al., An Experimental Comparative Study of the Behavior of ${ }^{23}{ }^{\mathrm{NP}},{ }^{238} \mathrm{Pu},{ }^{239} \mathrm{Pu},{ }^{241} \mathrm{Am}$ and ${ }^{242} \mathrm{Cm}$ in Bone, Health Phys. 22, 657-665 (1972).

97. L. G. Merker, "Design of Equipment and Facilities," Plutoniion Handbook, Volume II, Gordon and Breach, Sclence Publishers, New York, PP. 859-873 (1967).

98. P. B. Vernon, Health Hazards Associated with the Fabrication of PlutoniumAluminum Fuei Elements, Health Phys. 12, 1109-1113 (1966).

99. R. I. Gulley, "Plutonlum Handling and Control Practices at Pacific Northwest Laboratory," Comercial Plutonizon Fuelo Conf., CONF-660308, PP. 149158 (1966). 
100. D. C. Fraser, Health Physics Problems Associated with the Production of Experimental Reastor Fuels Containing $\mathrm{PuO}_{2}$, Health Phys. 13, 1133-1143 (1967).

101. R. E. Tomlinson, Radiochemical Plant Containment at Hanford, Nucl. Safety 3, 51-56 (1961).

102. W. L. Marter, Radiation and Contamination Contro? Improvements for a Plutoniwn Processing Plant, Health Phys. 8, 435-438 (1962).

103. F. P. Marchett1, A Compendium of Radiation Safety Information about Plutonizm, ANL-6884 (Apr 1964).

104. R. W. Fergus, A Practical Hand-Shoe Monitor, Health Phys, 19, 307-310 (1970).

105. J. G. Ello et a1., Gas Proportional Alpha, Beta-Goma Continuous Air Monitor, Health Phys. 11, 773-778 (1965).

106. E. Tanaka et a1., A High Sensitivity Contiruous Plutonizm Air Monitor, Health Phys. 14, 473-482 (1968).

107. J. M. Alexander, A Continuous Monitor for Prompt Detection of Airborme Plutonizm, Health Phys. 12, 553-556 (1966).

108. J. W. Healy, "An Approach to Plutonium Surface Contamination Levels," Proc. Rocky Flats Symp. Safety in Plutonizm Handling Facilities, CoNF710401, pp. 352-364 (1971).

109. D. M. Davis and F. D. Gupton, Health Physics Instmoment Monuul, ORNL-332 (Third Edition) (1963).

110. J. G. Ello, ANL, personal communication (1972).

111. R. J. Sherwood and D. M. S. Greenhalgh, A Personal Air Sampler, Ann. Occup. Hyg. 2, 127-132 (1 )).

112. H. J. Ettinger et al., Size Selective Scompling for Plutonizon-238, Health Phys. 23, 41-46 (1972).

113. K. R. Held and J. J. Jech, Assessing the Probable Severity of Plutonizm Inhalation Cases, Health Phys. 17, $433-447$ (1969).

114. W. C. Roesch and H. E. Palmer, Detection of Plutonizm in Vivo by WholeBody Counting, Health Phys. 8, 773-776 (1962).

115. K. L. Swinth and B. I. Griffin, A Developmental Scintilzation Counter for Detection of Plutonium in Vivo, Health Phys. 19, 543-550 (1970).

116. R. H. Wilson, "Controlling and Evaluating Plutonium Deposition in Humans," Plutonium Hanabook, Volume II, Gordon and Breach, Science Publishers, New York, pp. 831-844 (1967).

117. D. Ramsden, The Measurement of Plutonizom-239 in Vivo, Health Phys. 16, 145-153 (1969).

118. D. Ramsden et al., In-Vivo and Bioassay Results from Two Contrasting Cases of Plutonizon-239 Inhalation, Health Phys. 19, 9-17 (1970).

119. J. J. Jech et a1.. Interpretation of Human Urinary Excretion of Plutonizm for Cases Treated with DTPA, Health Phys. 22, 787-792 (1972).

120. G. W. Dolphin, The Biological Problems in the Radiological Protection of Workers Exposed to ${ }^{239} \mathrm{Pu}$, Health Phys. 20, 549-557 (1971). 
121. S. Jackson and G. W. Dolphin, The Estimation of Internal Radiation Dose from Metabolic and Uvinary Excretion Data for a Number of Important Radionuclides, Health Phys. 12, 481-500 (1966).

122. R. G. Del Pizzo et al., Rapid Estimation of ${ }^{241}$ Am Content in Plutonizm, Health Phys. 18, 725-727 (1970).

123. R. J. Epstein and E. W. Johanson, Apparatus for Monitoring ${ }^{239} \mathrm{Pu}$ in Wounds, Health Phys. 12, 29-35 (1966).

124. J. T. Byrne, "Plutonlum Management at Rocky Flats," Commercial Plutonium Fuels Conference, CONF-660308, Pp. 169-184 (1966).

125. USAEC, Serious Accidents, No. 325 (Mar 27, 1972).

126. H. M. Butler, Clothing for Use in Contamination Zones, Nucl. Safety 5 , 104-109 (1963).

127. E. C. Hyatt et al., "Evaluation of Respirator Performance by DOP Man Tests," Proc. Rocky Flats Symp. Safety in Plutonizm Handling Facilities, CONF-710401, Pp. 392-406 (1971).

128. F. C. Hardtke, "Neutron Shielding Calculations for Current Window Designs," Proc. Ninth Conf. Hot Laboratories and Equipment, American Nuclear Society, Chicago, I11., Pp. 351-362 (1961).

129. W. C. Hall and J. M. Peterson, "Materials for Shielding Nuclear Radiations from Plutonium Processing," Proc. Rocky Flats Symp. Safety in Plutonizm Handling Facilities, CONF-710401, pp. 307-310 (1971).

130. D. H. Stoddard and H. E. Hootman, ${ }^{252}$ Cf Shielding Guide, DP-1246 (1971).

131. G. Gold et al., Fast Neutron Personnel Dosimetry with Solid-State Track Recorders, paper presented at Health Physics Seventeenth Annual meeting, Las Vegas, Nev. (1972).

132. A. G. Januska and M. J. Robinet, ANL, private communication.

133. H. F. Henry, Editor, Studies in Nuclear Safety, K-1380, Oak R1dge Gaseous Diffusion Plant (1958).

134. E. D. Clayton and W. A. Reardon, "Nuclear Safety and Criticality of Plutonium," Plutonium Handbook, Volume II, Gordon and Breach, Sclence Publishers, New York, N.Y., pp. 875-919 (1967).

135. J. P. Nichols, Criticality Control in Fuel-Procsesing Plants, Nucl. Safety 4, 87-90 (1963).

136. W. E. Unger et al., Nuclear Safety in American Radiochemical Processing Plant8, Nucl. Saíety 12, 234-246 (1971).

137. M. Levenson and R. M. Adams, The Administration of Nuolear Safety at Argonne National Laboratory, Nucl. Safety 7, 1-6 (1965).

138. E. J. Vallario and H. R. Wasson, The Why and How of Nuclear Accident Doaimetry, Nucl. Safety 7, 218-225 (1965).

139. G. S. Hurst and K. H. RItchle, Radiation Accidents: Dosimetric Aspects of Neutron and Ganma-ray Exposures, ORNL-2748, Part A (1959).

140. L. L. Anderson et al., "Nuclear Accident Dosimetry at Argonne National Laboratory," Personnel Dosimetry for Radiation Aocidents, International Atomic Energy Agency, Vienna, Austria, pp. 645-663 (1965). 
141. J. C. Balley, Criticality-Accident Dosimetry Studies, K-1618 (1964).

142. Appendix F, Accident Dosimetry, Protection against Neutron Radiation, NCRP Report No. 38 (1971).

143. J. R. Horan and W. F. Gami11, The Health Physics Aspects of the SL-1 Accident, Health Phys. 9, 177-186 (1963).

144. A. J. Hill, "Fire Detection and Suppression in Glovebox Systems," Proc. Rocky Flats Symp. Safety in Plutonium Handling Facilities, CONF-710401, 212-220 (1971).

145. G. H. Orihood, "F1re Detection Systems in Gloveboxes," Proc. Rocky Flats Symp. Safety in Plutonizo Handling Facilities, CONF-710401, pp. 221-236 (1971).

146. T. E. Franck and C. H. Youngquist, "F1re Protection in Chemistry Hot Cells by Use of Halon-1301," Proc. 15th Conf. Remote Syotems Technology, American Nuclear Society, Hinsdale, I11., Pp. 158-166 (1967).

1.47. J. R. Gaskill et al., "Engineering Fire-Suppression Systems for Large Volumes Using Halon 1301," Proc. Rocky Flats Symp. Safety in Plutonium Handling Facilities, CONF-710401, pp. 248-256 (1971).

148. J. Holliday and W. A. Conway, The Extinguishing of Plutonium Fires, TRG Report $342(D)$, UKAEA (1962).

149. W. Y. Gisse1, Handling of Radiation Incidents, Nucl. Safety 2, 7-9 (1960).

150. D. W. Moeller and J. M, Selby, Plconning for Nuclear Emergencies, Nucl. Safety 17, 1-14 (Jan-Feb 1976). 